\title{
A Study on Physical Factors that may Influence the Spread and Occurrence of Influenza
}

Kedar V. Panday

West Virginia University

Follow this and additional works at: https://researchrepository.wvu.edu/etd

\section{Recommended Citation}

Panday, Kedar V., "A Study on Physical Factors that may Influence the Spread and Occurrence of Influenza" (2010). Graduate Theses, Dissertations, and Problem Reports. 2179.

https://researchrepository.wvu.edu/etd/2179

This Thesis is protected by copyright and/or related rights. It has been brought to you by the The Research Repository @ WVU with permission from the rights-holder(s). You are free to use this Thesis in any way that is permitted by the copyright and related rights legislation that applies to your use. For other uses you must obtain permission from the rights-holder(s) directly, unless additional rights are indicated by a Creative Commons license in the record and/ or on the work itself. This Thesis has been accepted for inclusion in WVU Graduate Theses, Dissertations, and Problem Reports collection by an authorized administrator of The Research Repository @ WVU. For more information, please contact researchrepository@mail.wvu.edu. 


\title{
A Study on Physical Factors that may Influence the Spread and Occurrence of Influenza
}

\author{
Kedar V Panday \\ Thesis submitted to the \\ College of Engineering and Mineral Resources \\ At West Virginia University \\ In partial fulfillment of the requirements \\ for the degree of \\ Master of Science \\ in \\ Mechanical Engineering \\ Ismail B. Celik, Ph.D., WVU, Chair \\ Alejandro Posada, Ph.D., WVU \\ William G. Lindsley, Ph.D., NIOSH
}

Mechanical and Aerospace Engineering Department

Morgantown, West Virginia

2010

Keywords: Influenza Virus, ILI, Biological Aerosols, Airborne Particles, Cough, CFD, Breathing Copyright 2010 Kedar V Panday 


\title{
Abstract \\ A Study on Physical Factors that may Influence the Spread and Occurrence of Influenza
}

\begin{abstract}
Kedar V Panday
Influenza is one of respiratory infections causing the highest morbidity and mortality rates. Every day tens of millions of people suffer from virus infection worldwide with varying severity and with a high economic impact. Influenza transmission from person to person occurs in various ways. This study is an attempt to understand airborne transmission in indoor locations by examining the relation between environmental parameters such as temperature and relative humidity with the number of influenza like illness (ILI) cases. It is proposed that the pattern of influenza activity is primarily a function of indoor relative humidity in temperate regions. This conclusion is based on previous virus viability experiments and on our observation of a strong correlation between influenza like illness cases and indoor relative humidity. Historical data reveals that the peak in influenza like illness cases occurs when the indoor relative humidity is around 10-30\%. This study also focuses on the aerosol mode of transmission via expelled particles of human cough. Experiments were carried out for concentration measurements at various locations of cough particles in an Environmental Chamber (EC) at a Morgantown NIOSH facility. A simulated cough machine capable of replicating human cough in real time flow and particle size distribution was used for the aerosol injection. A computational fluid dynamics (CFD) model was developed to simulate the human cough in a modeled room. The results of experiments and simulations are compared to assess the suitability and accuracy of CFD simulation for such flow. The last step in this study is to evaluate the potential of inhalation of dispersed cough droplets in room by breathing. Since the primary mechanism of infection transmission is believed to be via inhalation of virus laden droplets, a theoretical study was conducted to define the sphere of influence of human breathing.
\end{abstract}


To Mom and Dad 


\section{Acknowledgement}

First and foremost, I would like to thank my Aai-Baba and Tai (Mom-Dad and Sister), for everything they have done to see me reach this stage in life. Their constant support and encouragement all these years has made me more confident and has given me the strength to carry on in difficult situations.

I am grateful to Dr. Ismail B Celik, who has been a great advisor and a guide during past two years in West Virginia University, Morgantown. I would like to thank him for entrusting me with this project, which has been an eye opener, a challenge, and a continuous learning process. He has helped me to evolve as a student, an engineer, and most importantly as a person.

I am thankful to my other committee members, Dr. Alejandro Posada and Dr. William Lindsley. Dr. Posada guided me in all the possible way with lots of patience. He has gotten the best and worst of me at all the times as he was the one I interacted most during research. Dr. Lindsley has been very helpful in answering the simplest doubt I had, he has been always easy to approach and talk to person. If not my committee's timely advice, this thesis would be incomplete.

I would also like to extend my deepest gratitude to the other members of the CFD group. It has been a pleasure working with all of them. Special thanks are due to Dr. Jaggu and Ertan, who were constantly bombarded with questions or problems, but always gave their time to help in all the possible way.

A special note of thanks to Soumya, Vamsi, Manasa, KC and a best couple I know Shree-Pavani. They have been friends and a family, thousands of miles away from home. They have shown a strong support in all the conditions.

Last but not the least NIOSH, which was responsible for granting this project to the team at WVU. My sincere gratitude to all those people who have helped me in any capacity, big or small, as every drop makes an ocean. Without their help, this project would be a long way from success. 


\section{Table of Contents}

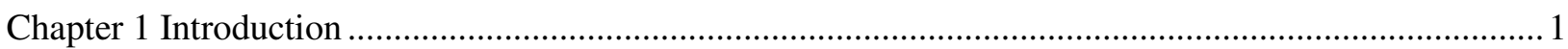

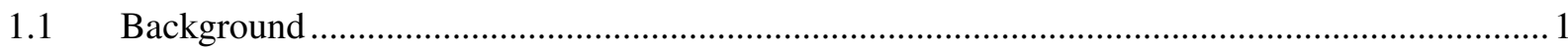

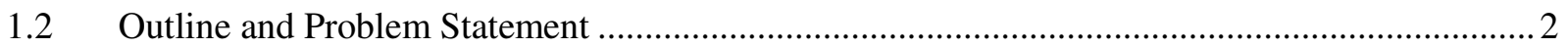

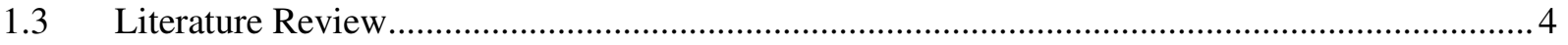

Chapter 2 Effect of Indoor Relative Humidity on the Influenza Virus Activity...................................... 8

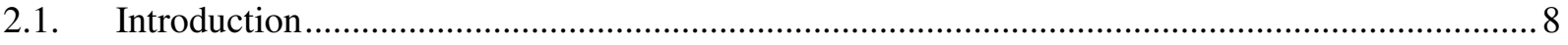

2.2. Number of Influenza-Like Illness Cases........................................................................ 9

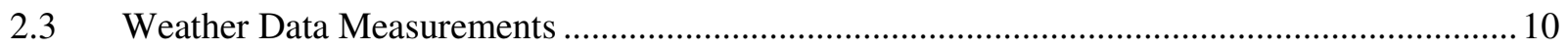

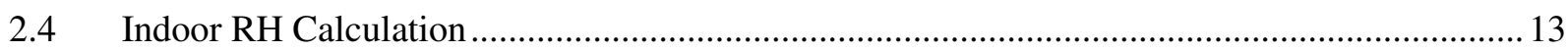

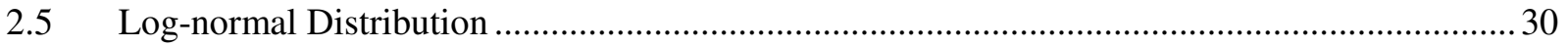

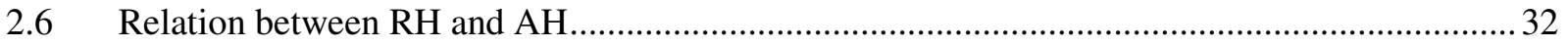

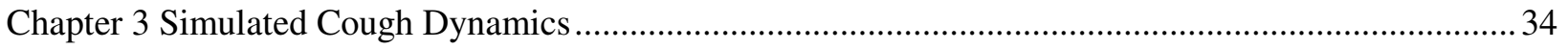

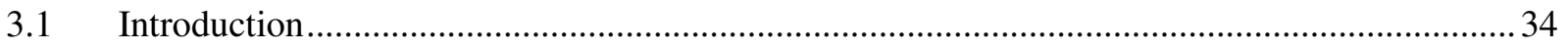

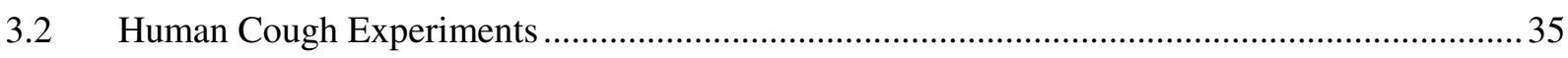

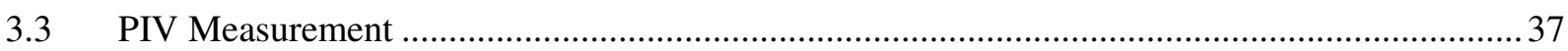

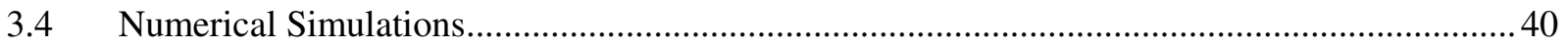

3.5 Effect of Air Ventilation on Particles Dispersion ................................................................ 55

3.6 Effectiveness of Personal Protective Equipment (PPE) ......................................................... 58

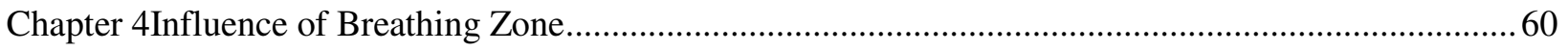

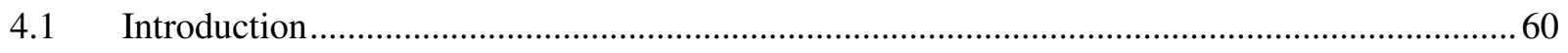

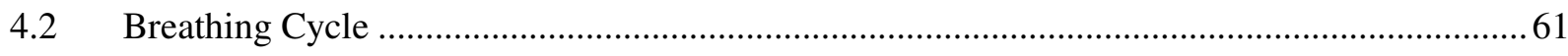

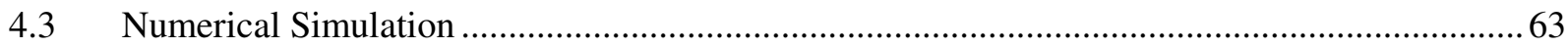

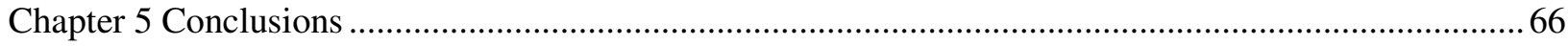

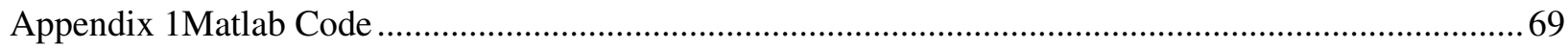

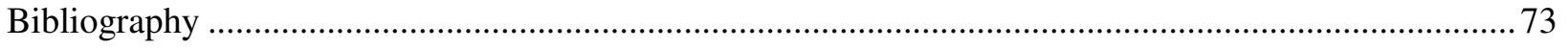




\section{List of Tables}

Table 1. Technical Specifications of weather stations installed at WVU ............................................... 11

Table 2. Mean and standard deviation of weather station measurement ................................................ 13

Table 3. Values of mean $(\mu)$ and standard deviations $(\sigma)$ for ILI in different cities ................................ 31

Table 4. GRIMM particle counter specifications (Grimm, 2008). ....................................................... 37

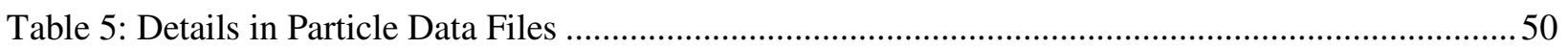




\section{List of Figures}

Figure 1. Indoor weather conditions recorded from four weather stations at WVU 13

Figure 2. Comparison of measured and calculated indoor relative humidity at: 16

Figure 3. Comparison of measured and calculated indoor RH at NETL, Morgantown (Daily Basis)....... 17

Figure 4. Comparison of measured and calculated indoor RH at NETL, Morgantown (Weekly basis). ... 18

Figure 5. Comparison between influenza like illness reported in USA and Monongalia County. ..... 19

Figure 6. Influenza activities during the last five years in USA. 19

Figure 7. Number of ILI cases in Monongalia county plotted against temperature and relative humidity. 21

Figure 8. Comparison of indoor RH and ILIs Morgantown, WV. .23

Figure 9. Comparison of indoor RH and ILIs Newark, NJ...... 25

Figure 10. Comparison of indoor RH and ILIs Cleveland, $\mathrm{OH}$ .27

Figure 11. Comparison of indoor RH and ILIs Columbus, OH...... .29

Figure 12. Lognormal curve fit: 31

Figure 13: comparison of specific humidity and ILIs during the previous influenza seasons... .33

Figure 14. Aerosol Particle Sampler Model 1.108 (GRIMM, 2008). 36

Figure 15. Sampling Probe 37

Figure 16. PIV setup. 38

Figure 17. PIV image showing sampler spectrometer: .39

Figure 18. Spectrometer around sampler probe. 39

Figure 19. Environmental Chamber Layout (Image courtesy of Dr. W.G. Lindsley, NIOSH). .40

Figure 20. NIOSH environment chamber experiment setup (a) setup-1 and (b) setup-2 .41

Figure 21. Environmental Chamber Model (Redrow, 2009) .42

Figure 22. Cough Velocity Profile (data provided by NIOSH) 42

Figure 23. Scalar Distribution in Computational Domain: (a) at $0.25 \mathrm{~s}$, and (b) at $0.5 \mathrm{~s}$ .44

Figure 24. Experiment v/s scalar simulation for setup-1: .47 
Figure 25. Experiment v/s scalar simulation for setup-2

Figure 26. Graphical Representation of the virtual sampling procedure.

Figure 27. Experiment v/s Particle simulation for setup-1:

Figure 28. Experimental setup for study of air ventilation .56

Figure 29. Effect of Ventilation on particle count at various locations in EC

Figure 30: Particle count for mannequin condition at no mask, surgical mask and N95 respirator .59

Figure 31. Assumed Model for Steady Inhalation (Hayashi et al., 2001) ..............................................62

Figure 32. Transient Respiration Process during light work (Gao and Niu, 2005)................................62

Figure 33. Assumption of Breathing Process (Zhu et al., 2004).......................................................... 63

Figure 34. Computational grid generated in Gambit for breathing region...............................................64

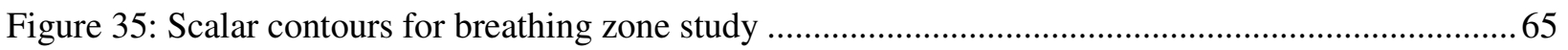




\section{SYMBOLS}

$\begin{array}{ll}\mathrm{P}_{\mathrm{sat}} & \text { Saturation vapor pressure }(\mathrm{kPa}) \\ \mathrm{P}_{\mathrm{v}, \mathrm{act}} & \text { Actual vapor pressure }(\mathrm{kPa}) \\ \mathrm{T} & \text { Temperature }(\mathrm{K}) \\ \mathrm{T}_{\mathrm{s}} & \text { Saturation temperature }(\mathrm{K}) \\ \phi & \text { Relative Humidity }(\%) \\ \omega & \text { Specific Humidity }\left(\mathrm{kg}_{\text {water }} / \mathrm{kg}_{\text {air }}\right)\end{array}$

\section{ACRONYMS}

\begin{tabular}{ll} 
ACH & Air Changes per Hour \\
AH & Absolute Humidity \\
AIA & American Institute of Architects \\
AIIR & Airborne Infection Isolation Rooms \\
APS & Aerosol Particle Sampler \\
CDC & Center for Disease Control and Prevention \\
CFD & Computational Fluid Dynamics \\
EC & Environmental Chamber \\
ESB & Engineering Science Building \\
GUI & Graphic User Interface \\
HPC & High Performance Computing \\
ILI & Influenza like illness \\
MCHD & Monongalia County Health Department \\
NETL & National Energy Technology Laboratory \\
NIOSH & National Institute of Occupational Safety and Heath \\
NREVSS & National Respiratory and Enteric Virus Surveillance System \\
PDF & Probability Distribution Function Curve \\
PIV & Particle Image Velocimetry \\
PPE & Personal Protective Equipment \\
RH & Relative Humidity \\
TUI & Text User Interface \\
UC & Urgent Care facility \\
USA & United States of America \\
WHO & World Health Organization \\
WVU & West Virginia University \\
\hline
\end{tabular}




\section{Chapter 1}

\section{Introduction}

\section{$1.1 \quad$ Background}

Viruses are the most common cause of respiratory infection caused in indoor environment. Influenza virus affects both upper and lower respiratory tract and is among the type of virus causing more respiratory infection. Influenza, commonly called flu, is a widely spread infection of relatively more severe intensity (Morawska, 2006). Influenza can cause mild to severe illness, sometimes may lead to death. Influenza symptoms are fever, headache, muscle pains, weakness, cold, sore throat and cough; and can last from 3 days to two weeks.

Influenza is a highly contagious airborne disease that causes about three to five million cases of severe illness and about 250 to 500 thousand deaths in the world per year (WHO, 2010). The estimated cost of building-influenced respiratory infections (influenza, rhinovirus, tuberculosis) amounts to about $\$ 10$ billion in healthcare costs, $\$ 19$ billion in costs arising from absence caused by illness and $\$ 3$ billion in other performance losses per year (Morawska, 2006). From the health cost and perspective alone, it is imperative that the transmission of influenza and similar respiratory viruses be better understood.

In recent years, much focus is shifted towards understanding the modes of virus transmission and studying the effects of environmental parameters on airborne route of virus transmission. Droplets exhaled from influenza infected persons by talking, breathing, coughing or sneezing disperses through ambient air. This study aims to understand the effects of environmental parameters on the number of influenza cases in temperate regions, the study of droplet concentration in a room after cough particles are expelled, and potential of inhaling these droplets via respiration. 


\subsection{Outline and Problem Statement}

Influenza virus can be transmitted by four ways: 1) direct physical contact with infected people, 2) transmission by indirect contact with fomites, 3) transmission via large droplets, and 4) airborne transmission of particles with diameter $<4 \mu \mathrm{m}$ (Weber et al., 2008; Morawska, 2006). Microorganisms and viruses can become airborne when droplets are generated during talking, coughing or sneezing. The number of droplets, velocity at which particles are exhaled, and the particles size distribution may vary from person to person.

Direct contact and fomites are modes of virus transmission where a person may catch influenza infection by touching a surface or object that has influenza virus on it and then touching their own mouth, eyes, or nose (CDC, 2010). Infection transmission via direct contact can be avoided by practicing precautionary measures. Even if a great care has been taken by an individual to avoid direct contact influenza transmission, virus transmission does not stop (Morawska, 2006). Hence, virus transmission by other routes like airborne and large droplet does exist and should be studied. Droplets exhaled from infected persons evaporate when they are exposed to open surrounding. Evaporation reduces the diameter of particles increasing the distance and time they can travel (Redrow, 2009). Evaporation rate is a function of temperature and relative humidity $(\mathrm{RH})$. Virus viability of airborne particles is dependent on these environmental parameters. Ultraviolet light and air pollutants also play a role on evaporation (Tang, 2009). These factors can have positive or negative impact on airborne virus transmission.

Surrounding environment plays an important role in the viability of influenza virus as particles disperse in air. The infectivity of virus depends on its type (i.e., if virus is enveloped or non-enveloped). Influenza virus is an enveloped virus which envelop is derived from host cell membrane. Virus envelop consists of small part of cell's plasma membrane. Enveloped viruses tend to survive longer at lower humidity and lower temperature (Sobsey \& Meschke, 2003, Posada et al., 2010). Influenza virus shows a particular survival trend as a function of humidity; virus survivability is higher at low humidity, lower at moderately high humidity while at higher humidity survivability is moderately well (Schaffer, 1976; Harper, 1961; Lowen et al., 2007).

Airborne transmission of influenza disease has its own importance in a way that transmission can take place over a long period. Cough, being one of the symptoms of influenza infected person, is believed to be a prime source of airborne diseases as it has high exhaust velocity with large number of particles over varying sizes (Gupta et al., 2009). Trajectory traced by coughed particles, distance travelled and time to 
disperse cough particles in room are important parameters required understanding the dynamics of human cough. Airborne coughed particles are a major concern of virus transmission mode around the world (Gupta et al., 2009; Atkinson and Wein, 2008). Coughed particles result in short to long-range transmission. The short-range infection transmission refers to the transmission on the close proximity of the infected and susceptible host. Larger droplets fall down more quickly than smaller particles and also take part in short-range transmission, with small particles. Talking and breathing generates lesser number of particles per process with lower velocity compared to coughing and sneezing; particles generated by either of the process has tendency to enter in the inhalation region of other host sharing same space. Airborne particles can be inhaled deep in respiratory tract by a susceptible host. Hence the study is focused on two issues; first to understand dynamics of human cough, results obtained from first part can be used in second part of the work in studying potential of human respiration process to absorb infected airborne particles into respiratory tract.

Buildings ventilation helps in reducing viral-laden droplets in ambient air. Particles expelled from human cough or sneeze can remain airborne depending on their diameter. If rooms are vented with introduction of fresh air, the particle counts in the room can be lowered ensuring healthy ambience in all domestic and commercial buildings. In indoor space, potential of virus transmission by airborne route depends partially on the ventilation system present (Tang et al., 2006). NIOSH environmental chamber is used to study the impact of ventilation system on particle concentration by changing the air changes rates. Risk of infection by aerosol transmission can be reduced by altering ventilation system and its parameters like air changes and filtration type. 


\subsection{Literature Review}

The effect of weather parameters on survival of influenza virus has been studied for decades. There are some researches carried out from decades to study the environmental parameter affecting virus survivability the most (Harper, 1961; Lester, 1948; Hemmes, 1960). The results from these are useful to determine the parameters having maximum influence on survivability or viability of influenza virus.

Lowen et al (2006) performed experiments with guinea pigs to demonstrate the possibility of virus transmission by airborne route. They placed two groups of guinea pigs in two different cages. One cage contained infected guinea pigs while the other cage had healthy ones. Both cages were placed in a room such that the air moved from infected to healthy guinea pigs. The experiments showed that the few guinea pigs caught infection, thus validating the postulation that airborne transmission is possible. There are other studies which also showed that airborne transmission is possible (Mubareka et al., 2009; Tellier, 2009).

Harper (1961) reported the influence of RH on the survival of four different viruses: vaccinia virus, influenza virus, Venezuelan equine encephalomyelitis virus, and poliomyelitis virus. He demonstrated experimentally that airborne influenza virus remains viable for 23 hours at low temperatures $\left(7-8^{\circ} \mathrm{C}\right)$. $\mathrm{He}$ also showed virus viability decreases at moderate temperatures $\left(20.5-24^{\circ} \mathrm{C}\right)$, and there is further decrease in the viability at high temperatures $\left(32^{\circ} \mathrm{C}\right)$. His study also included the impact of $\mathrm{RH}$ on viability of influenza virus. His results showed that influenza virus viability is better at low RH and low temperature while at higher temperature and higher RH viability dropped to $15 \%$ in just half an hour.

Tang (2010) studied the incidence of common respiratory infection in relation with climate factors in hospitalized children in Hong Kong. The number of laboratory confirmed influenza and RSV cases from May 2000 to December 2007 were collected and the trend of positive cases was plotted against RH and temperature. Statistical data analysis using monthly average showed that the influenza A and RSV incidence increased with higher environmental RH, this may be because the RH in their studies never fell below 50\%. Tang (2009) studied the effect of weather conditions on infectious agents like virus, bacteria and fungi. The temperate and RH range in which virus survival is better is comparable with recommended standard values (e.g., ASHRAE). Infection transfer could be controlled or stopped at high temperature and RH but these elevated parameters are not recommended by ASHRAE standards for human comfort. 
Shaman and Kohn (2008) presented a hypothesis that viability of influenza virus transmission and survival can be better understood in relation with absolute humidity. They claimed that absolute humidity has a bigger effect on influenza virus transmission than relative humidity. They showed that $50 \%$ of influenza transmission and $90 \%$ of its viability can be correlated with $\mathrm{AH}$, whereas $12 \%$ of its transmission and $36 \%$ of its viability can be correlated with RH. Low absolute humidity during winter time favors influenza virus survival and transmission. Shaman et al. (2010) found that the onset of influenza activity in USA is approximately after two weeks from the lowest AH level was recorded. The study was carried out with influenza activity and AH data over 30 years from 1972 to 2002. Their results indicate that absolute humidity alone drives the seasonal variation of influenza transmission in temperate regions. They also proposed that along with $\mathrm{AH}$, school calendar also have effect on influenza transmission.

Chao et al. (2010) have claimed that the influenza A (H1N1) onset in United States is a function of school opening dates. They collected data of school commencement dates from various states to compare it with ILI onset. The data of ILIs in United States was obtained from Google Flu Trends. Upon correlating both data of school start date and reporting of ILIs, they found ILIs are highly related to the school commencement. For schools starting in August first week, ILIs are reported after 19 days after schools start while for those schools which start in first week of September, the ILIs are recorded after 9 days from schools start. They proposed that the environmental parameters has least to do with influenza onset and that school starts date which drives the high infectivity in United States.

Lowen et al. (2007), after providing evidence that the airborne transmission of influenza virus is possible, continued the study with guinea pigs model finding that influenza virus transmission is dependent on RH and temperature. Twenty experiments were performed with eight guinea pigs in which all factors remained constant except for the $\mathrm{RH}$ and/or temperature inside the chamber. In a particular experimental setup the temperature in the chamber was kept at $20^{\circ} \mathrm{C}$ and experiment was repeated with five different RHs: $20 \%, 35 \%, 50 \%, 65 \%$, and $80 \%$. The results showed that transmission was highly efficient at low RH values of $20 \%$ and $35 \%$, while at $50 \%$ only one guinea pig was infected, at $65 \%$ three infected guinea pigs were found, and at $80 \%$ there was no infection transmission. To test the impact of temperature on influenza a similar set of experiments were carried out keeping RH constant and varying temperature. At $50 \% \mathrm{RH}$ transmissibility at $5^{\circ} \mathrm{C}$ was greater than compared with that at $20^{\circ} \mathrm{C}$; same trend was found at $80 \%$ RH. Similarly at higher temperature and lower humidity $\left(35^{\circ} \mathrm{C}\right.$ and $\left.35 \%\right)$ there was no transmission observed. Evidence that the cold temperature and low RH are favorable parameters to influenza spread 
can be useful to suggest that airborne transmission of virus prevails over the contact transmission in temperate regions.

Richmond-Bryant (2008) studied the transport of exhaled particulate matter in airborne infection isolation rooms (AIIR). The goal was to study the exposure of a health care worker to pathogenic agents in AIIR. A computational fluid dynamics (CFD) simulation model in FLUENT v6.1.22 was used for this purpose while grid for simulation was generated in GAMBIT v2.3.16. A fine tetrahedral mesh of $1.3 \times 10^{6}$ cells was generated with mouth area of $0.001225 \mathrm{~m}^{2}$. Ventilation air was supplied to the AIIR at the rate of 8.66ACH. A transient simulation was performed to study the decay of particle concentration from single cough/sneeze. The realizable k- $\varepsilon$ turbulence model was employed in FLUENT. Concentration number was computed with an in-house code in FORTRAN 95 that received data from particle trajectory files obtained from the FLUENT simulation. CFD simulation with health care workers with actual breathing and coughing suggest that the unintended exposure to coughed particles is possible even though ventilation is practiced in a room. Hence, health care workers should use personal protective equipment (PPE).

Gupta et al. (2009) has carried out a study to measure the flow dynamics of human cough. The study was focused on various flow parameters like flow rate, direction, mouth opening area, and size distribution of droplets. Twenty human subjects including male and female were tested for these parameters. Cough flow direction monitored via photography showed that the flow direction can be defined by two angles. Flow time during cough for all subjects was from 0.75 to 0.8 second. The mouth opening area was mostly constant during a cough with variation in mouth opening among subjects. The study gave inputs to be used for CFD modeling while carrying out simulation of cough particle dispersion.

Zhu et al. (2004) performed a study on inhalation region by means of CFD analysis and experiments. Inhalation region of human respiration was studied of unsteady breathing (a sinusoidal breathing was assumed) with 10 breathing cycles /min having flow rate of $14.4 \mathrm{~L} / \mathrm{min}$. Occupant was assumed to be breathing through nose having opening area of $4.2 \mathrm{~cm}^{2}$. Unstructured grid having 434,000 cells was used in CFD model. They adopted a low Reynolds number k- $\varepsilon$ turbulence model for breathing analysis in a stagnant environment. The findings of CFD analysis was compared with the experiments involving a manikin and tracer gas. The value of inhalation region was calculated from CFD and experiments both; on the basis of percentage of contaminant inhaled when it is diffused from an arbitrary position. 
Calculation showed result of $0.1 \%$ against $4 \%$ of experiments at $5 \mathrm{~cm}$ from nose. Results of simulation were found to agree well with the experimental results. 


\section{Chapter 2}

\section{Effect of Indoor Relative Humidity on the Influenza Virus Activity}

\subsection{Introduction}

Virus transmission via airborne route can occur over longer time span compared to transmission via larger droplets. For transmission to occur, airborne droplets from respiratory system of infected person to respiratory tract of susceptible host, virus in such droplets must remain airborne for a sufficient amount of time and should remain viable to be inhaled by susceptible host. Influenza viruses can survive in aerosols for several hours depending on the environmental conditions (Weber \& Stilianakis, 2008, Posada et al., 2010). Outside of respiratory tract, influenza virus survivability depends on type of envelop it carries while it is generated and propagated in the environment. Droplets are generated over wide range of sizes with different velocities at different events like breathing, coughing, sneezing or talking. Larger droplets can evaporate to become smaller droplets which in turn evaporate further to become droplet nuclei ultimately becoming airborne (Chao et al., 2008). If the evaporation occurs before droplets fall on the ground, it can remain in air for long time. Hence, it becomes important to study the effects of environmental parameters on virus enclosed in airborne droplets, which are capable of being suspended in air for longer time.

Weather conditions in various seasons vary from tropical to temperate regions. The correlation of influenza activity to climatic parameters postulated in tropical or subtropical regions cannot be extended to temperate regions. In temperate regions, influenza activity is recorded predominantly in winter months. That is, in northern hemisphere influenza activity is primarily recorded from November to March while in southern hemisphere it is recorded from May to September. This indicates influenza epidemics occur in a seasonal pattern in temperate regions (Lowen et al., 2007). In tropical regions, influenza activity is recorded throughout the year; however some relation can be established with rainy season (Weber \& Stilianakis, 2008).

The effects of environmental parameters on survival of airborne infectious agents were studied within a hospital by Tang in 2009. He proposed that environmental exposure may be a common hazard by viruses 
while they travel between hosts. Weather control recommendations for hospitals were compared with the parameters in which virus survive better. At higher humidity and higher temperature virus does not survive for long time. At the same time such conditions are not favorable for human comfort (Tang, 2009). Lowen et al (2007) showed that influenza virus is transmitted among guinea pigs more efficiently in cold and dry conditions than in hot and humid conditions. They also proved that there was no influenza transmission at high temperatures $\left(>30^{\circ} \mathrm{C}\right)$.

On average, Americans spend approximately $90 \%$ or more of their time indoor (EPA, 2010). Also, medical doctors request people with influenza symptoms to stay in their homes to prevent further influenza transmission. The indoor temperature comfort level for winter is between $20^{\circ} \mathrm{C}$ and $24^{\circ} \mathrm{C}(\mathrm{CDC}$, 2010). When outside temperature is low, the inside air needs to be heated to maintain the temperature comfort level. If moisture is not added to the air as it is heated the RH level may drop considerably making indoor ambient air dry. As discussed above virus viability is higher at low RH conditions. Hence, the extreme level of indoor dryness achieved in winter may become an important factor in influenza occurrence. This study provides evidence that influenza activity is correlated to indoor relative humidity. Since indoor relative humidity is dependent on outside relative humidity with given outside and inside temperature, a calculation model is proposed to relate indoor RH to ILI occurrence. Results agree well with Lowen et al. (2007) experimental evidence on guinea pigs which states influenza virus transmission is dependent on relative humidity and temperature. The correlation established in this study is valid only for temperate regions.

\subsection{Number of Influenza-Like Illness Cases}

Monongalia County Health Department (MCHD) (West Virginia, USA) collects weekly influenza-like illness from Monongalia hospitals and health institutes. These influenza cases are correlated to the indoor weather conditions measured at four places at West Virginia University (WVU), Morgantown WV to determine the most important parameter affecting ILI cases.

World Health Organization (WHO) and National Respiratory and Enteric Virus Surveillance System (NREVSS) collaborating laboratories located in all 50 states and Washington, D.C. report the number of respiratory specimens tested for influenza and the number positive by influenza type and subtype to CDC (McKay, 2010). However, CDC does not make state-level data publicly available. Hence, ILI cases are obtained from Google flu trends for four different cities namely Morgantown WV, Cleveland $\mathrm{OH}$, 
Newark NJ, and Columbus OH during the last five influenza seasons. Google Flu Trends tracks influenza activity in USA for all states and major cities with a close agreement to CDC data (Ginsberg J, 2009). This data can be used for studies pertaining to influenza like illness.

\subsection{Weather Data Measurements}

Four weather stations were installed at WVU Engineering Sciences Building (ESB), Residential complex (Towers), Student Health Center and Urgent Care (UC) facility in Morgantown WV to monitor indoor weather conditions. The selection of these places was based on the higher probability of infection as epidemics are spread rapidly in the places which are logical contact points of infected people with susceptible hosts. For example the residential complex provides housing for around 1,800 students which may become a source for virus propagation.

Weather stations installed at Towers, Hospital and Urgent Care are Vantage Pro2 weather stations (Davis Instruments, Hayward CA). Weather instrument installed in ESB is a ProWeatherStation (Tycon Power Systems, Draper UT). Station at ESB is equipped with an additional wireless station for recording outside weather conditions along with indoor conditions. These instruments measure indoor temperature, relative humidity, and absolute pressure. Weather instruments at all stations are configured to record data every 30 minutes. Devices at all locations are monitored and data is downloaded on a weekly basis. Weather data was collected from September 16, 2009 to present. Table 1 shows the technical specifications of the weather stations used. 
Table 1. Technical Specifications of weather stations installed at WVU

\begin{tabular}{|l|c|c|}
\hline Parameter & Vantage Pro2 & Tycon Power \\
\hline Temperature \\
\hline Range & $0-60^{\circ} \mathrm{C}$ & $0-50^{\circ} \mathrm{C}$ \\
\hline Accuracy & $\pm 0.5^{\circ} \mathrm{C}$ & $\pm 3^{\circ} \mathrm{C}$ \\
\hline Resolution & $0.1^{\circ} \mathrm{C}$ & $0.1^{\circ} \mathrm{C}$ \\
\hline Relative Humidity \\
\hline Range & $0-100 \%$ & $10-99 \%$ \\
\hline Accuracy & $\pm 5 \%$ & $\pm 3 \%$ \\
\hline Resolution & $1 \%$ & $1 \%$ \\
\hline Barometric Pressure & \\
\hline Range & $0.08-0.108 \mathrm{MPa}$ & $0.09-0.107 \mathrm{MPa}$ \\
\hline Accuracy & $135 \mathrm{~Pa}$ & $\pm 300 \mathrm{~Pa}$ \\
\hline Resolution & $100 \mathrm{~Pa}$ & $33.83 \mathrm{~Pa}$ \\
\hline
\end{tabular}

The weekly average values of indoor temperature, $\mathrm{RH}$ and absolute pressure measured by four weather stations at WVU is plotted in Figure 1. The temperature maintained in the four buildings ranges from 19$26^{\circ} \mathrm{C}$. It can be seen from Figure $1(\mathrm{~b})$ that as winter starts, indoor $\mathrm{RH}$ decreases, reaching a minimum value of circa 10\%, this low indoor RH favors virus viability (Lowen A. , Mubareka, Steel, \& Palese, 2007). Mean temperature and standard deviation of each weather station is presented in Table 2 which shows that the indoor temperature does not vary much; a constant value of $23^{\circ} \mathrm{C}$ can be assumed during the cold winter days. 


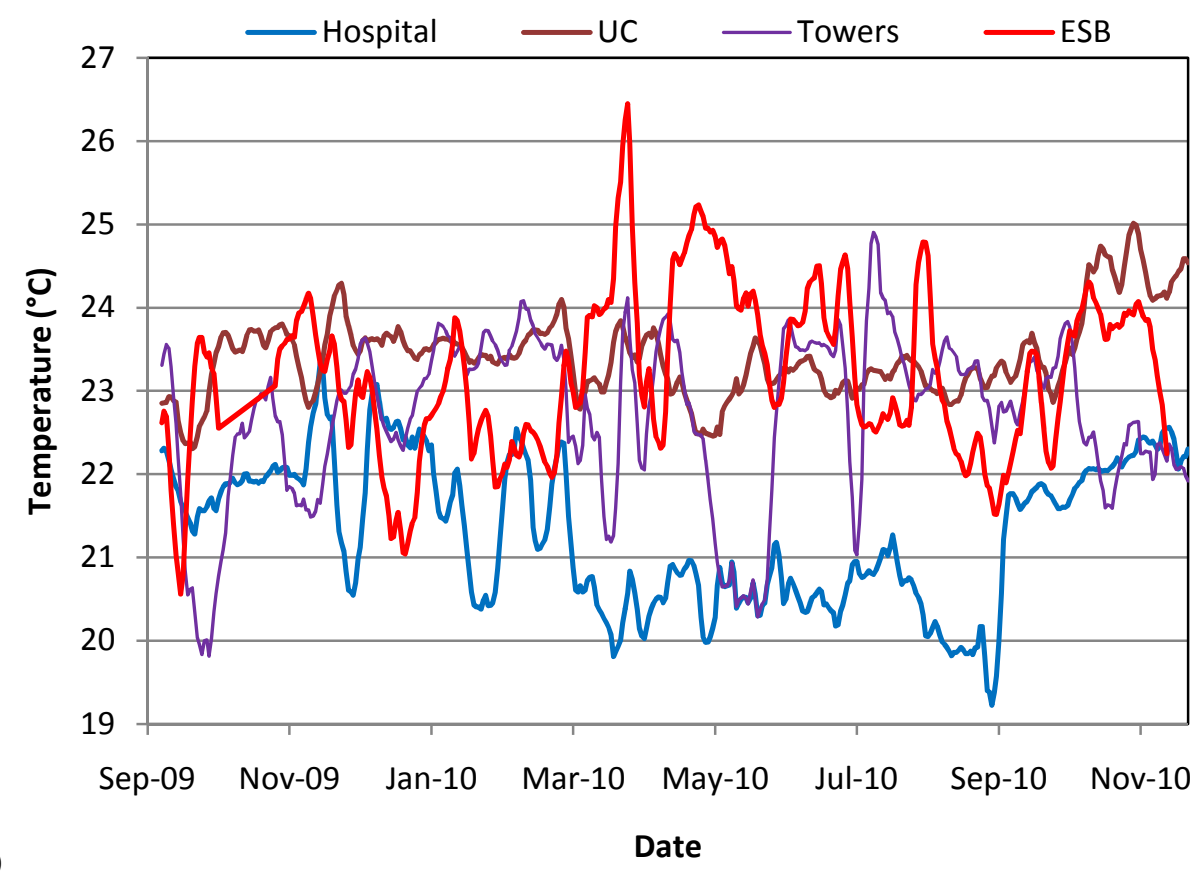

(a)

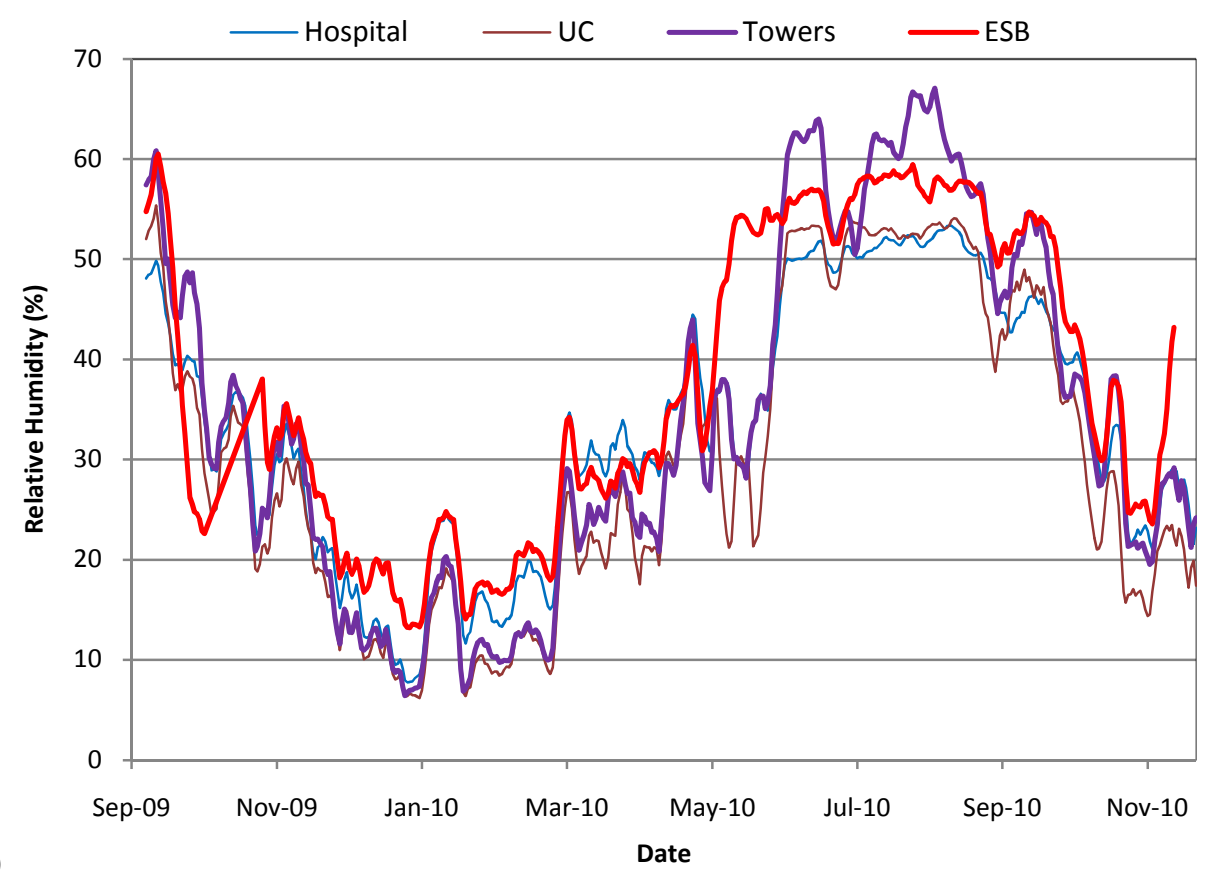




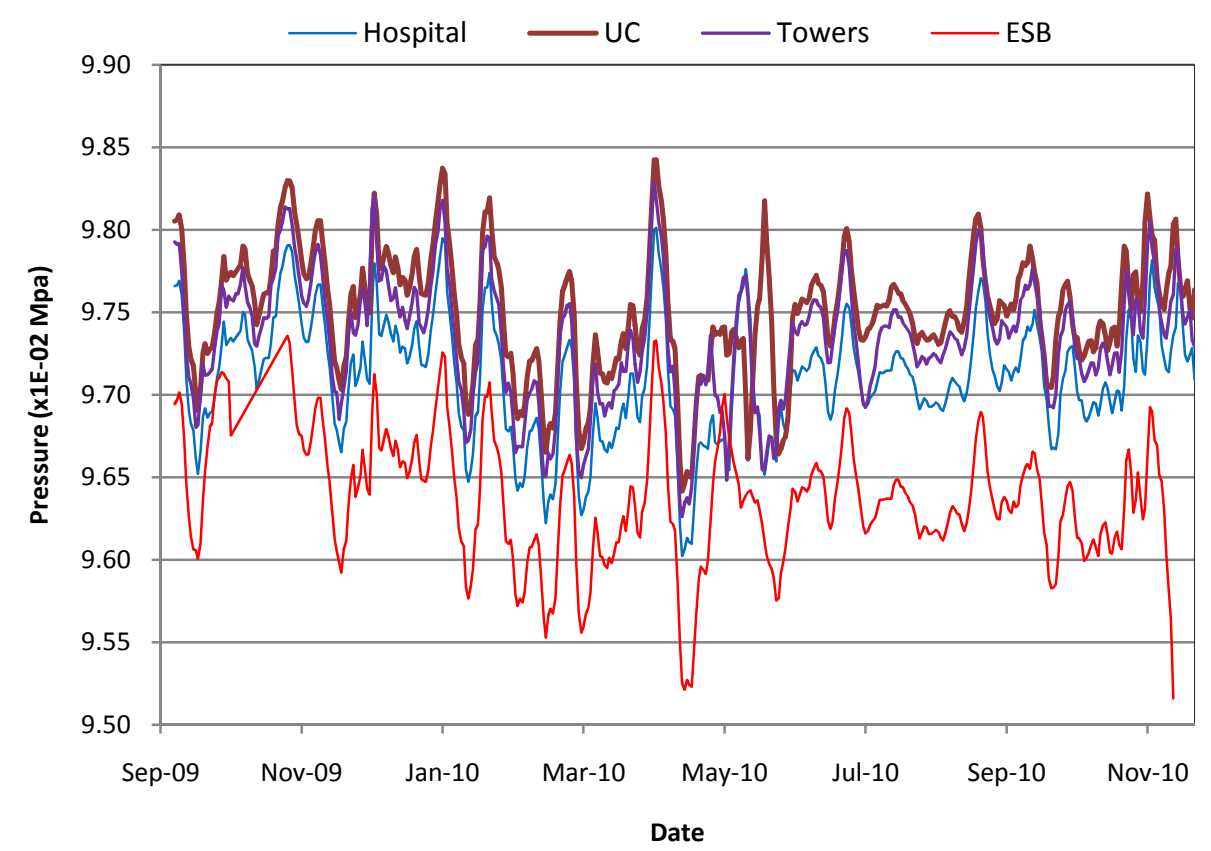

(c)

Figure 1. Indoor weather conditions recorded from four weather stations at WVU (a) temperature, (b) relative humidity, and (c) absolute pressure.

Table 2. Mean and standard deviation of weather station measurement

\begin{tabular}{|l|l|l|}
\hline $\begin{array}{l}\text { Weather Station } \\
\text { Location }\end{array}$ & $\begin{array}{l}\text { Mean } \\
\text { Temperature }\left({ }^{\circ} \mathbf{C}\right)\end{array}$ & $\begin{array}{l}\text { Standard } \\
\text { Deviation }\left({ }^{\circ} \mathbf{C}\right)\end{array}$ \\
\hline Towers & 22.75 & 1.16 \\
\hline Hospital & 21.20 & 0.97 \\
\hline Urgent Care & 23.30 & 0.47 \\
\hline ESB & 23.14 & 1.07 \\
\hline
\end{tabular}

\subsection{Indoor RH Calculation}

Outside weather conditions at the four selected cities was obtained from website source WeatherUnderground (2010). The calculation of indoor relative humidity from the outside weather conditions is based on psychrometric equations. It is assumed that all the air from outside is heated in winter and cooled in summer with no addition or removal of moisture in air conditioning system. Humidifiers are used to increase the relative humidity in winter in only $14 \%$ of all households (Diamond, 2001). The saturation vapor pressure $\mathrm{P}_{\text {sat }}$ is obtained from the Goff-Gratch equation (Hall \& Brouillard, 1985) using the temperature (Equation 1). 


$$
\begin{aligned}
\mathrm{P}_{\mathrm{sat}}= & \text { ALOG }\left[-7.90298 \times\left(\mathrm{T}_{\mathrm{s}} / \mathrm{T}-1\right)+5.02028 \mathrm{LOG}\left(\mathrm{T}_{\mathrm{s}} / \mathrm{T}\right)-1.3816 \times 10^{(-7)} \times\left(10^{(11.344(1-\mathrm{T} / \mathrm{Ts})}-1\right)+\right. \\
& \left.\left.8.1328 \times 10^{(-3)} \times\left(10^{(-3.49149(\mathrm{Ts} / \mathrm{T}-1)}-1\right)\right]\right\} \times[101.325]
\end{aligned}
$$

Where, $\mathrm{T}_{\mathrm{s}}$ is saturation temperature equal to $373.16 \mathrm{~K}$ and $\mathrm{T}$ is the temperature in Kelvin at which saturation vapor pressure is calculated (outside temperature in this case). Saturation pressure obtained from this equation is given in atmospheres.

The actual vapor pressure $\mathrm{P}_{\mathrm{v} \text {,act }}$ corresponding to outside weather conditions is obtained from the definition of RH (Equation 2), and the value of saturation vapor pressure (from Equation 1) and outside RH. Actual vapor pressure is kept constant in this calculation process.

$$
P_{v, a c t}=R H \times P_{s a t}
$$

Indoor temperature is assumed to be constant at $23^{\circ} \mathrm{C}$ (Table 2), as measured with the four weather stations at WVU. Indoor saturation vapor pressure $\mathrm{P}_{\text {sat }}$ corresponding to indoor temperature is calculated using Equation 1. With this saturation pressure and the actual water vapor pressure, the indoor relative humidity can be calculated from Equation 2. Indoor RH calculated by above procedure can be related to ILI cases to study the possible correlation between the two.

Weather data from ESB gives indoor and outdoor temperature and RH both of which could be used to calculate indoor RH. A sample calculation was carried out to confirm the validation of above calculation methodology. Calculated indoor RH is compared with measured indoor RH in ESB to decide if the indoor RH values obtained from above procedure can be used in further study.

Figure 2 shows the indoor RH measured with individual weather station and the indoor RH computed from the outside measurements. The measured and calculated indoor RH values compare very well in winter while data deviates in summer. The possible reason for deviation could be the condensation occurring in air cooling system. The assumption of no water addition or removal from air conditioning system does not hold true in summer. The calculation model does not account for condensation in summer which might have lead to difference in measured and calculated data. This procedure can be used to determine indoor RH for various cities where only outside conditions are available. 


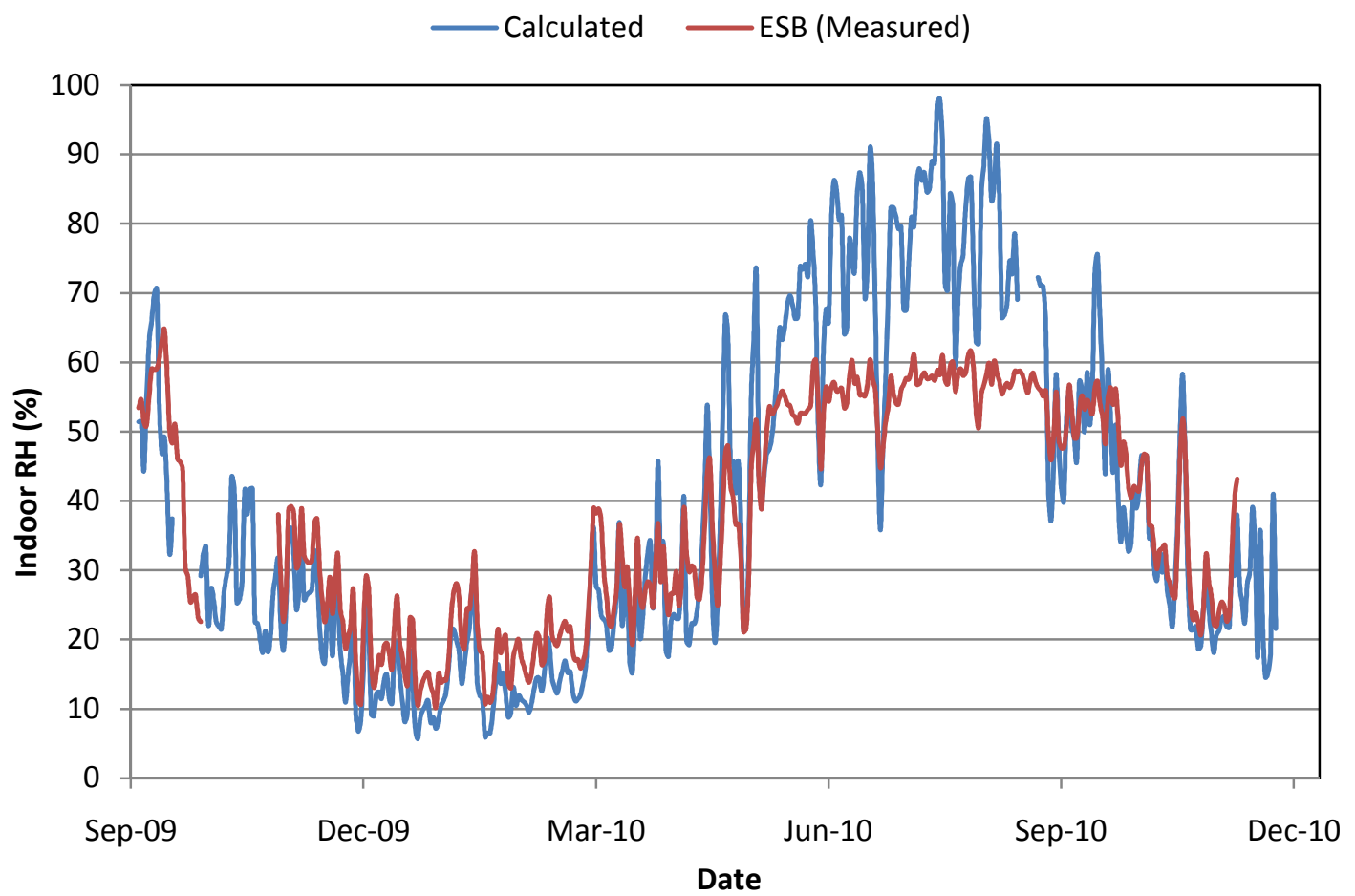

(a)

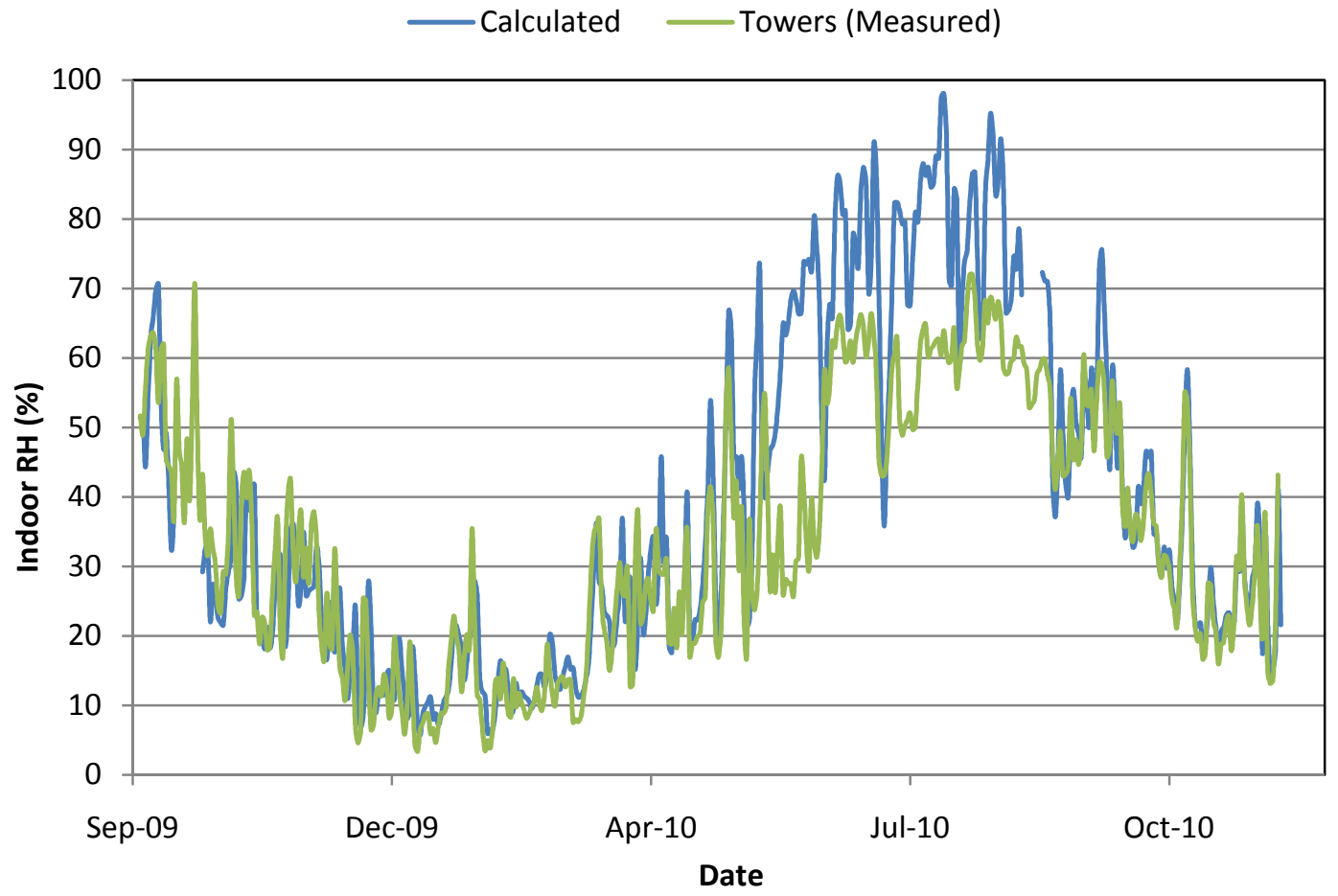

(b) 


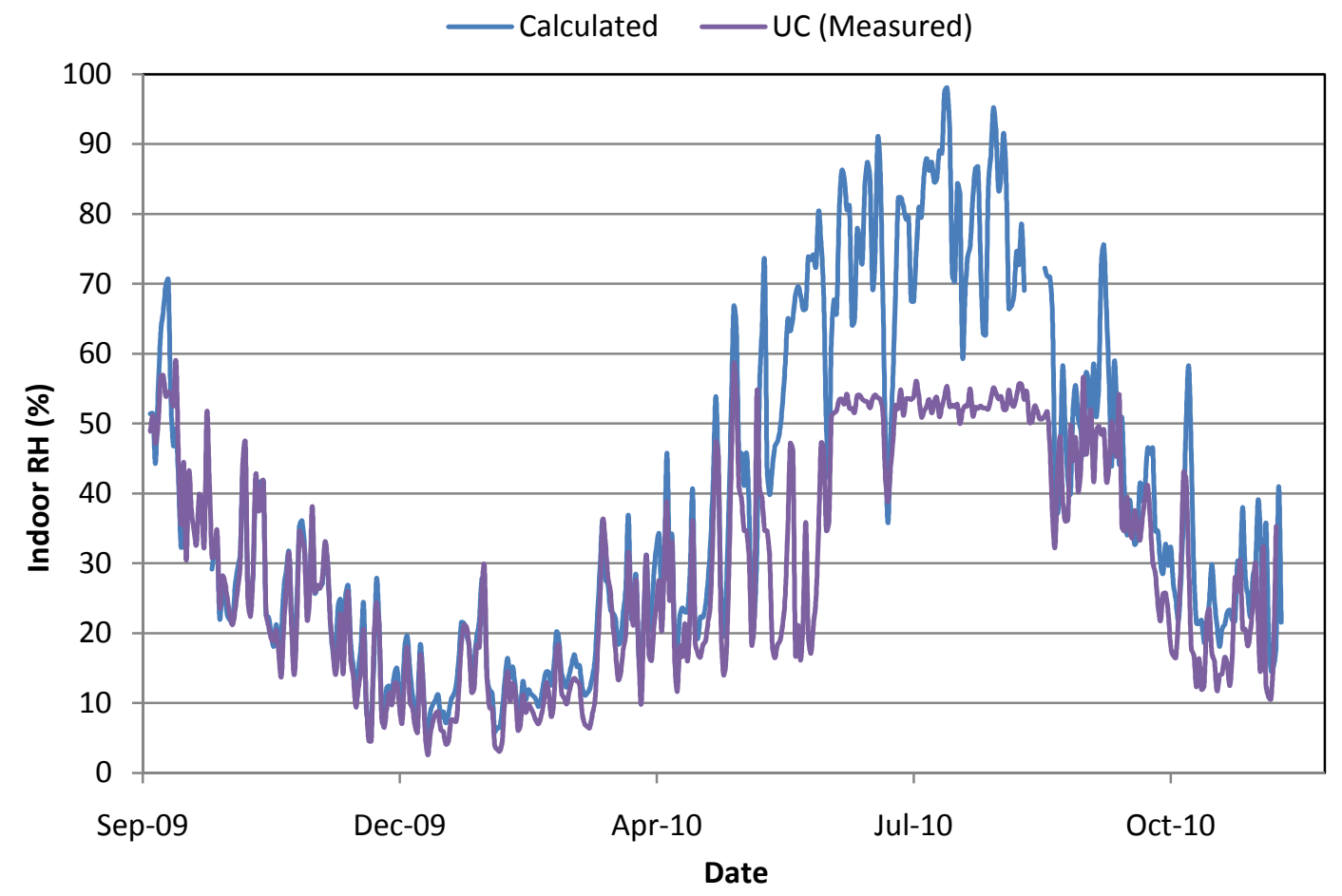

(c)

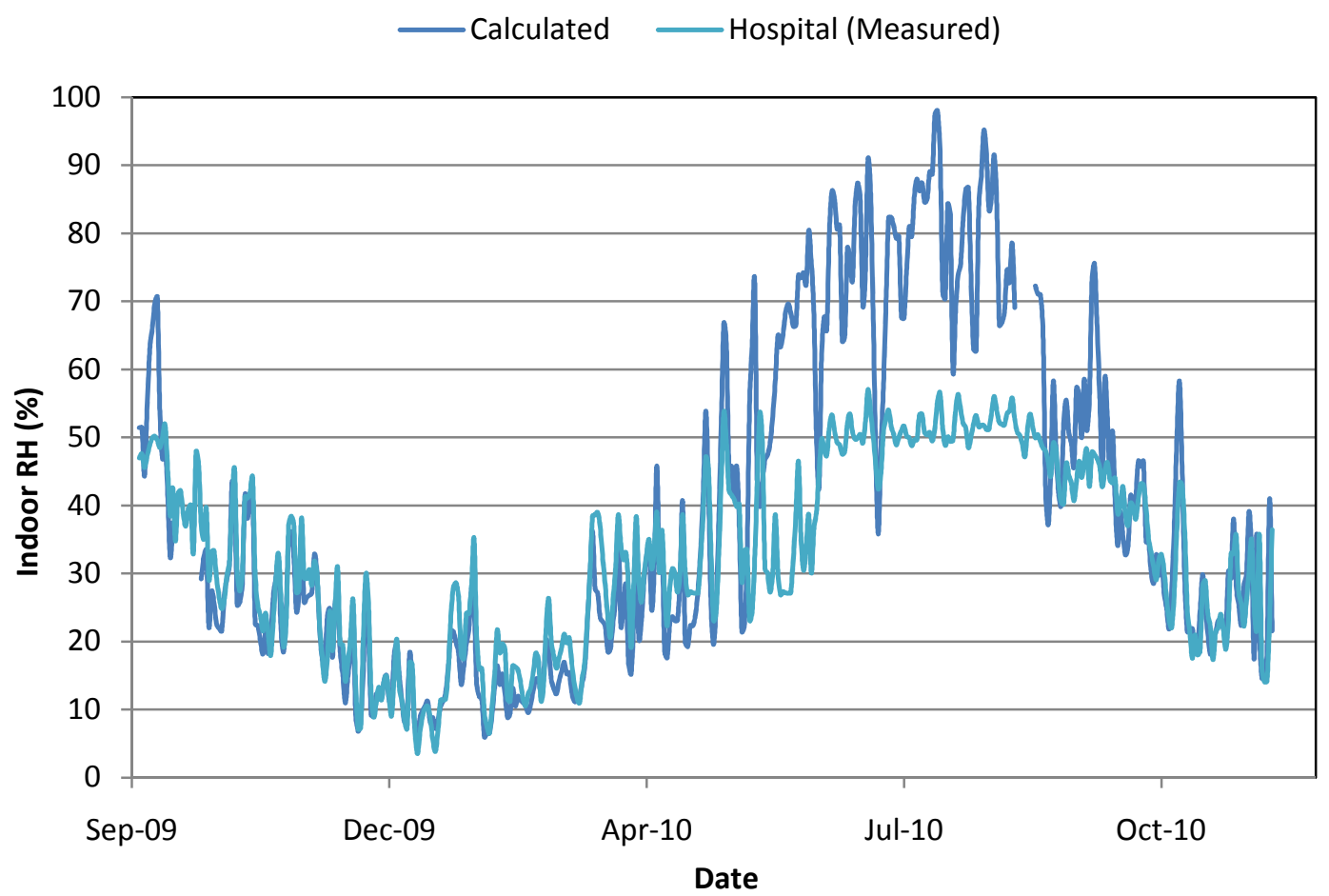

(d)

Figure 2. Comparison of measured and calculated indoor relative humidity at:

(a) ESB, (b) Towers, (c) Urgent care, and (d) Hospital. 
The procedure used for calculation of indoor RH from outside weather parameters was also validated with data from National Energy Technology Laboratory (NETL). Two year indoor and outdoor temperature and RH measurements (from June 1, 2008 through May 31, 2010) were collected from four different rooms of the NETL office in Morgantown WV. Indoor RH was calculated using above method from outside weather data obtained from NETL. A daily and weekly average of measured indoor RH is compared with calculated values of RH. The comparison is shown in Figures 3 and 4. Calculated values deviate by a considerable margin from measured values during summer, but the proposed procedure works fine during the winter. A similar trend is observed from ESB data (Figure 2).

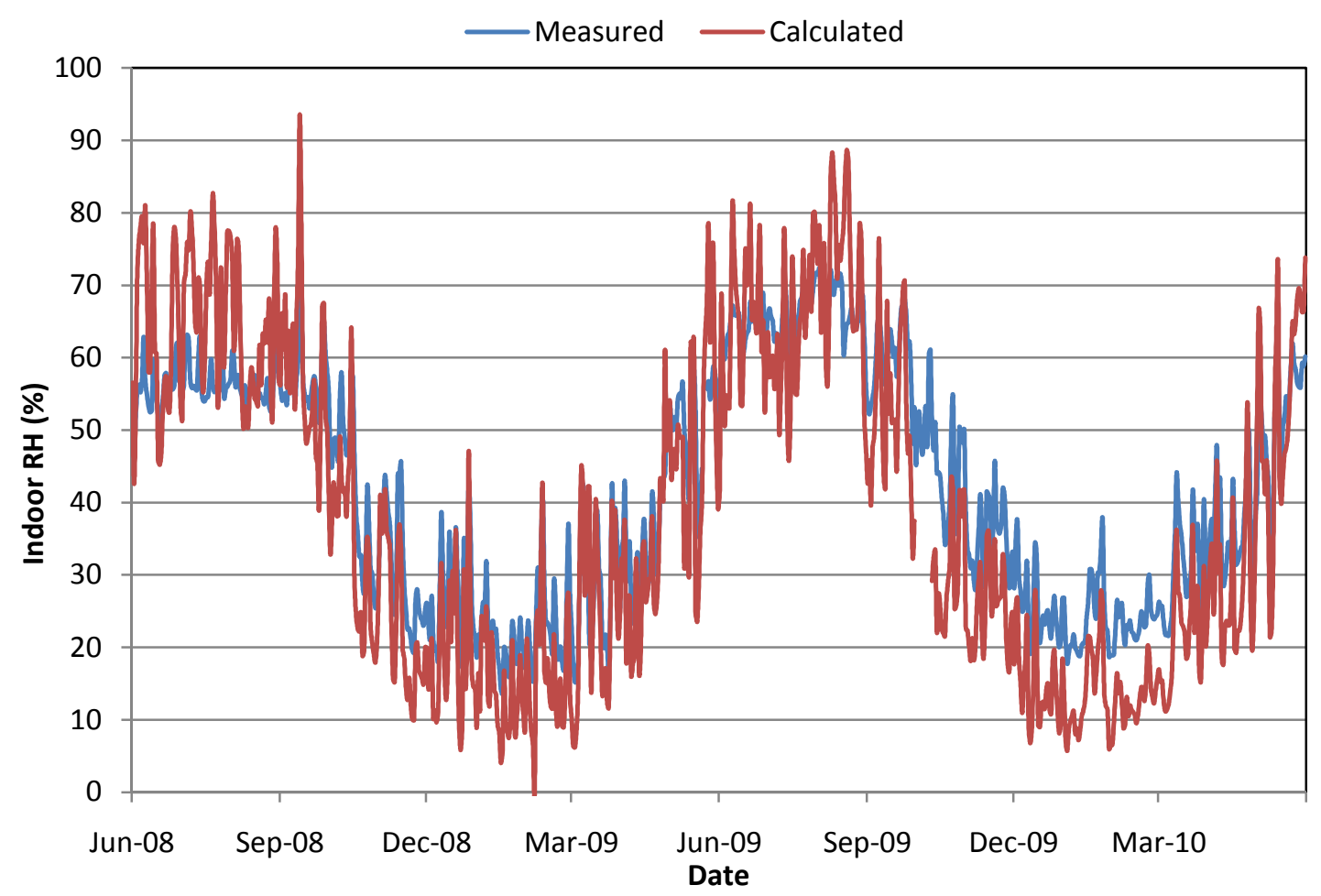

Figure 3. Comparison of measured and calculated indoor RH at NETL, Morgantown (Daily Basis). 


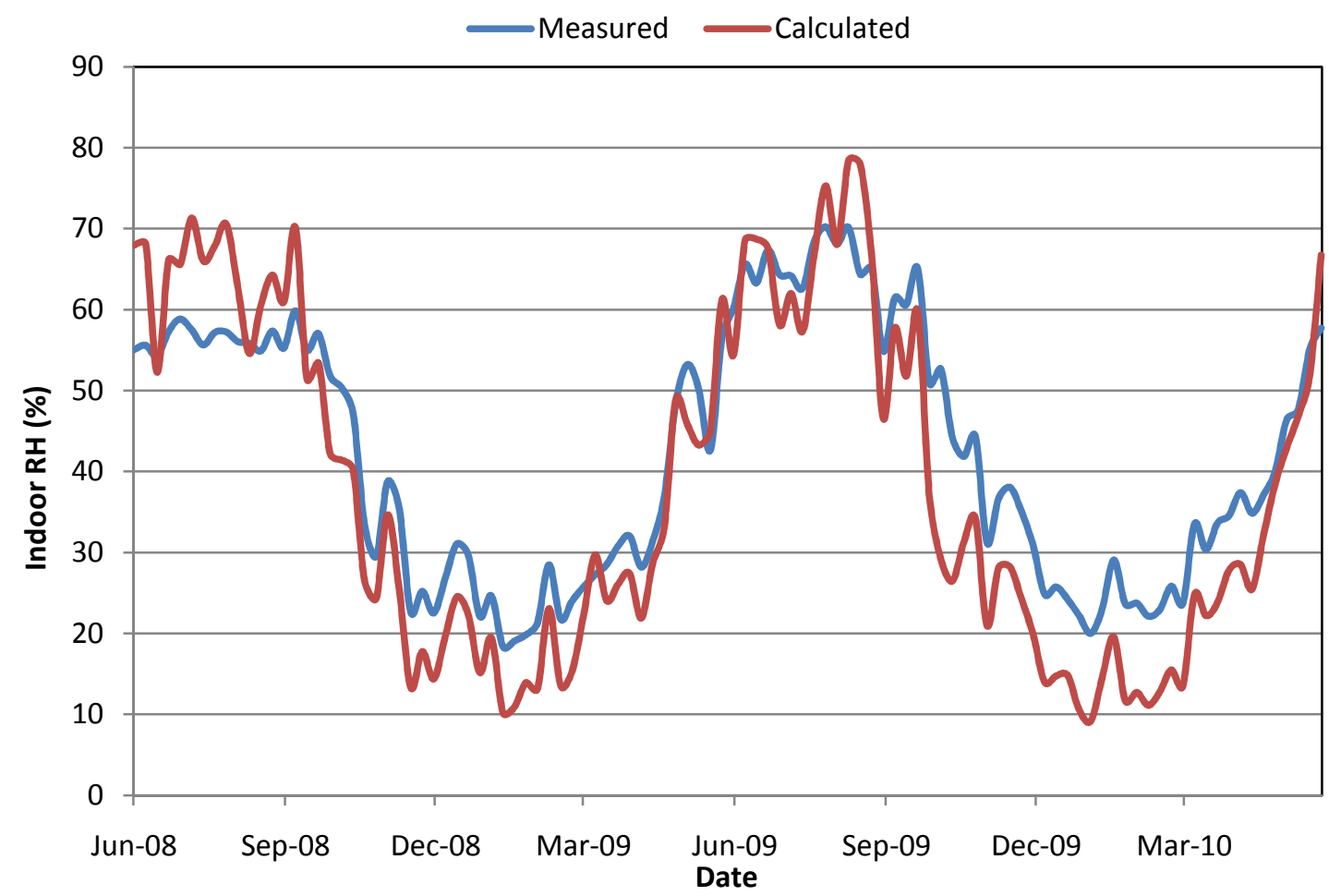

Figure 4. Comparison of measured and calculated indoor relative humidity at NETL, Morgantown (Weekly basis).

The number of positive influenza like illness cases in USA reported to CDC and influenza like illness cases in Monongalia County are compared in Figure 5. This comparison is carried out to understand the trend of ILI cases in a small town and in USA in broader sense. The data trends obtained from two different sources are very similar. The peak in influenza activity during the influenza season 2009-10 was in October-09 (Figure 5). While in previous influenza seasons, the peak was in March (Figure 6). 


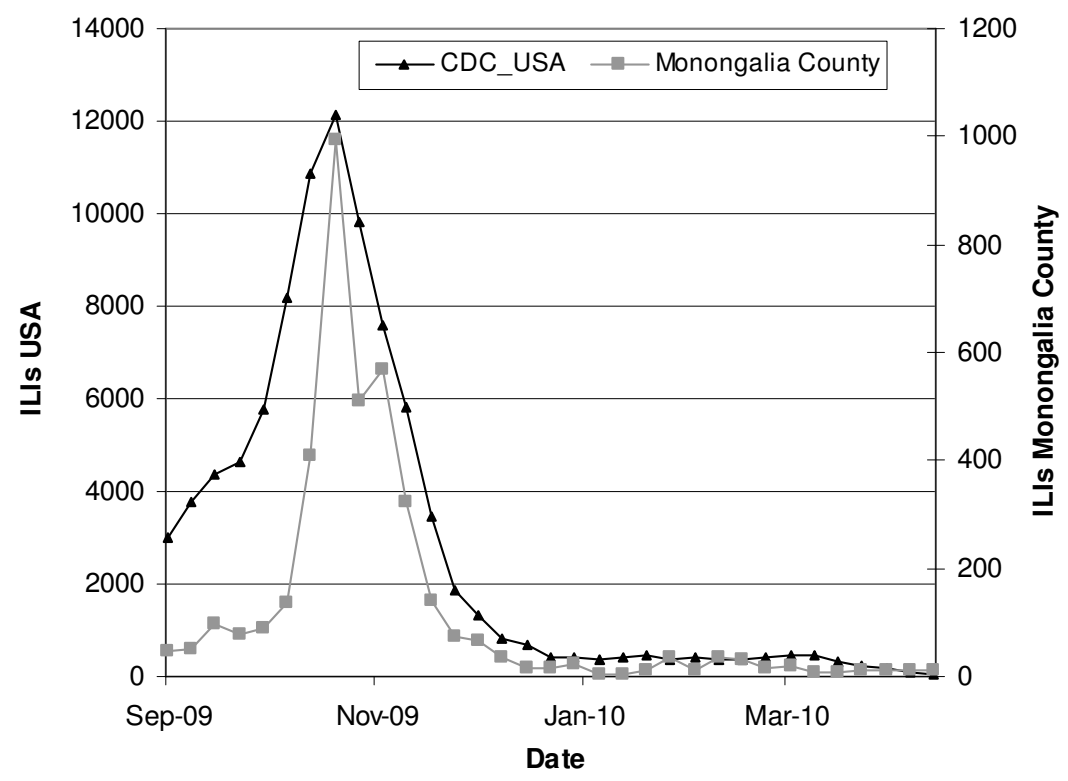

Figure 5. Comparison between influenza like illness reported in USA (WHO, 2010) and Monongalia County (Hinklet, 2010).

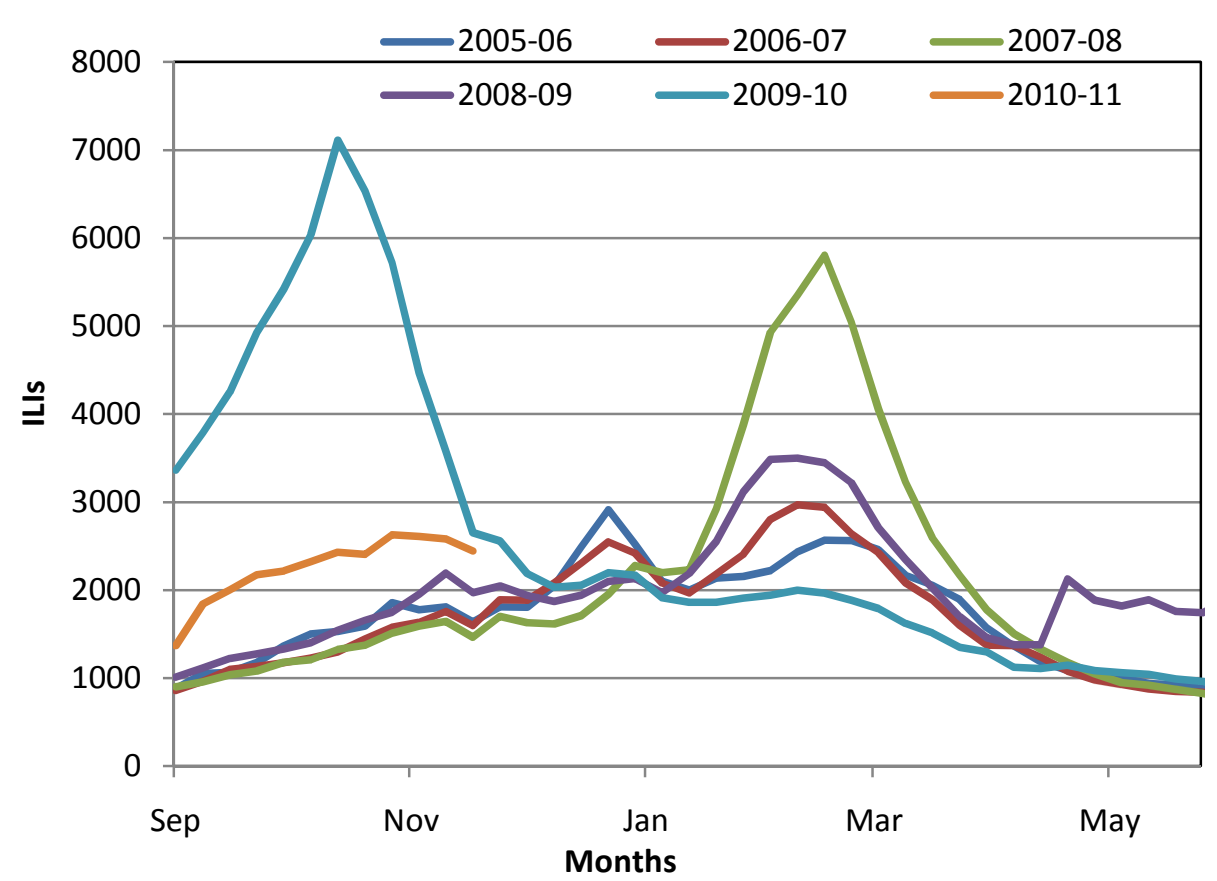

Figure 6. Influenza activities during the last five years (Google, 2010) in USA.

The number of influenza like illnesses reported from Monongalia County is plotted against the outside and indoor temperature and $\mathrm{RH}$ in Figure 7. The indoor temperature and $\mathrm{RH}$ plotted are the daily average 
data of the four weather stations. Outside data is from the weather station installed in the ESB. It is seen that the indoor temperature does not deviate too much from the average value of $23^{\circ} \mathrm{C}$. Indoor $\mathrm{RH}$ shows more variation than temperature. Figure 7(b) shows an increase in ILIs activity when indoor RH starts decreasing. The vertical downward arrows in Figure 7 show when influenza vaccines were applied at WVU. A solid ellipse at the end of October 2009 corresponds to the date when hand sanitizers were installed at WVU.

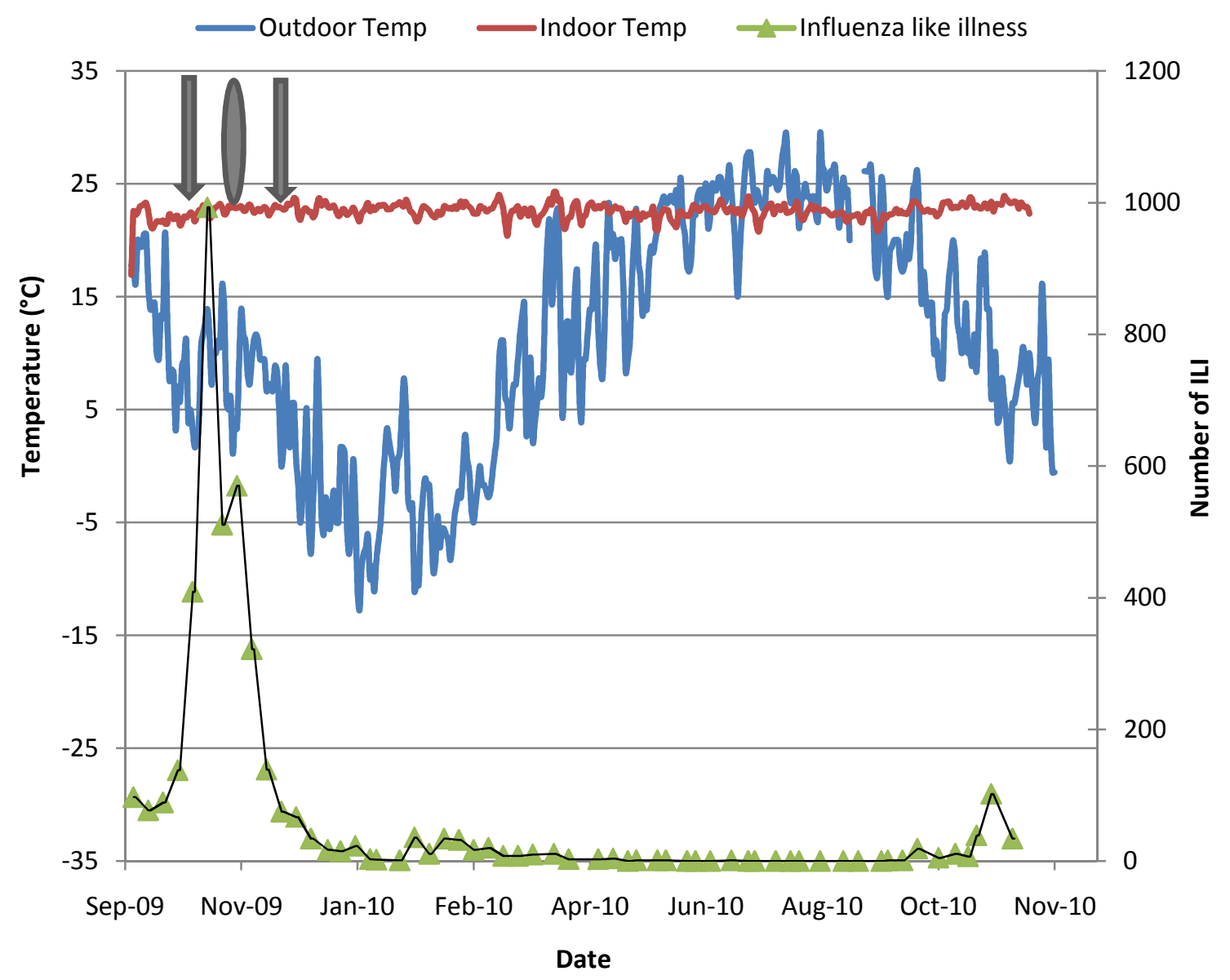

(a) 


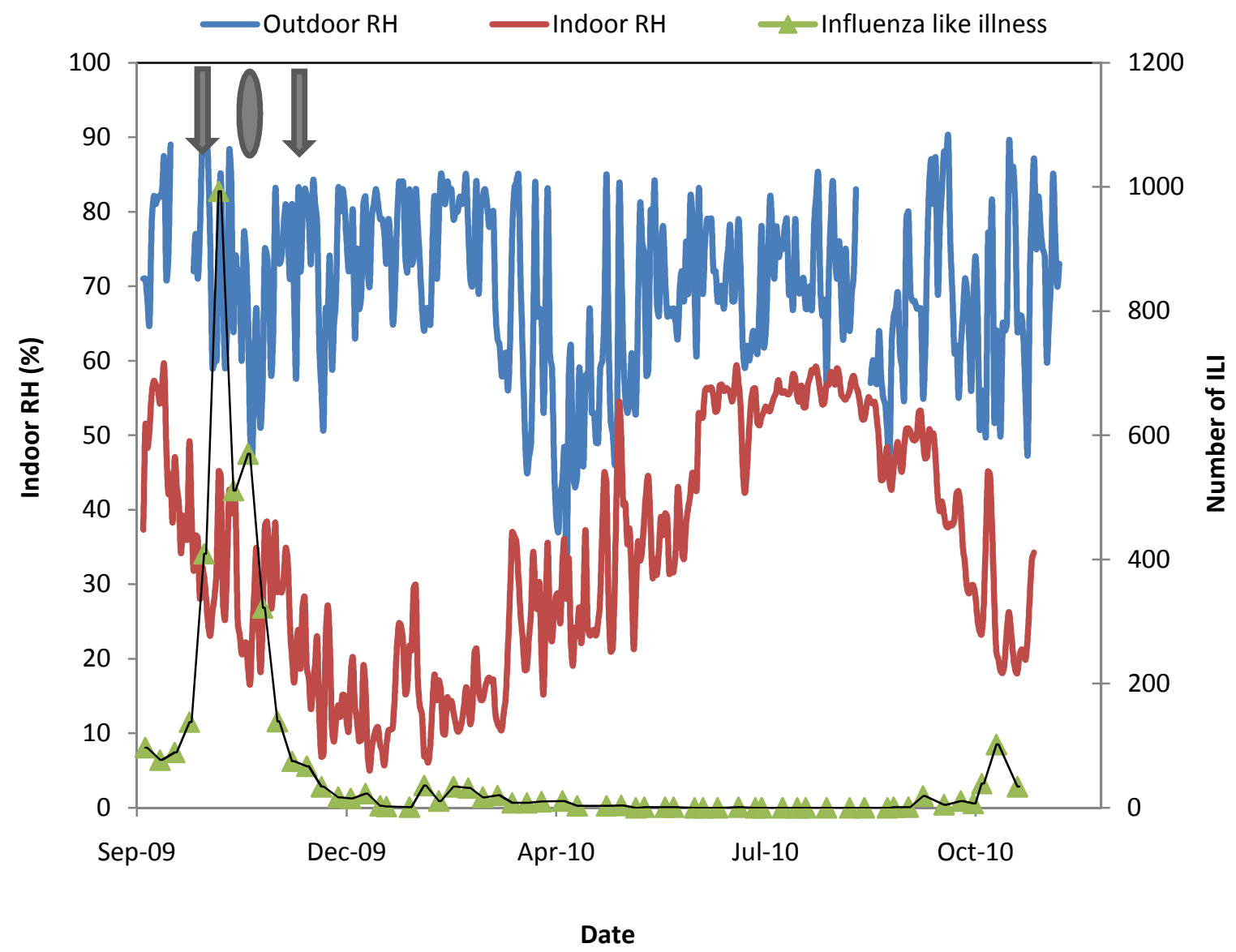

(b)

Figure 7. Number of Influenza like illness cases reported in Monongalia county plotted against temperature and relative humidity; (a) inside and outside measured temperature vs. ILI, (b) inside and outside measured RH vs. ILI.

Downward arrows show the time of influenza vaccines given in WVU and solid ellipse corresponds to the time when hand sanitizers were installed at WVU.

ILIs obtained from four cities in temperate region of USA are compared with the calculated indoor RH in Figures 8-11. The findings, from this comparison that lead to establish a relation between ILI occurrence and Indoor RH, are as follows.

Figure 8(a) shows the variation of ILIs in Morgantown WV during previous five influenza seasons with indoor RH during the last five years. Indoor RH is calculated as weekly average and compared with the number of ILIs reported in corresponding week. Figure 8(b) shows a cumulative graph of ILIs in a respective RH range. It is noticed that a higher number of cases is reported when indoor RH ranges from $10 \%$ to $30 \%$. The values on histogram bars in Figure 8(b) show the number of weeks which recorded the respective indoor RH. Total number of ILIs would be divided by this number to get the ILI occurrence on per week basis to taken into account the amount of time spent in particular $\mathrm{RH}$ range. If more of the time 
is been spent in indoor $\mathrm{RH}$ of $10 \%$ to $30 \%$ than compared to $70 \%$ to $100 \%$ then the chances could be more to catch influenza infection in lower RH because people spend more time in lower RH. Hence to include the effect of time, ILI cases are divided by number of weeks in the corresponding bins making sure the comparison of data is carried out when it is on same platform. The data comparison based on this criterion is independent of time variable. Figure 8(c) shows the histogram showing the ILI recorded per week against indoor $\mathrm{RH}$ ranges.

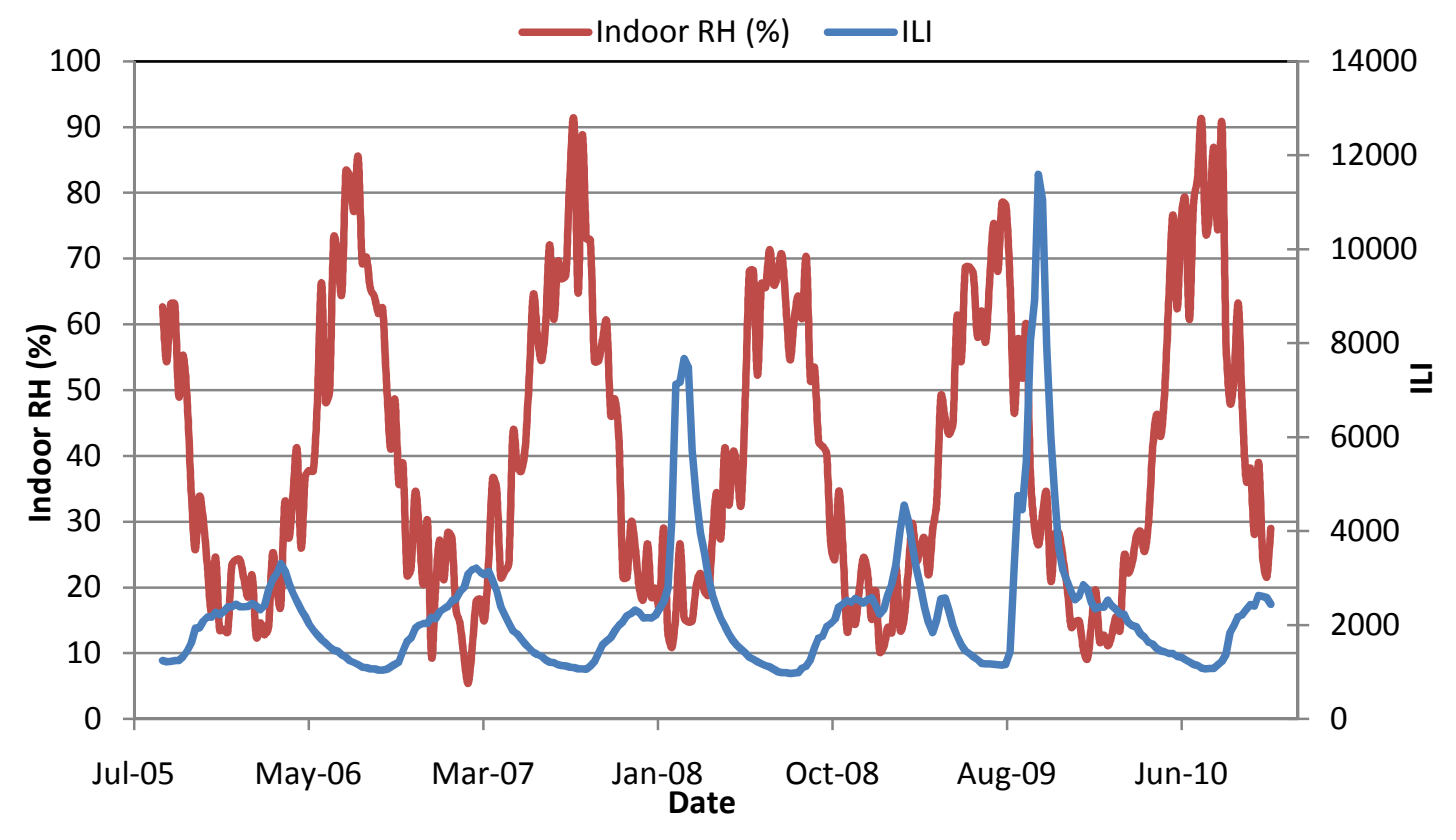



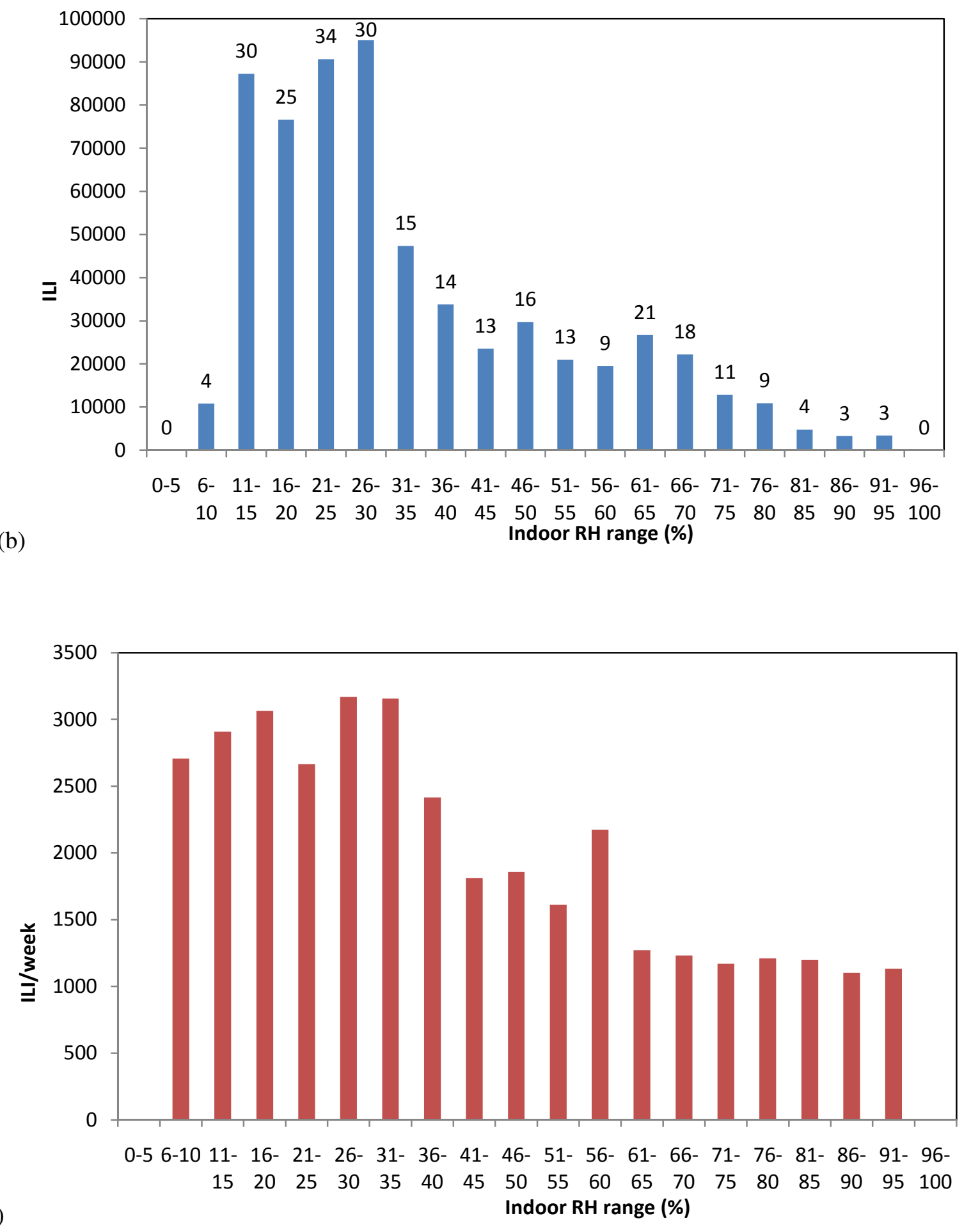

Figure 8. Morgantown, WV: (a) comparison of indoor RH and ILIs during the period of 5 influenza seasons starting from year 2005, (b) a cumulative graph showing total number of ILIs recorded in five influenza seasons in various $\mathrm{RH}$ ranges, the number above each bar indicates the number of weeks in each indoor RH range, (c) graph showing ILI/week against indoor RH 
In Newark NJ, the peak of ILIs occurred in February during the last five influenza seasons, except for 2009-2010 (Figure 9). This maximum has occurred when indoor relative humidity decreased below $20 \%$. Unlike previous years, 2009-2010 influenza activity is considerably higher and has peaked three months earlier. The peak in 2008-2009 influenza season may be due to 2009 H1N1 outbreak in April to June. Figure 9(b) shows the total number of ILIs during the last five seasons for each indoor RH range. Maximum ILIs are reported when indoor RH ranges from 5\% to 30\%. Histogram plotted in Figure 9(c) shows the effect of time on ILI plotted in Figure 9(b).

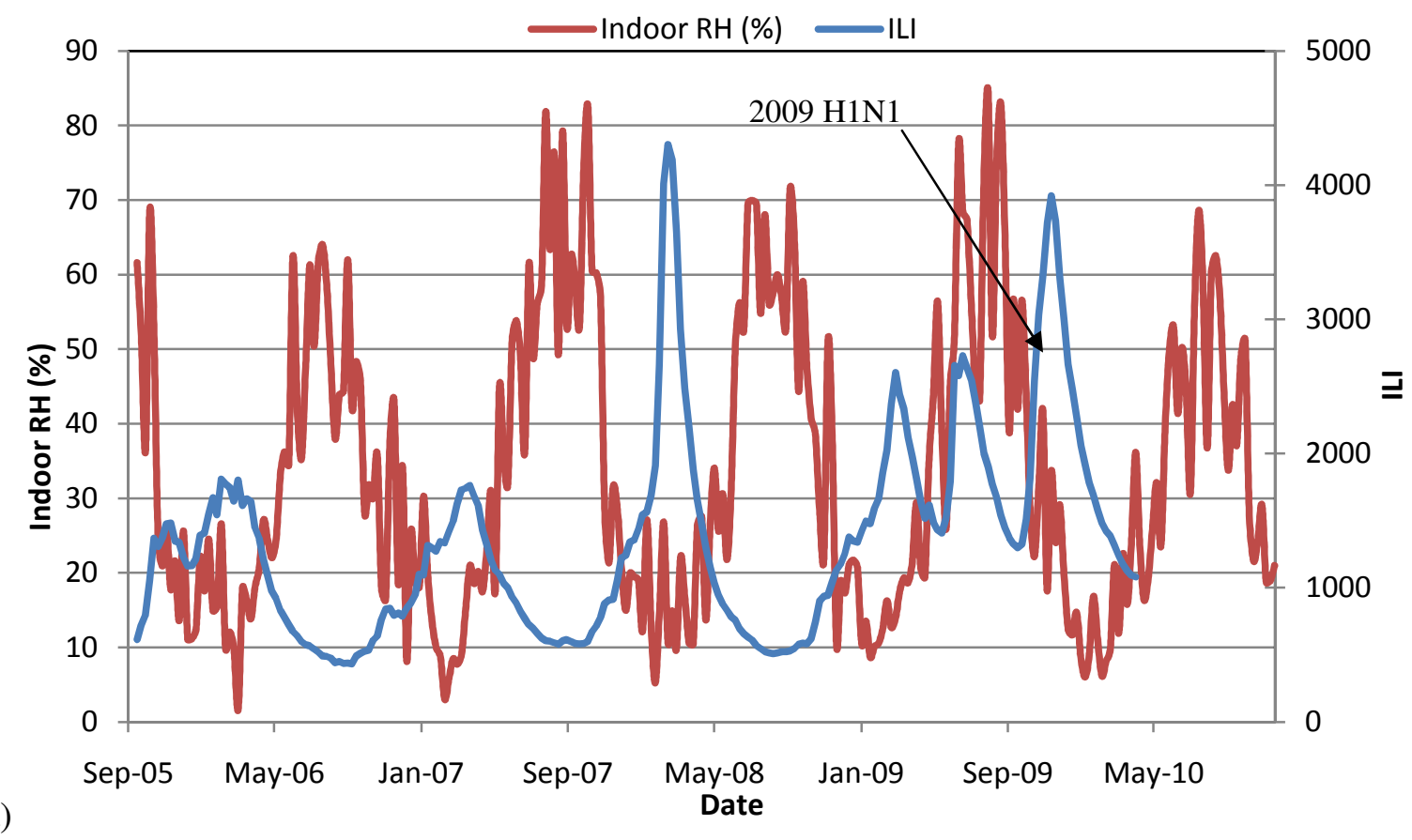




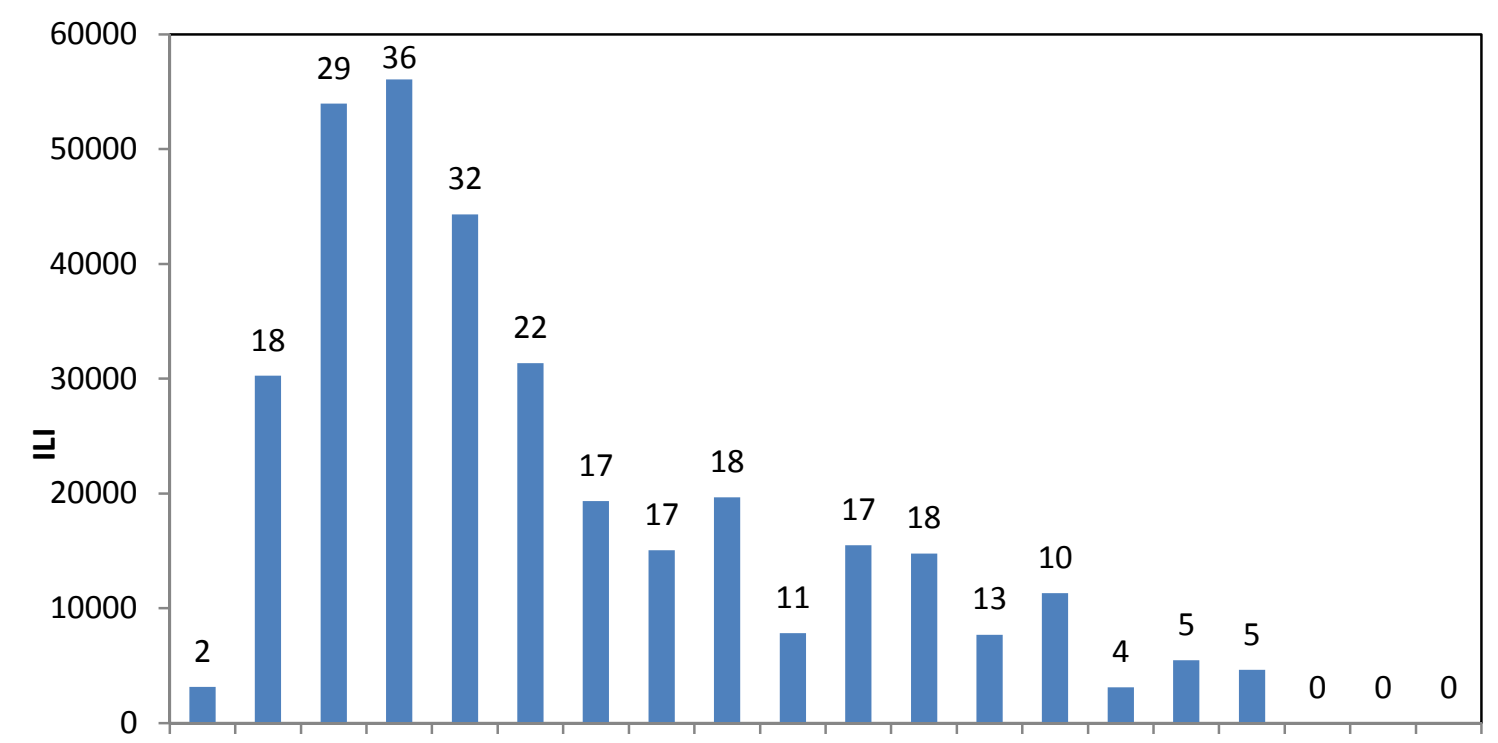

0-5 6-10 11- 16- 21- 26- 31- 36- 41- 46- 51- 56- 61- 66- 71- 76- 81- 86- 91- 96$\begin{array}{lllllllllllllllllll}15 & 20 & 25 & 30 & 35 & 40 & 45 & 50 & 55 & 60 & 65 & 70 & 75 & 80 & 85 & 90 & 95 & 100 \\ \text { Indoor RH range (\%) }\end{array}$

(b)

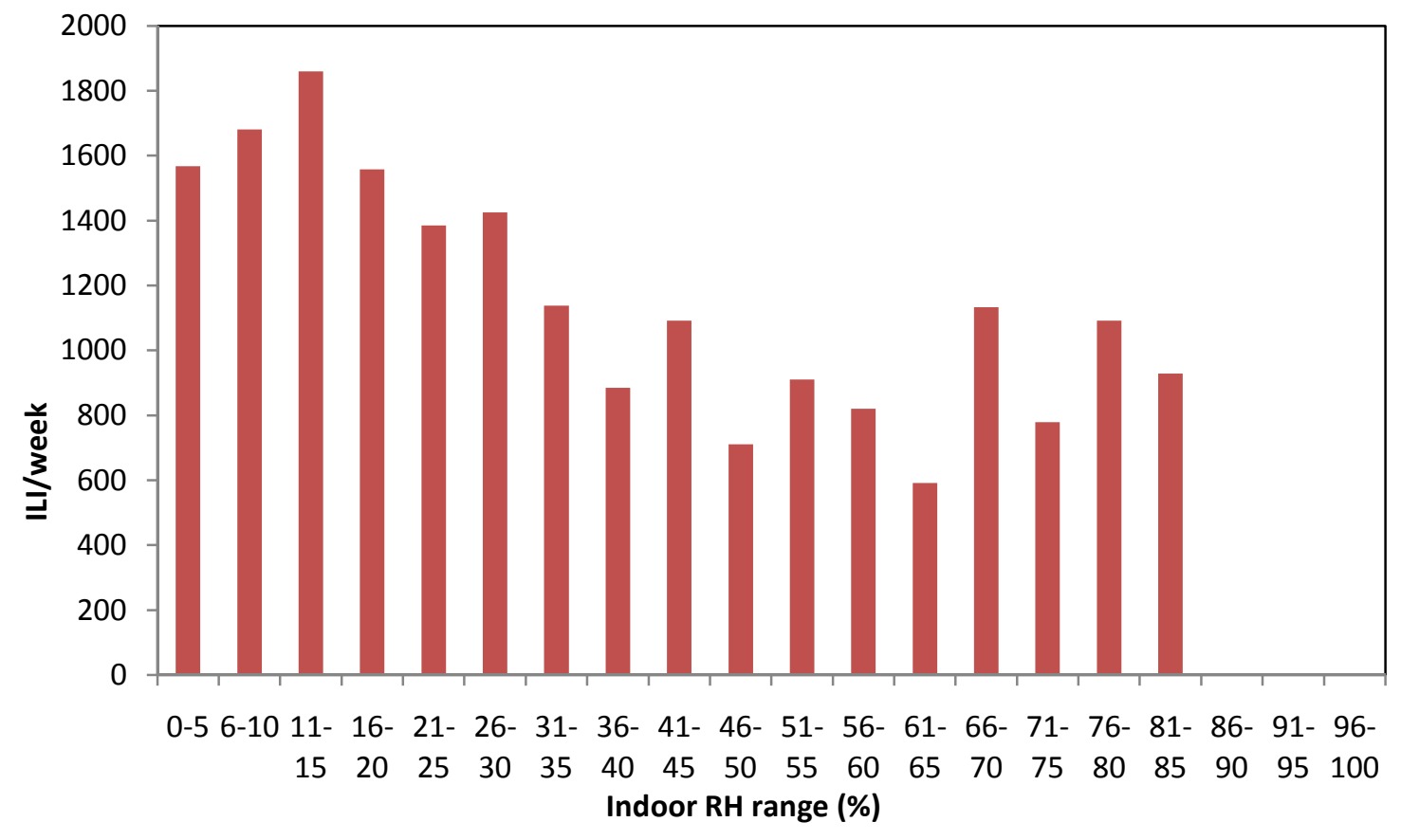

Figure 9. Newark, NJ: (a) trend comparison of indoor RH and ILIs over the period of 5 influenza seasons starting from year 2005, (b) a cumulative graph showing total number of ILIs recorded in five flu seasons in various RH ranges, the number above each bar indicates the number of weeks in each indoor RH range, (c) graph showing $\mathrm{ILI} /$ week against indoor $\mathrm{RH}$ 
The ILIs activity in Cleveland OH Figure 10(a) is very similar to that in Newark and Morgantown with some difference in severity of the ILIs. The 2009 H1N1 influenza peak in Cleveland is not as significant as in Newark. The shift of ILI peak towards left by 3 months is also noticed in Cleveland. However, Figure 10(b) shows different results as compared to Morgantown and Newark. The ILIs activity is higher when the indoor RH is between $0 \%$ and $35 \%$. Cleveland is located on the bank of a lake (Lake Erie) which exhibit different weather patterns compared to the other cities considered in this study. The outdoor temperature and $\mathrm{RH}$ are comparatively lower than other cities in this study for the same time period. To maintain the desired temperature in indoor environment outdoor air needs comparatively more heating hence indoor RH drops to as low as circa 0-5\%. And hence there are higher peaks of ILI cases for lower indoor RH as shown in histogram (Figure 10b). Figure 10(c) shows the ILI per week plotted against indoor RH range.

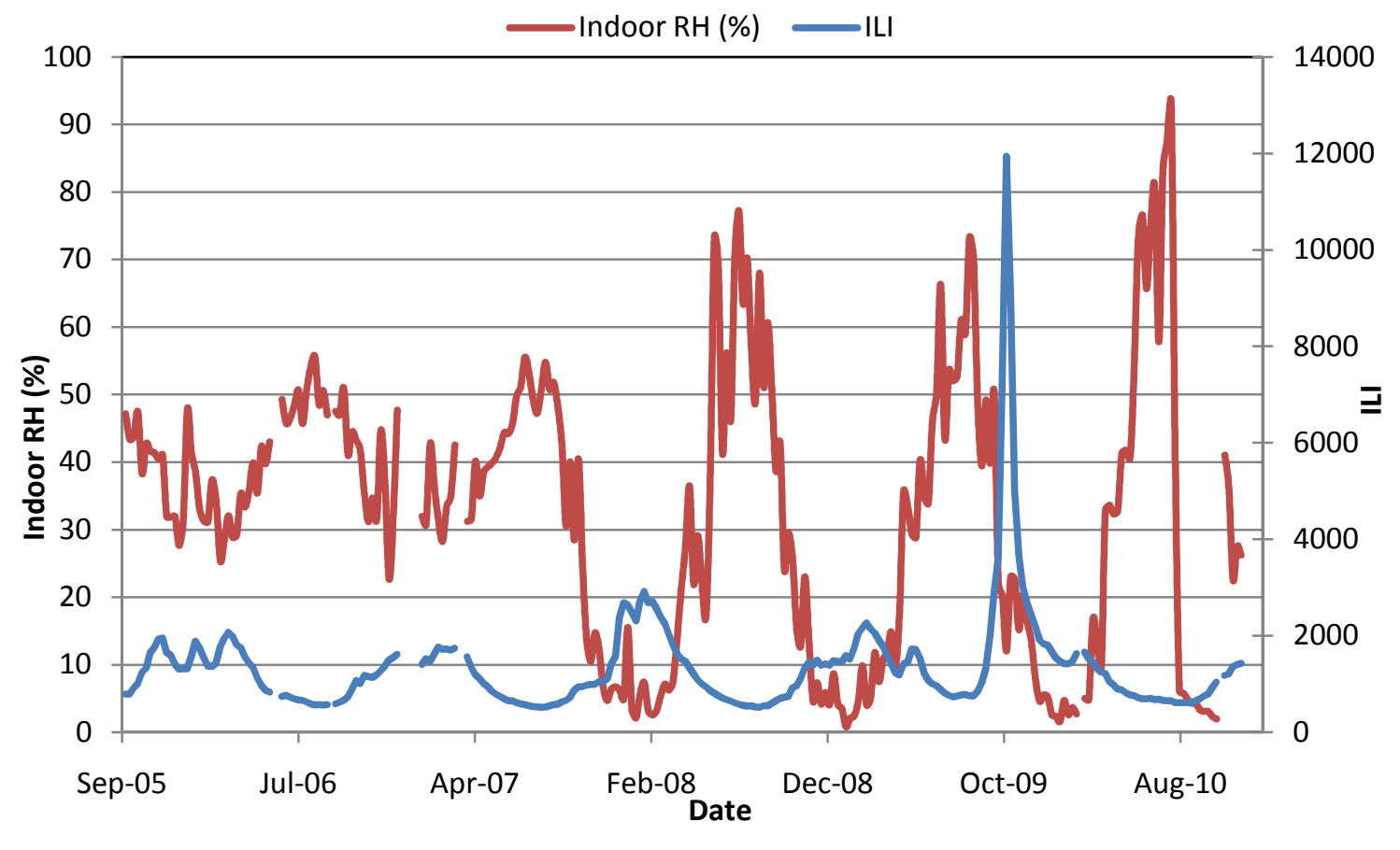




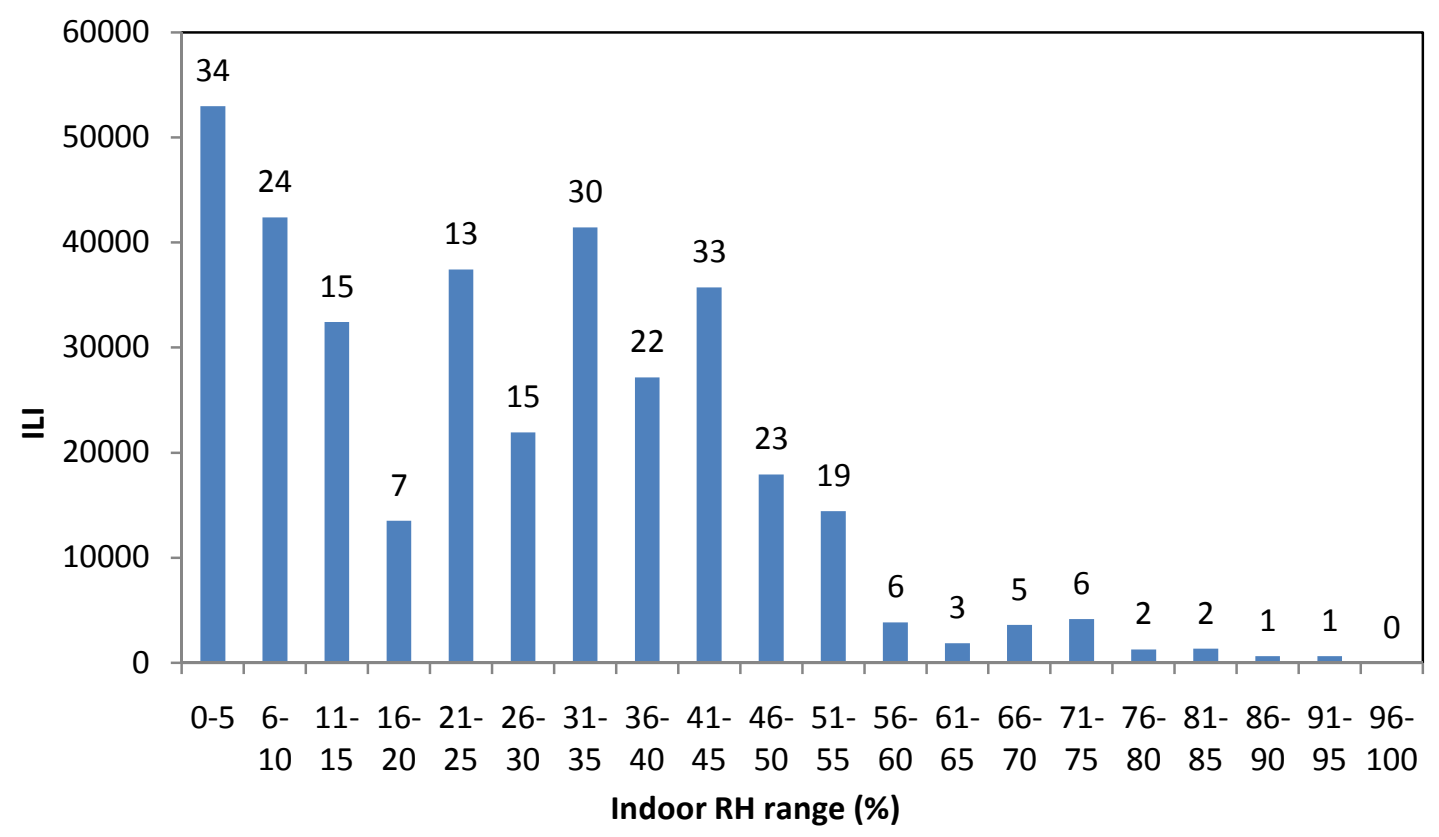

(b)

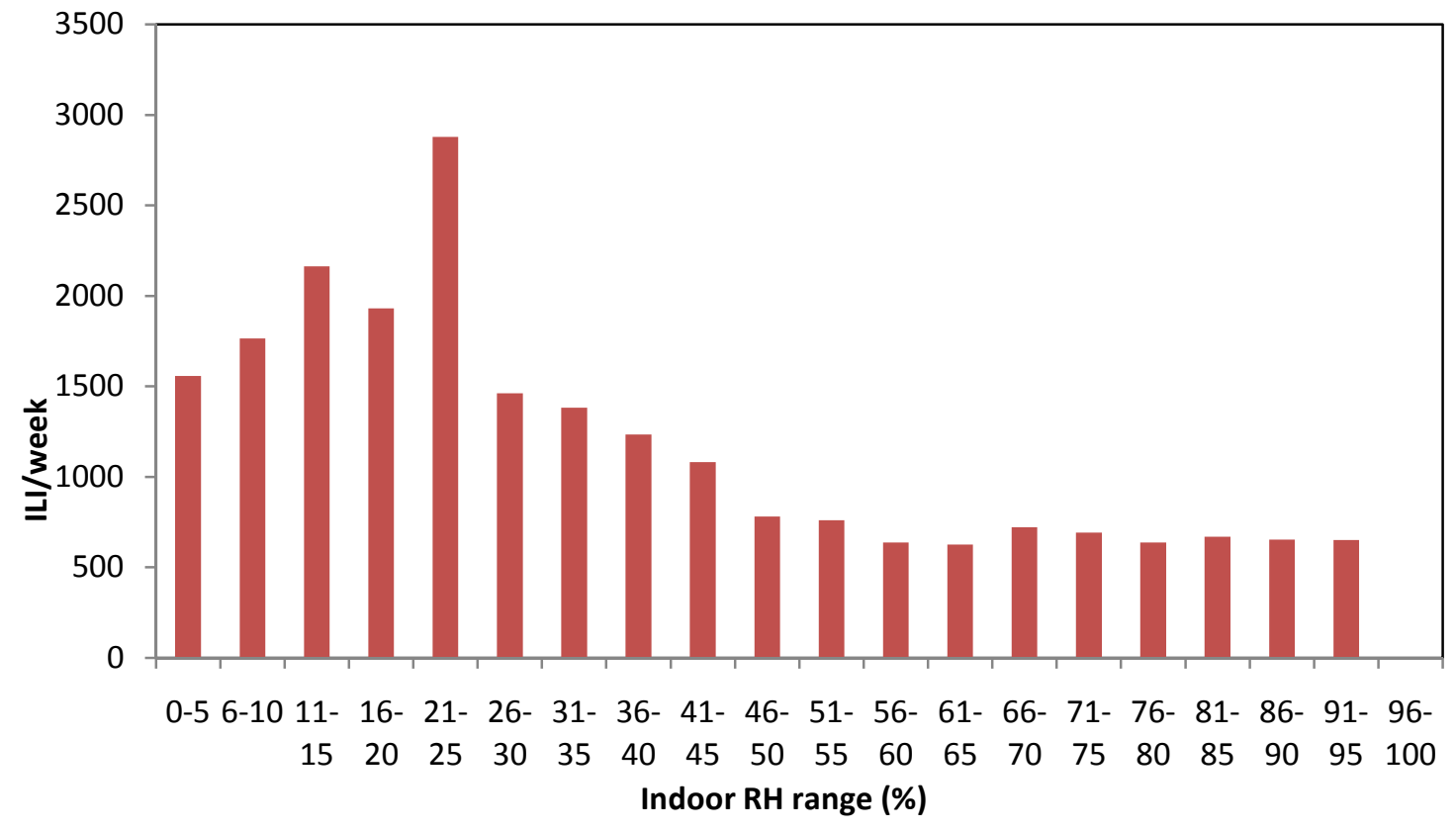

Figure 10. Cleveland, OH: (a) trend comparison of indoor RH and ILIs over the period of 5 influenza seasons starting from year 2005, (b) a cumulative graph showing total number of ILIs recorded in five flu seasons in various $\mathrm{RH}$ ranges, the number above each bar indicates the number of weeks in each indoor RH range, (c) graph showing ILI/week against indoor RH 
ILI activity in Columbus $\mathrm{OH}$ is illustrated in Figure 11(a). A distinct peak of ILIs is observed again in October 2009 to November 2009. This peak activity has occurred 3-4 months ahead of time if compared to the previous influenza seasons. Graphical data illustrated in Figure 11(b) is similar to the influenza activity seen in Morgantown WV and Newark NJ, but different than Cleveland OH. The indoor RH range in which maximum ILIs is recorded is $10 \%$ to $30 \%$. A bar-graph showing the variation of ILI per week against indoor RH is plotted in Figure 11(c). The graph shows that at lower indoor RH there are more ILI cases recorded in Columbus $\mathrm{OH}$.

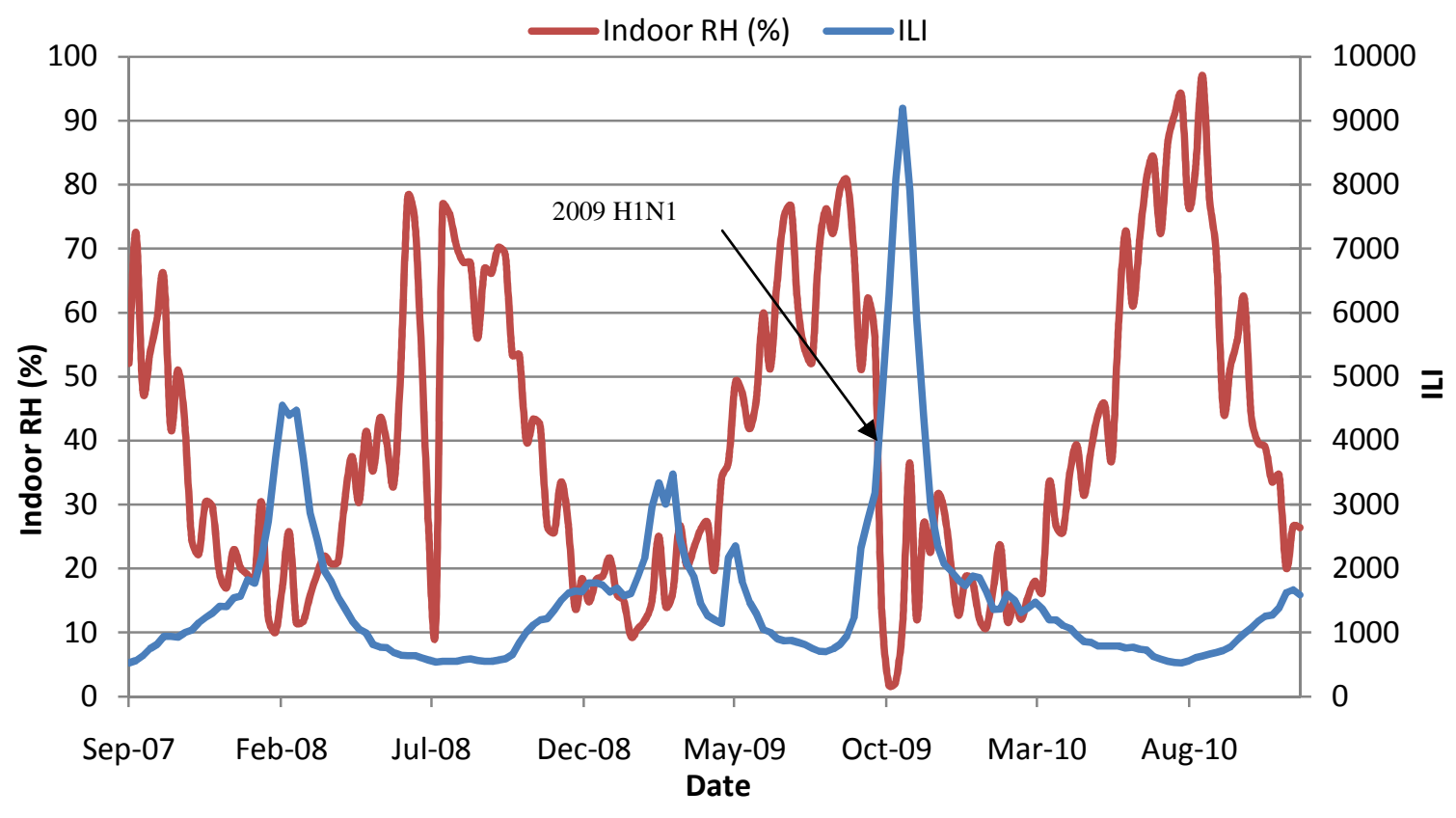

(a) 


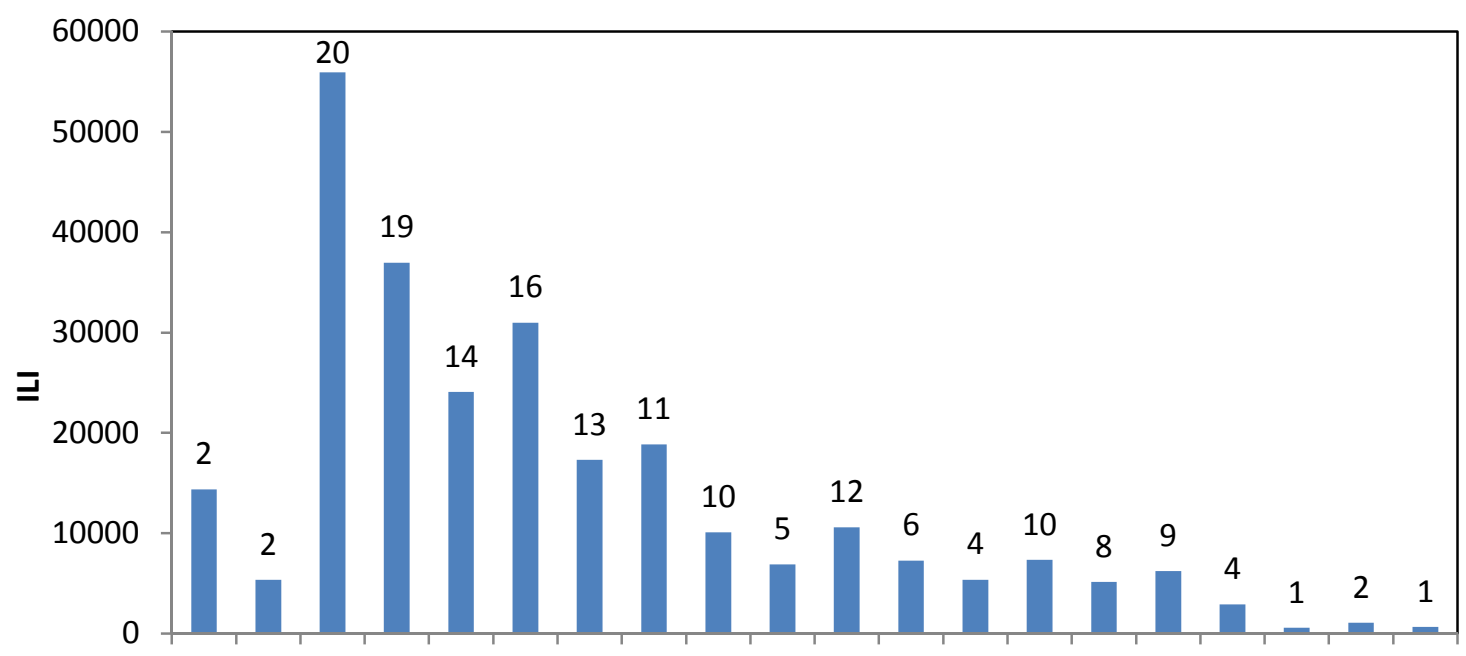

0-5 6-10 11- 16- 21- 26- 31- 36- 41- 46- 51- 56- 61- 66- 71- 76- 81- 86- 91- 96$\begin{array}{llllllllllllllllll}15 & 20 & 25 & 30 & 35 & 40 & 45 & 50 & 55 & 60 & 65 & 70 & 75 & 80 & 85 & 90 & 95 & 100\end{array}$

(b)

Indoor $\mathrm{RH}$ range (\%)

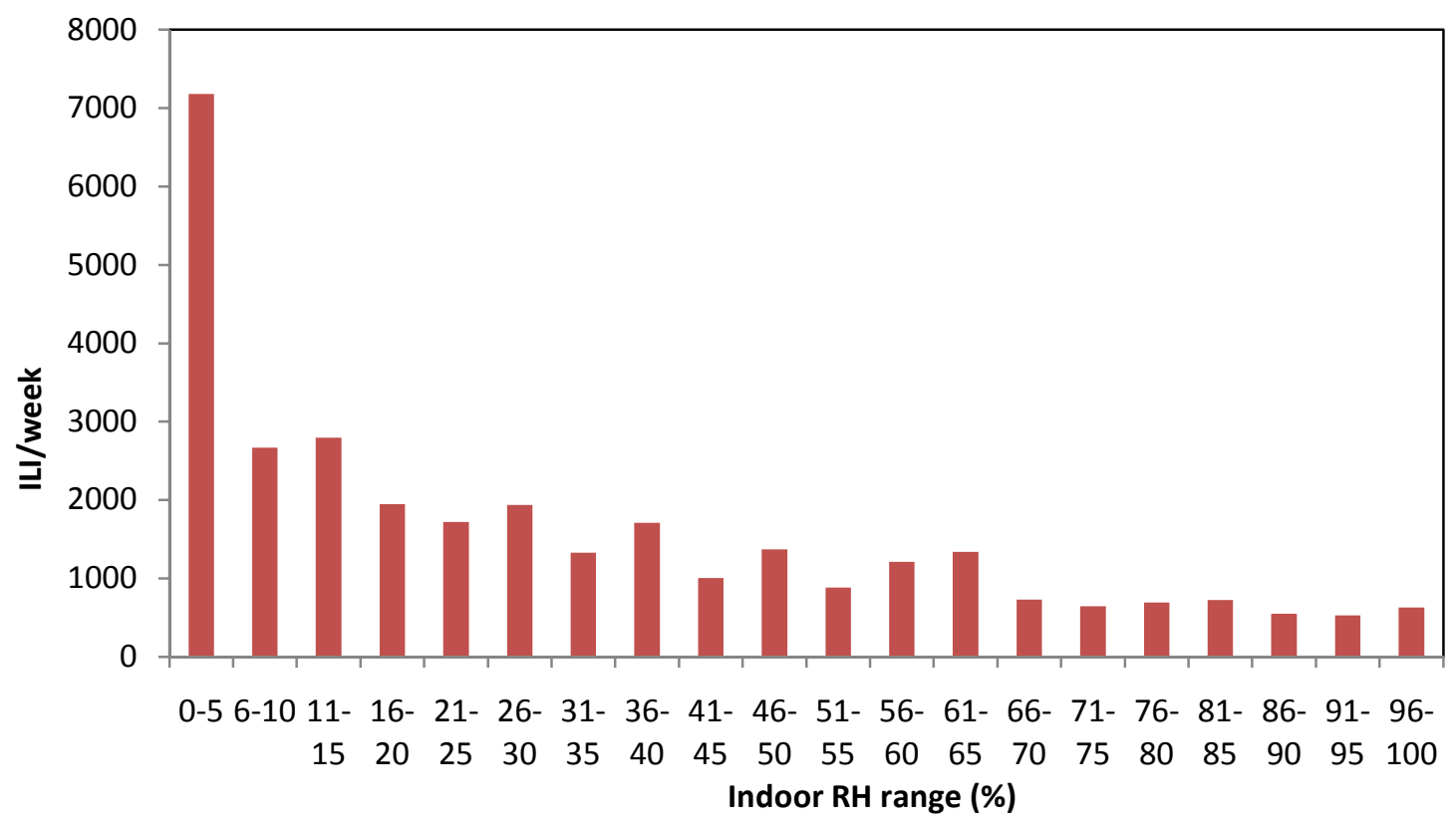

(c)

Figure 11. Columbus, OH: (a) comparison of indoor RH and ILIs during the previous influenza seasons, (b) cumulative graph showing total number of ILIs recorded in three influenza seasons in various RH ranges, the number above each bar indicates the number of weeks in each indoor RH range, (c) graph showing ILI/week against indoor RH 


\subsection{Log-normal Distribution}

Figures 8(b) -11(b) show the variation in occurrence of ILI in four major cities in USA located in temperate regions. Visual inspection of above histograms indicates a lognormal probability distribution function (PDF) would be appropriate for this phenomenon. If a lognormal distribution curve can be fit into the ILIs trend, it can be generalized as a probabilistic risk analysis of ILI occurrence when indoor RH falls in a particular range.

Lognormal distribution is applicable when a log of random variable is normally distributed, meaning it confirms to a bell curve. Lognormal distribution is given by Equation 3 (Celik, 2008)

$$
f(x ; \mu, \sigma)=\frac{1}{\sqrt{2 \pi} \sigma x} e^{-\frac{1}{2 \sigma^{2}}[\ln (x)-\mu]^{2}} \quad x>0
$$

where, $\mu$ and $\sigma$ are the mean and standard deviation, respectively.

Three of the four cities are analyzed using lognormal distribution hypothesis. Cleveland $\mathrm{OH}$ is not considered in this analysis because it shows a different trend between indoor RH and ILIs. Figure 12(a), 12(b) and 12(c) shows a lognormal curve fitted to the results of Morgantown WV, Newark NJ, and Columbus OH. Similarly, Figure 12(d) shows a lognormal curve fitted to the total number of ILIs in three cities.

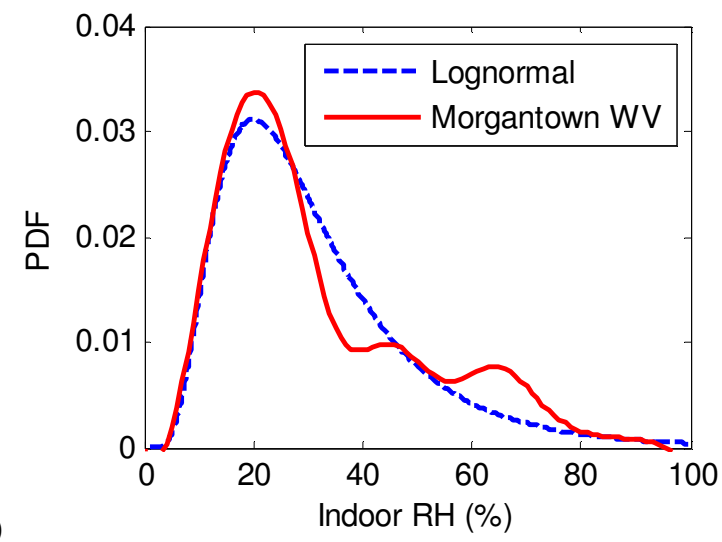

(a)

(b)

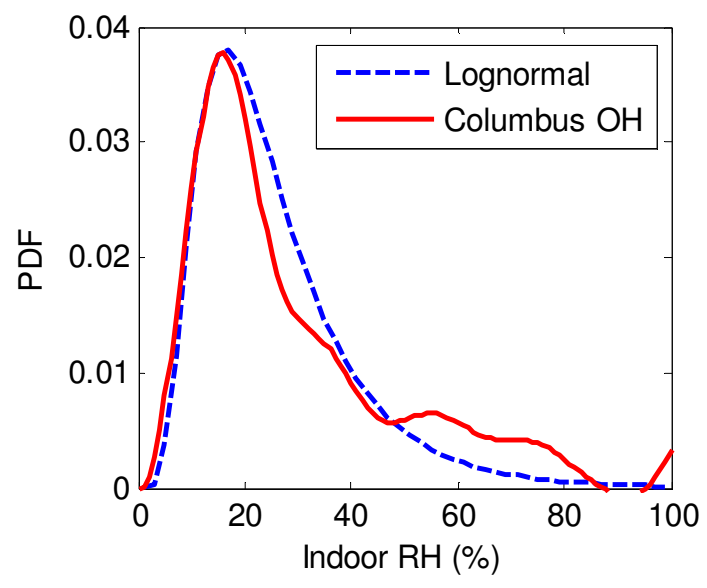




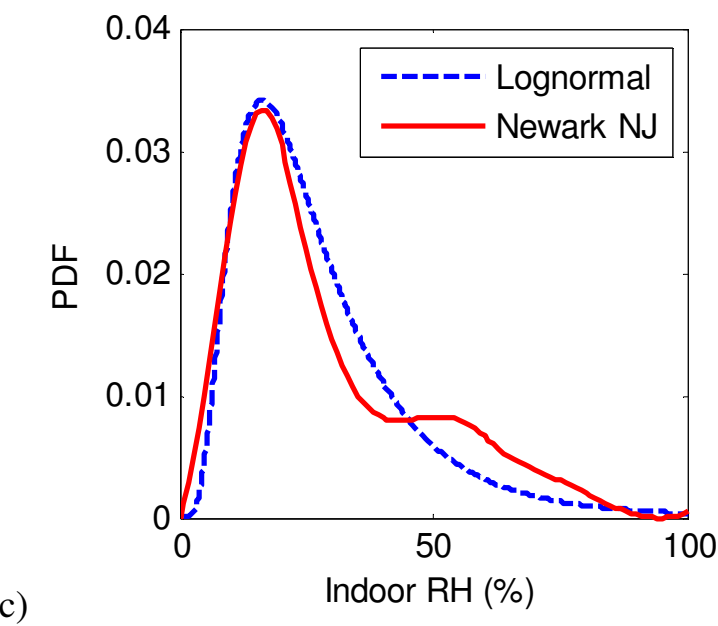

(d)

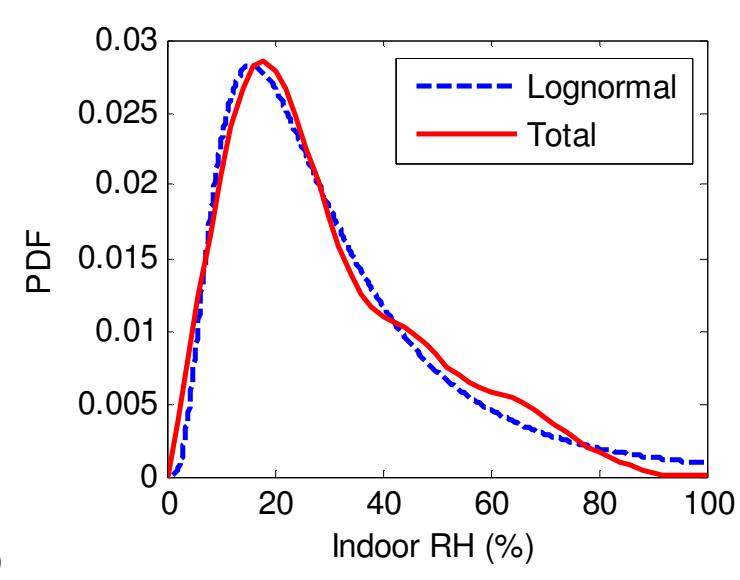

Figure 12. Lognormal curve fit:

(a) Morgantown WV, (b) Columbus OH, (c) Newark NJ, and (d) total of all three cities.

The statistical parameters in Equation 3 are given different values to obtain a good fit. Table 3 lists values of these parameters used for different cities. The variations in $\mu$ and $\sigma$ are in the range of 10 to $12 \%$ indicating that the lognormal distribution is a good fit to describe the statistics of ILIs against indoor RH.

Table 3. Values of mean $(\mu)$ and standard deviations $(\sigma)$ for ILI in different cities

\begin{tabular}{|l|c|c|}
\hline City & $\boldsymbol{\mu}$ & $\boldsymbol{\sigma}$ \\
\hline Morgantown WV & 3.3 & 0.55 \\
\hline Newark NJ & 3.15 & 0.6 \\
\hline Columbus OH & 3.15 & 0.55 \\
\hline Total & $\mathbf{3 . 3}$ & $\mathbf{0 . 6 7}$ \\
\hline
\end{tabular}

The lognormal distribution findings are very interesting. The ILIs trend in temperate region over past five years (3 years in case of Columbus $\mathrm{OH}$ ) can be brought down to a single curve describing the overall correlation of indoor RH and ILIs. A well defined probability risk analysis of ILI occurrence can be made with the help of lognormal distribution curve. A sample probability calculation is shown next:

E.g., calculate the probability risk when indoor RH is in the range of 10 to $30 \%$.

$\mathrm{P}\left(10<\mathrm{RH}_{\text {in }}<30\right)=(30-10) \times 0.025=0.50=50 \%$ 


\subsection{Relation between $\mathrm{RH}$ and AH}

In a recent study (Shaman and Kohn 2009), it is proposed that the onset of influenza activity is more of the function of absolute humidity (AH) than that of indoor RH. In this study indoor RH is proposed to be the related to ILI cases. The conflict is addressed as below:

$\mathrm{AH}$ is related to $\mathrm{RH}$ with the help of actual vapor pressure of the air. Specific humidity is a measure of AH (Shaman and Kohn 2009). Specific humidity is used for the further comparison and is calculated by using following formula:

Specific Humidity $=\omega=0.622 \frac{P_{v, a c t}}{P-P_{v, a c t}}$

where $\omega$ is specific humidity, $\mathrm{P}_{\mathrm{v}, \text { act }}$ is actual vapor pressure and $\mathrm{P}$ is ambient air pressure.

Relative humidity $=\phi=\frac{P_{v, a c t}}{P_{s a t}}$

where $\phi$ is relative humidity, $\mathrm{P}_{\mathrm{v}, \text { act }}$ is actual vapor pressure and $\mathrm{P}_{\mathrm{sat}}$ is saturation vapor pressure. Equation 5 and equation 2 are one and same

From equation 4 and 5, we can get

$$
\omega=0.622 \frac{\phi P_{s a t}}{P-P_{v, a c t}}
$$

Rewriting,

$$
\omega=\left(0.622 \frac{P_{s a t}}{P-P_{v, a c t}}\right) \phi
$$

Therefore,

$$
\omega=\text { const } \times \phi
$$

At any given point, specific humidity and relative humidity are related with a constant value which can be derived from the corresponding environmental conditions like temperature and pressure.

ILI cases in Morgantown are compared with the specific humidity to study the correlation. Figure 13 shows this correlation. 


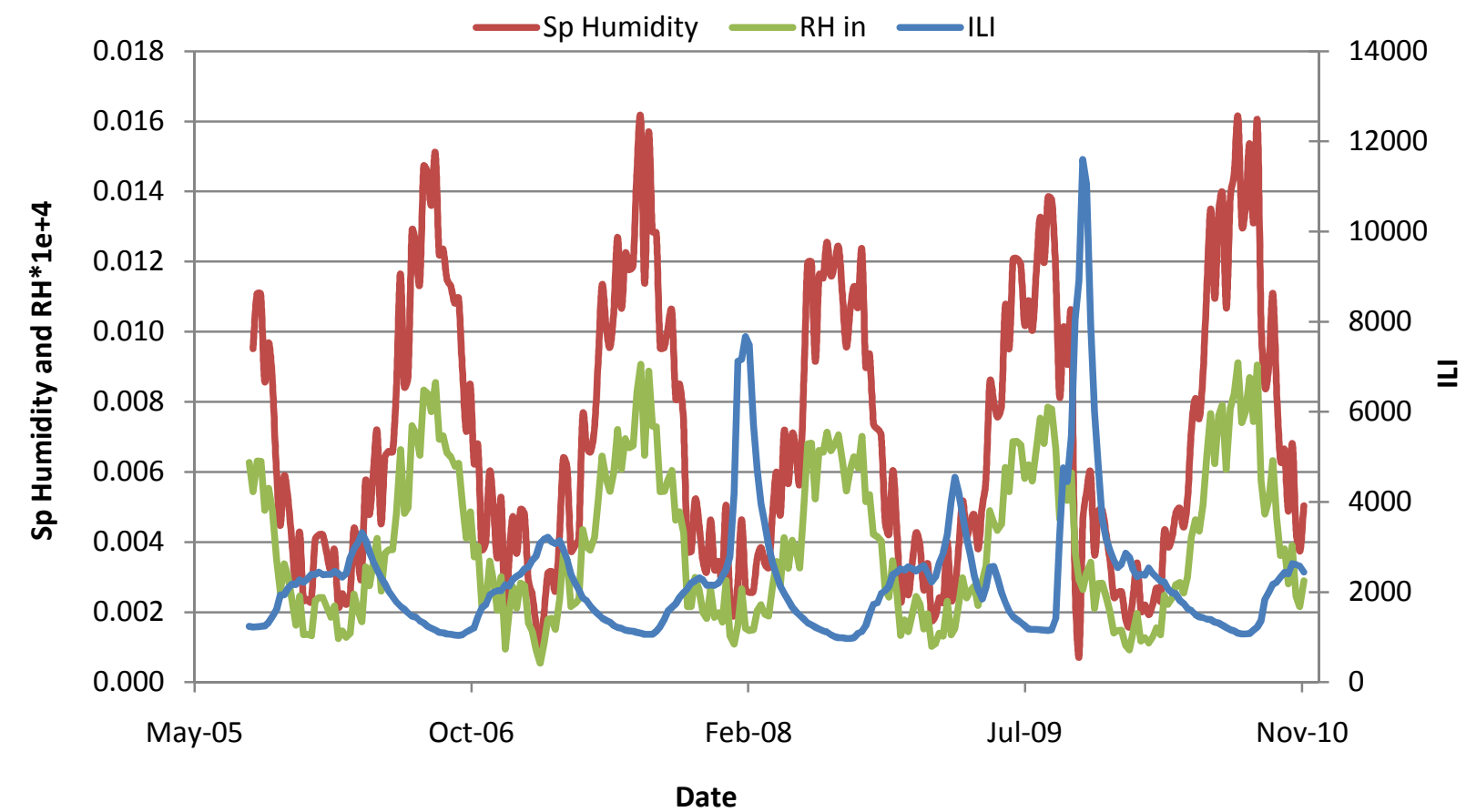

Figure 13: comparison of specific humidity and ILIs during the previous influenza seasons

It can be observed from Figure 13 that, indoor RH and specific humidity (which is the measure of $\mathrm{AH}$ ) vary in exactly same pattern. A similar correlation could be achieved either from indoor RH or AH with ILI cases in Morgantown. Hence it is difficult to comment that mere one of the parameter is the only one to have correlation with ILI. 


\section{Chapter 3}

\section{Simulated Cough Dynamics}

\subsection{Introduction}

Infection transfer via airborne route occurs when particles exhaled from an infected person travel through the air and are then inhaled by susceptible hosts. Particles can be exhaled by coughing, sneezing, or talking with different sizes and exit velocities. When an infected person coughs, viral-laden droplets are expelled into the air. Larger particles tend to settle down quickly on surfaces while smaller particles have a tendency to remain airborne for a longer time. The maximum velocity during cough ranges from 20 to $30 \mathrm{~m} / \mathrm{s}$, hence particles generated during coughing may travel longer distances in a short time than particles generated during talking. Coughed or sneezed particles may travel over $3 \mathrm{~m}$ distance during the initial time since maximum velocity is comparatively higher (Gao \& Niu, 2005). The particle cloud is denser near the mouth and concentration reduces with distance from the mouth due to turbulence and diffusivity. A reason for selecting cough over sneeze for this study can be explained as; coughing is a very common symptom of influenza. Influenza-like illness is defined as fever $>100^{\circ} \mathrm{F}$ and cough and/ or sore throat without another identified cause. However, influenza patients actually typically don't sneeze very often. Sneezing is more characteristic of something like a rhinovirus, which cause the common cold (Lindsley, 2010).

For the prevention of airborne influenza transmission, it is important to know how cough droplets are expelled from human mouth and dispersed in the surrounding air. Droplets coughed out of influenza infected persons are considered to be transporters of infection (Zhu et al., 2005).

The main purpose here is to study the dispersion and transport of droplets generated during coughing. Hence, it becomes imperative to study the cough particle spread in a room as a function of time. Experiments were performed in an enclosed room to study human cough particle dispersion. A Computational Fluid Dynamics (CFD) model was developed to extend the findings of experimental results. The experimental results were compared with the CFD simulation to validate the numerical results. 


\subsection{Human Cough Experiments}

The National Institute of Occupational Safety and Health (NIOSH) have been working on experiments of human cough in an effort to develop effective measures for infection and pandemic prevention (Redrow, 2009). They have set up an experimental laboratory called 'Environmental Chamber' (EC) in their Morgantown WV facility. NIOSH has developed a cough machine to understand the cough particle distribution and spread from an infected person. The cough machine replicates an average human cough with same flow rate as a function of time and particle size distribution. The cough machine is used in EC to study cough dynamics. West Virginia University (WVU) is extending the findings of cough machine experiments with computer simulated human cough using commercial CFD code FLUENT. Replica of EC and cough machine is simulated with the help of commercial grid generation software GAMBIT. FLUENT simulations are flexible as one or more than one parameter can be modified to study its impact on cough particle distribution in room. FLUENT simulation data is compared with experimental results from NIOSH laboratory which helps in understanding of human cough dynamics (Redrow, 2009).

Environmental chamber consist of three main parts: (1) a cough machine that discharges an aerosol-laden cough through a head form (called the coughing head form) which is a simple mannequin standing with its back towards wall, (2) a second head form (called the breathing head form) connected to a breathing machine to simulate respiration cycle, and (3) aerosol particle samplers counting concentrations in the coughing and breathing systems at several selected locations (Szalajda et al., 2010).

Experiments in NIOSH environmental chamber are carried out to study cough particle concentration at various heights and positions. Simulated cough machine in NIOSH uses potassium chloride with density of $1987 \mathrm{~kg} / \mathrm{m}^{3}$ as a coughing material to produce dry particles of same size as human cough. Potassium chloride as a fairly same particle density as human cough and hence is selected in all the experiments. Cough machine can produce particles ranging from $0.3 \mu \mathrm{m}$ to $4 \mu \mathrm{m}$ in 9 bins. The particles are fairly continuously distributed; the 9 bins refer to the size fractions that are reported by the GRIMM. Particles of potassium chloride are collected in a piston cylinder. The aerosol concentration and particle size distribution in the cough machine cylinder were monitored using an Aerodynamic Particle Sizer (APS) (Model 3321, TSI, Shoreview, MN) is used to measure particle count for respective particle size bin. APS measures the particle size distribution in piston-cylinder assembly of cough machine and reports the results to the computer. Piston is driven by a linear motor. Parameters like piston stroke and pressurized air are selected in such a way that the machine coughs replicate an average human cough. 
Triggered cough particles travels in the room in which five real-time aerosol spectrometers, GRIMM Technologies Inc. (Airning, Germany) are used to measure the particles concentration at various locations. These particle samplers measure the particle concentration in a real time data and represent this information on the screen or can store in a computer when connected.

Aerosol spectrometer and dust monitor model \#1.108 (GRIMM, Airning Germany) is used during experiments in environmental chamber. Model \#1.108 can detect aerosol particles in the range of $0.3 \mu \mathrm{m}$ to $20 \mu \mathrm{m}$ in 15 size channels (called bins) and represents count in particle number concentration. Sampling time can be changed according to requirement, for the purpose of experiments; normal mode of sampling is selected giving particle count after every 6 seconds (GRIMM, 2008). With the help of data obtained from experiments, particle distribution, time required for particles to reach a particular location and number of particles reached at that location can be studied.

Figure 14 shows an aerosol particle sampler model \#1.108. Main specification of GRIMM samplers are tabulated in Table 4. Sampling air is pulled into the measuring instrument with the help of a small suction pump. Air is drawn from the blue color port shown in Figure 14. During the experiments, the sampler is kept in vertical position with a steel probe accessory attached to it. Figure 15 shows a schematic of attached probe. The spectrometer distribution around aerosol sampler is such that it does not interfere significantly with the air flow. In normal mode (with no probe attached), air is pulled vertically downwards into the sampler which may result in experimental errors of concentration measurement as the horizontal flow will be interrupted. With the help of probe uniform air intake from all direction is ensured leading to an accurate and precise particle concentration measurement.

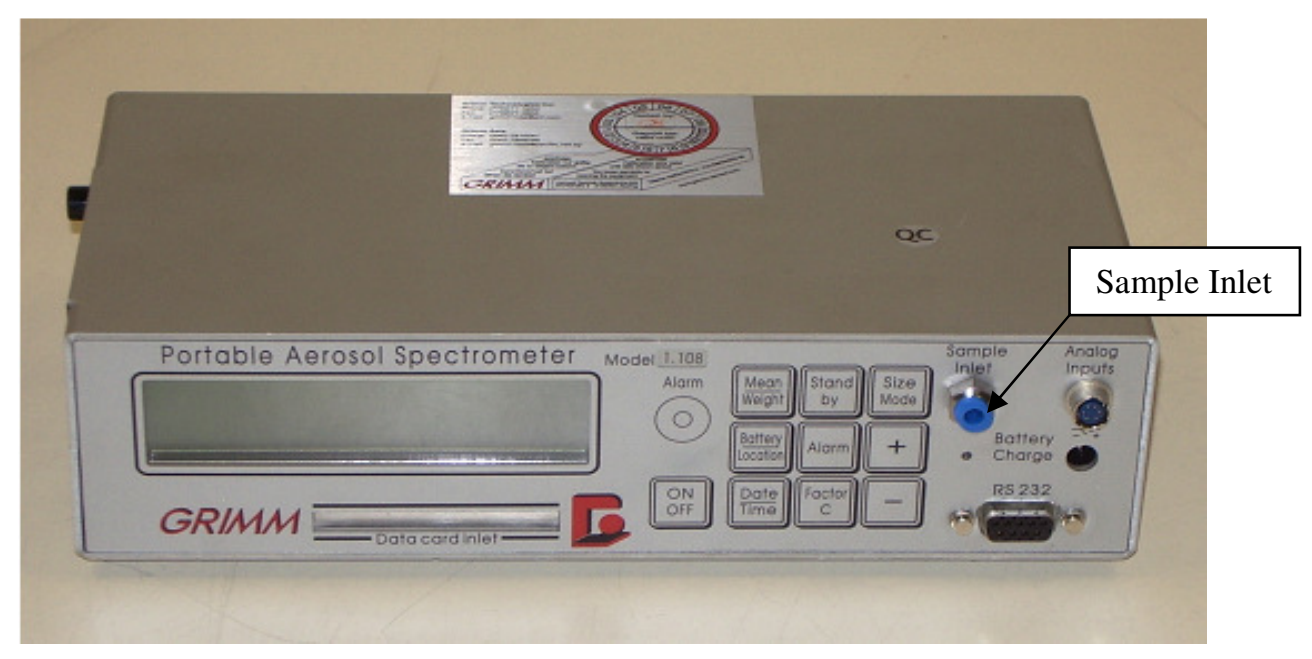

Figure 14. Aerosol Particle Sampler Model 1.108 (GRIMM, 2008). 


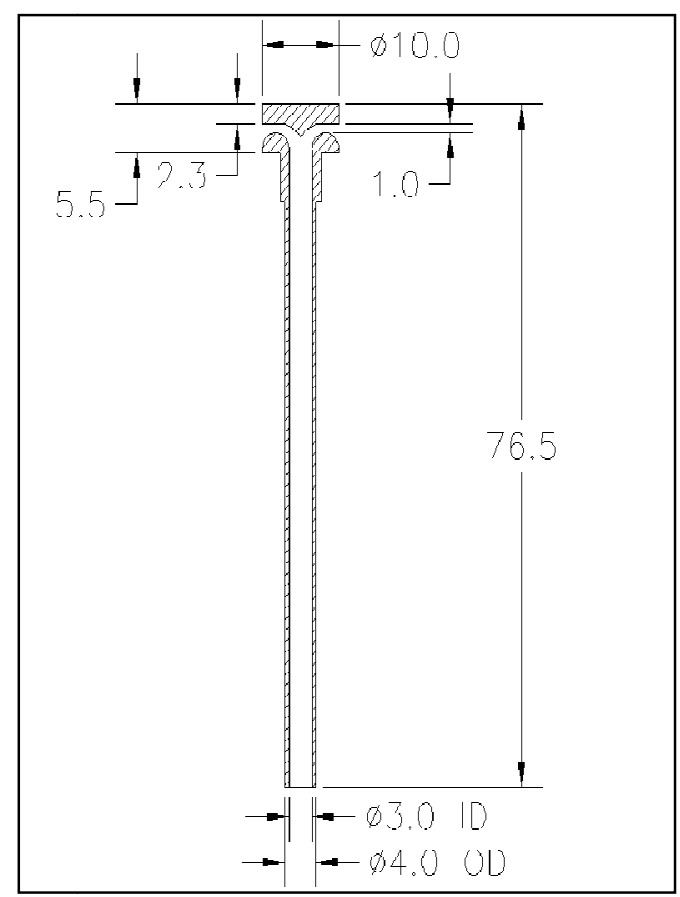

Figure 15. Sampling Probe

(Image courtesy of Dr. W.G. Lindsley, NIOSH)

Table 4. GRIMM particle counter specifications (Grimm, 2008).

\begin{tabular}{|l|l|}
\hline Parameter & Value \\
\hline Particle concentration & 1 to $2,000,000$ particles/liter \\
\hline Measuring range & $0.3 \mu \mathrm{m}$ to $20 \mu \mathrm{m}$ in 15 size channels \\
\hline Volume flow-rate & 1.2 litre/minute \\
\hline Sampling time & $6 \mathrm{sec}($ normal), $1,2,3 \mathrm{sec}$ (fast mode) \\
\hline Data storage & internal $80 \mathrm{~KB}$, with storage card $4 \mathrm{MB}$ \\
\hline Interface & $\mathrm{RS}-232$ Interface $(\mathrm{USB}$, modem optional) \\
\hline Temperature range & 0 to $+40^{\circ} \mathrm{C}\left(32\right.$ to $\left.104{ }^{\circ} \mathrm{F}\right)$ \\
\hline Humidity range & relative humidity $<95 \%$ (non condensing) \\
\hline
\end{tabular}

\subsection{PIV Measurement}

The virtual plane of influence from which air is drawn into the Grimm particles sampler can be measured using the Particle Image Velocimetry (PIV) technique. PIV is a flow measurement technique which can 
be used to measure the entire or localized velocity/flow field. The estimated velocity field is computed from local correlations of snapshot-pairs of the particle-seeded flow, obtained by high-speed cameras (Raffel et al., 2007).

A high intensity laser light is positioned to illuminate the test plane/volume, and the scattered light from the tracer particles is recorded with the digital cameras followed by processing the images. Schematic diagram of PIV setup is shown in Figure 16. This methodology is an effective way to estimate the influence of sampler suction in the surrounding with minimum interruption to the flow. The experiments are carried out in two different positions of sampler: in vertical and in horizontal plane. PIV measurements were helpful to conclude the spectrometer limits in $\mathrm{x}, \mathrm{y}$, and $\mathrm{z}$ directions.

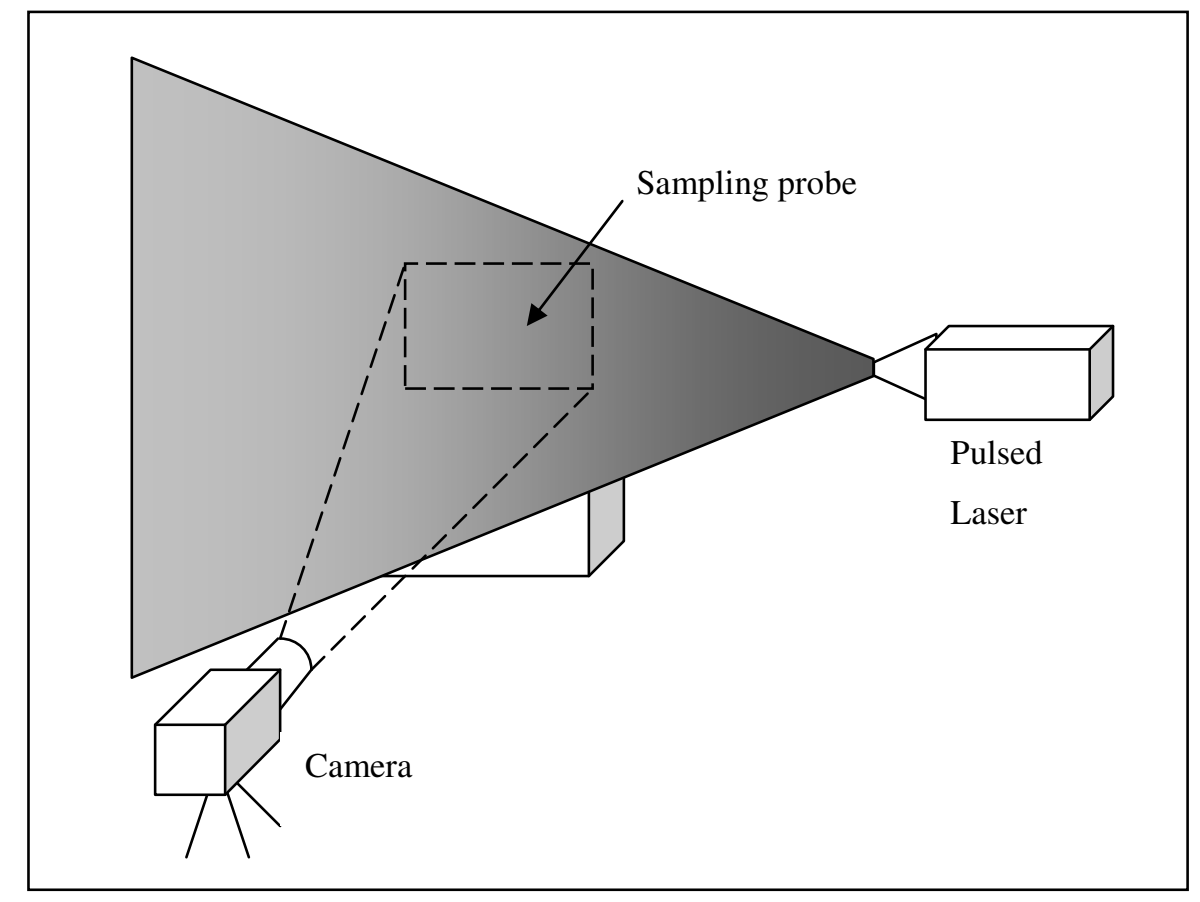

Figure 16. PIV setup.

A wooden ruler is positioned with the center position of GRIMM probe. After calibration, the ruler was removed to clear the study plane. Images obtained from PIV measurement are shown below in Figure 17(a) and 17(b). Figure 17(a) shows the influence of sampler in vertical plane (x-y plane) while Figure 18(b) shows it in horizontal plane (x-z plane). Images shown in Figure 17(a) and 17(b) are superposition of two images. One being the image taken before experiment started (which shows ruler calibration) and other image is actual image from PIV measurement (which shows the flow field around the probe). Disturbance created in the surrounding of probe can be seen from these images. 
(a)

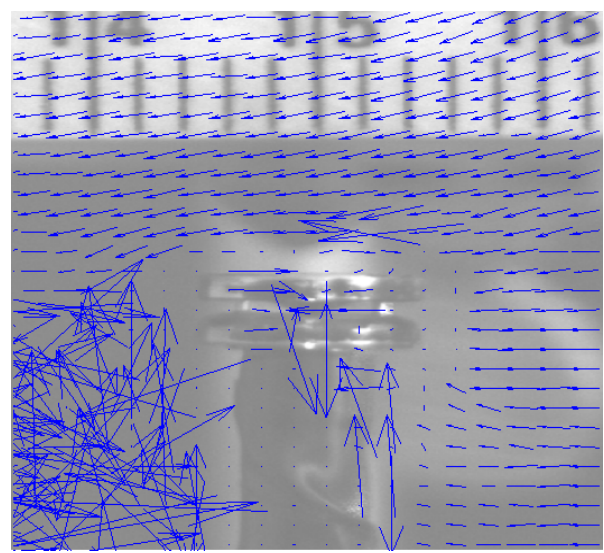

(b)

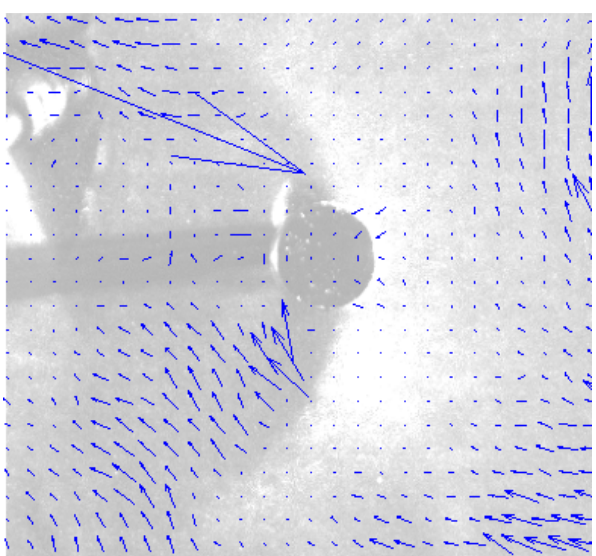

Figure 17. PIV image showing sampler spectrometer:

(a) $x-y$ plane, and (b) $x-z$ plane.

(Courtesy: Dr. Doddril, WVU)

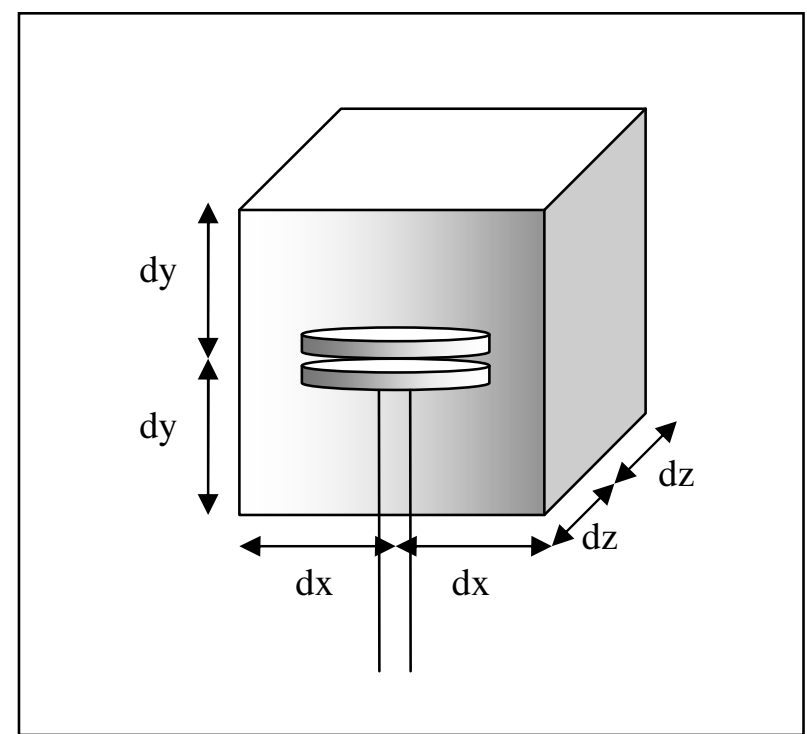

Figure 18. Spectrometer around sampler probe.

The influence of suction by sampler can be felt at approximately $1 \mathrm{~cm}$ from probe center in either direction, this can be seen clearly in Figure 17(a), the ruler is in centimeters with $15 \mathrm{~cm}$ mark positioned with center of the probe. Hence, it seems reasonable to assume that the Grimm volume of influence is a cube of $2 \mathrm{~cm}$ such as shown in Figure 18. The result from PIV measurement is used in step 2 of the postprocessing (explained in detail in following sections) of FLUENT simulation results. Spatial volume in terms of $\mathrm{dx}, \mathrm{dy}$, and $\mathrm{dz}$ is used in Matlab code which compares particle coordinates with GRIMM position in EC. 


\subsection{Numerical Simulations}

For this study, CFD simulations were carried out using the FLUENT v6.3.26 software (Fluent, Ansys, Canonsburgh, PA) (Fluent 2005), on a mesh generated by John Redrow (2009) using GAMBIT v2.3.14 pre-processor (Fluent, Ansys, Canonsburgh, PA) (Gambit, 2006). The environmental chamber is $2.7432 \mathrm{~m}$ deep, $2.7432 \mathrm{~m}$ wide, and $2.3876 \mathrm{~m}$ high. There is no ventilation air applied to experimental chamber. The room has nine possible locations for positioning GRIMM samplers and coughing head form. Coughing head form is placed at position \#5, as shown in Figure 19. The diameter at mouth of coughing head form is $0.01905 \mathrm{~m}$. As per study performed on human subjects by Gupta et al. (2009), the mouth opening area is of the order of $4.0 \pm 0.95 \mathrm{~cm}^{2}$ for male and $3.37 \pm 1.4 \mathrm{~cm}^{2}$ for female. Hence diameter of mouth opening of cough machine is comparable with previous work in this field.

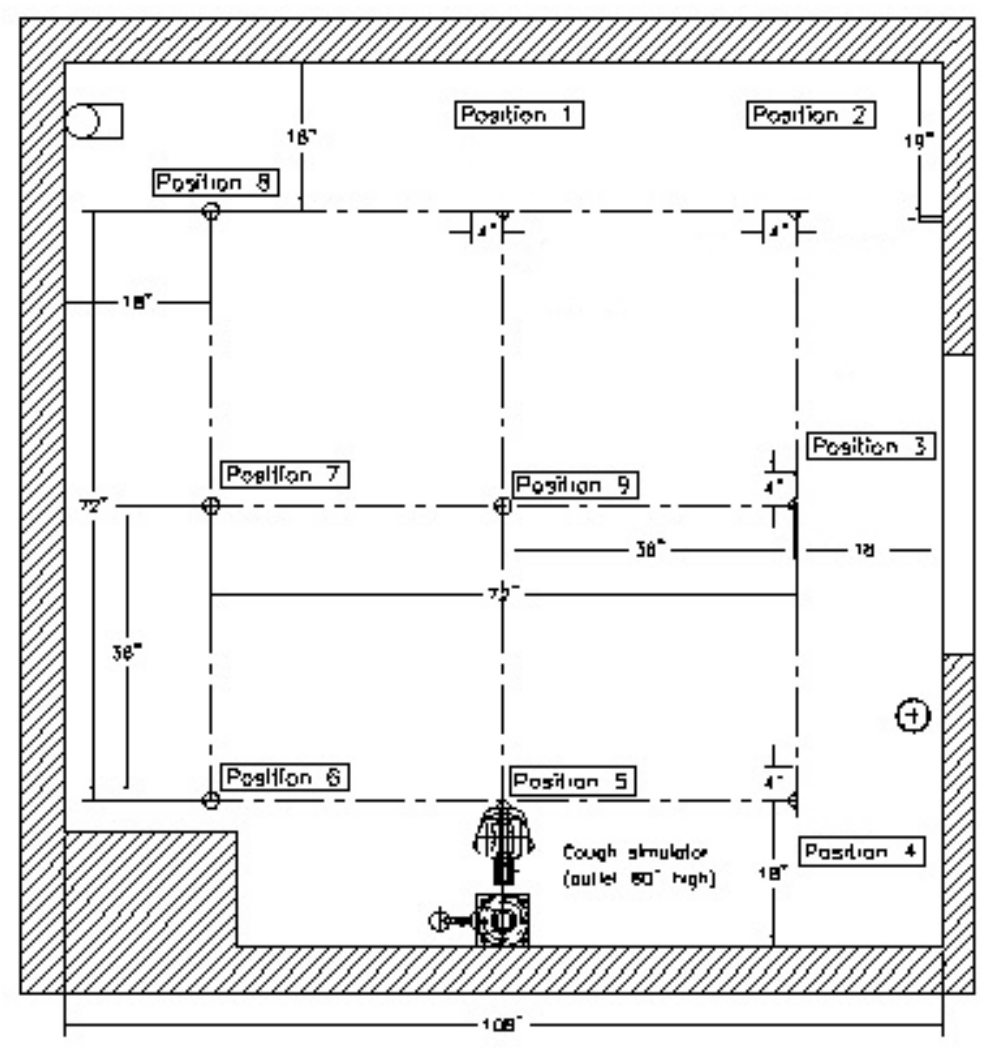

Figure 19. Environmental Chamber Layout (Image courtesy of Dr. W.G. Lindsley, NIOSH).

Two sets of the multiple experiments performed in NIOSH EC are going to be simulated. The only difference between these two setups was the position of GRIMMs (Figure 20); position of GRIMMs 3 and 4 is not changed while other GRIMMs are changed to obtain a new setup in EC. To obtained accurate 
and precise particle counts, two experiments were carried out with setup-1 while three for setup- 2 . The experimental chamber is claimed to be air-tight, with no airflow in the room prior to the cough. There is no air inlet or outlet in the chamber.

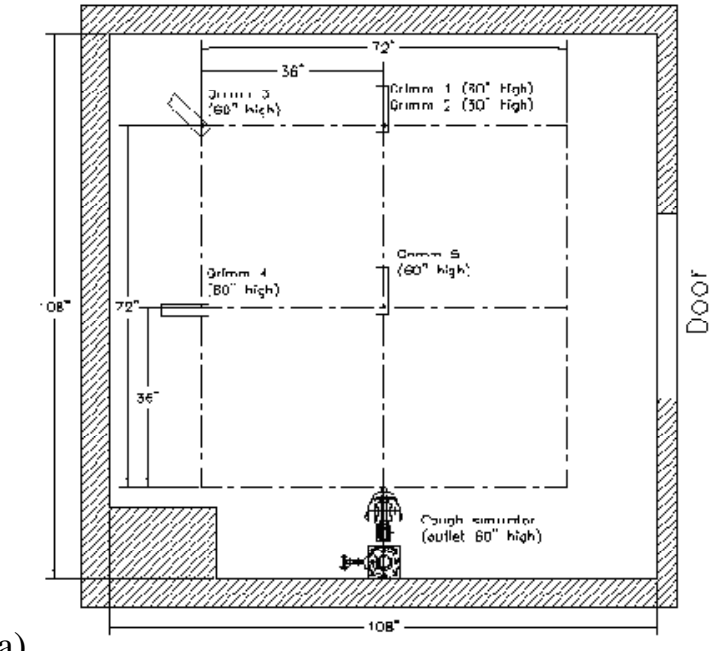

(a)

Figure 20. NIOSH environment chamber experiment setup (a) setup-1 and (b) setup-2 (Image courtesy of Dr. W.G. Lindsley, NIOSH)

Environmental chamber is modeled by John Redrow (2009) in GAMBIT with exact dimensions. The geometry of cough machine is simplified for the ease of meshing in GAMBIT. Modeled EC is shown in Figure 21. The mesh created in GAMBIT by John Redrow (2007) has a total of 774,971 tetrahedral cells. More details about mesh and grids can be found in Chapter 5 of John Redrow's thesis (Redrow, 2009). 


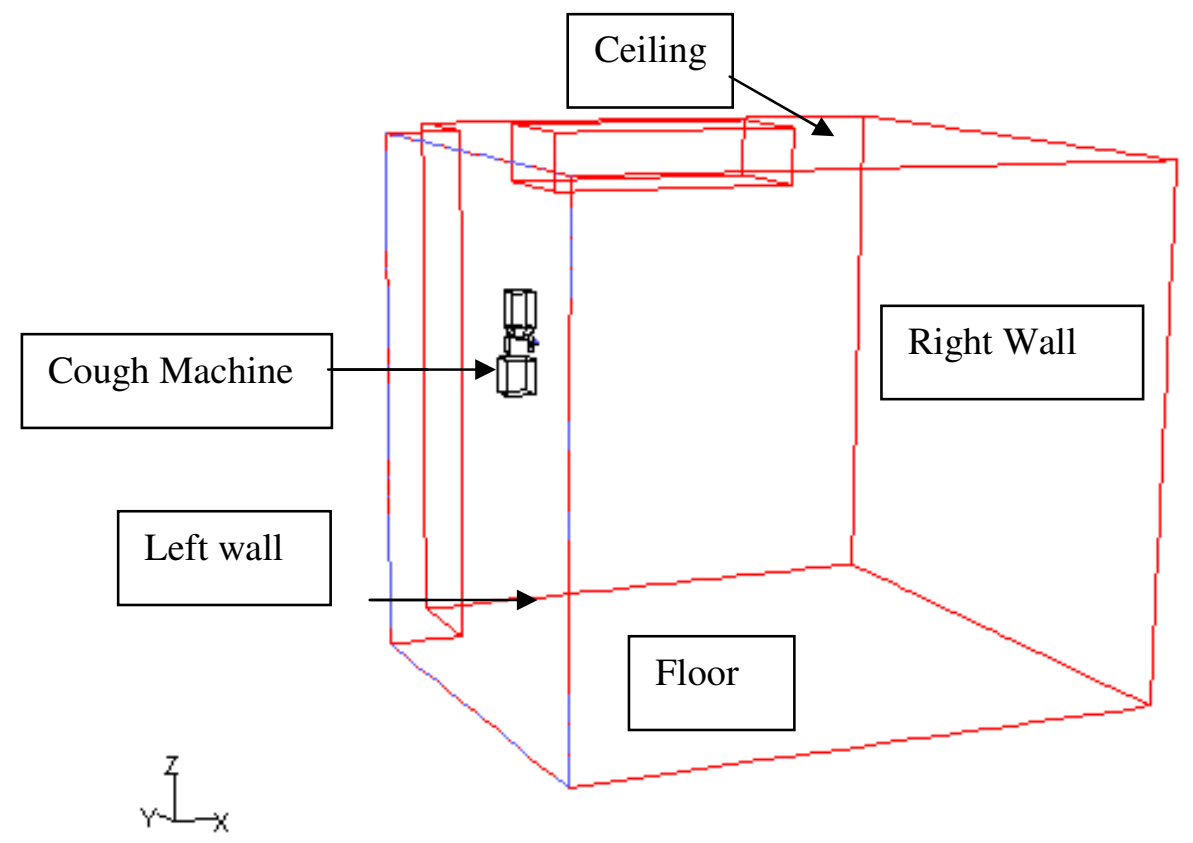

Figure 21. Environmental Chamber Model (Redrow, 2009)

In the simulation, all boundaries of the $\mathrm{EC}$ are assumed to be a pressure outlet boundary with zero gauge pressure. FLUENT simulations were carried out with Realizable k- $\varepsilon$ turbulent model. A transient cough velocity profile obtained from NIOSH experiments is used for the simulations to prescribe the flow conditions at the mouth. The cough velocity profile used is shown in Figure 22.

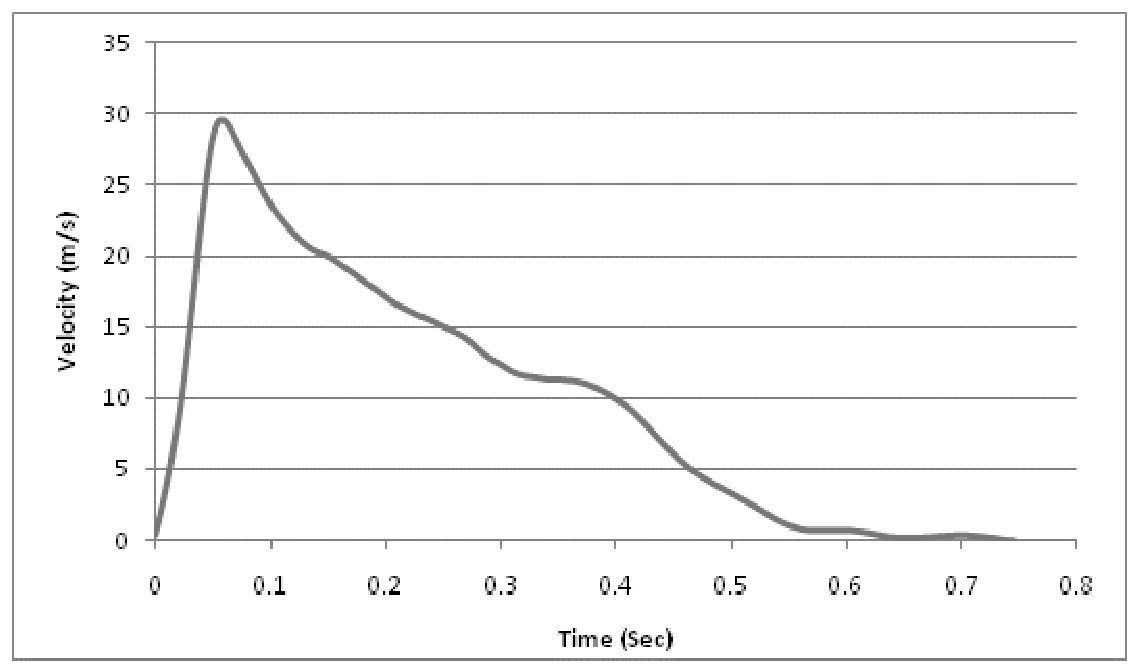

Figure 22. Cough Velocity Profile (data provided by NIOSH) 
The aim in this section is to compare actual particle counts from experiments to the particle counts obtained from CFD simulation. A passive scalar simulation is studied ahead of the particle injection to establish a realistic cough spread from mouth, also with the intent of comparing the trend of scalar concentration at each spectrometer location to the experimental data. Once a realistic cough was simulated, a new simulation was initiated with the same input parameters and boundary conditions with introduction of particle injection. This is because scalar CFD calculations are fast and conclusions can be drawn quicker.

A scalar at a normalization concentration of 1.0 is prescribed at the mouth inlet during a cough period of 0.75 seconds. A user-defined function (UDF) was used to calculate the scalar diffusivity by dividing the turbulent viscosity (calculated by FLUENT) by the Schmidt number (constant, set at 0.7 ). The Reynolds number in CFD simulation is 141912. After the cough ends, scalar at mouth is removed and boundary condition at mouth is changed to a wall. Simulation was run for 60 seconds. Scalar dispersion was monitored in the plane of cough flow. Scalar distributions at 0.25 and 0.50 seconds are shown in Figures 23(a) and 23(b), respectively. These figures show the scalar on a vertical plane perpendicular to cough machine. Five small sampling surfaces were placed in the modeled room representing the five GRIMMs. These planes are placed separately and not during the mesh generation for the ease of computation and to reduce the complexity in GAMBIT. Area-weighted average of scalar concentration was monitored on individual GRIMM surfaces. Comparison of scalar simulation with experimental setup-1 and setup-2 were carried out. The methodology of comparison of experimental particle count and scalar simulation is explained further. 


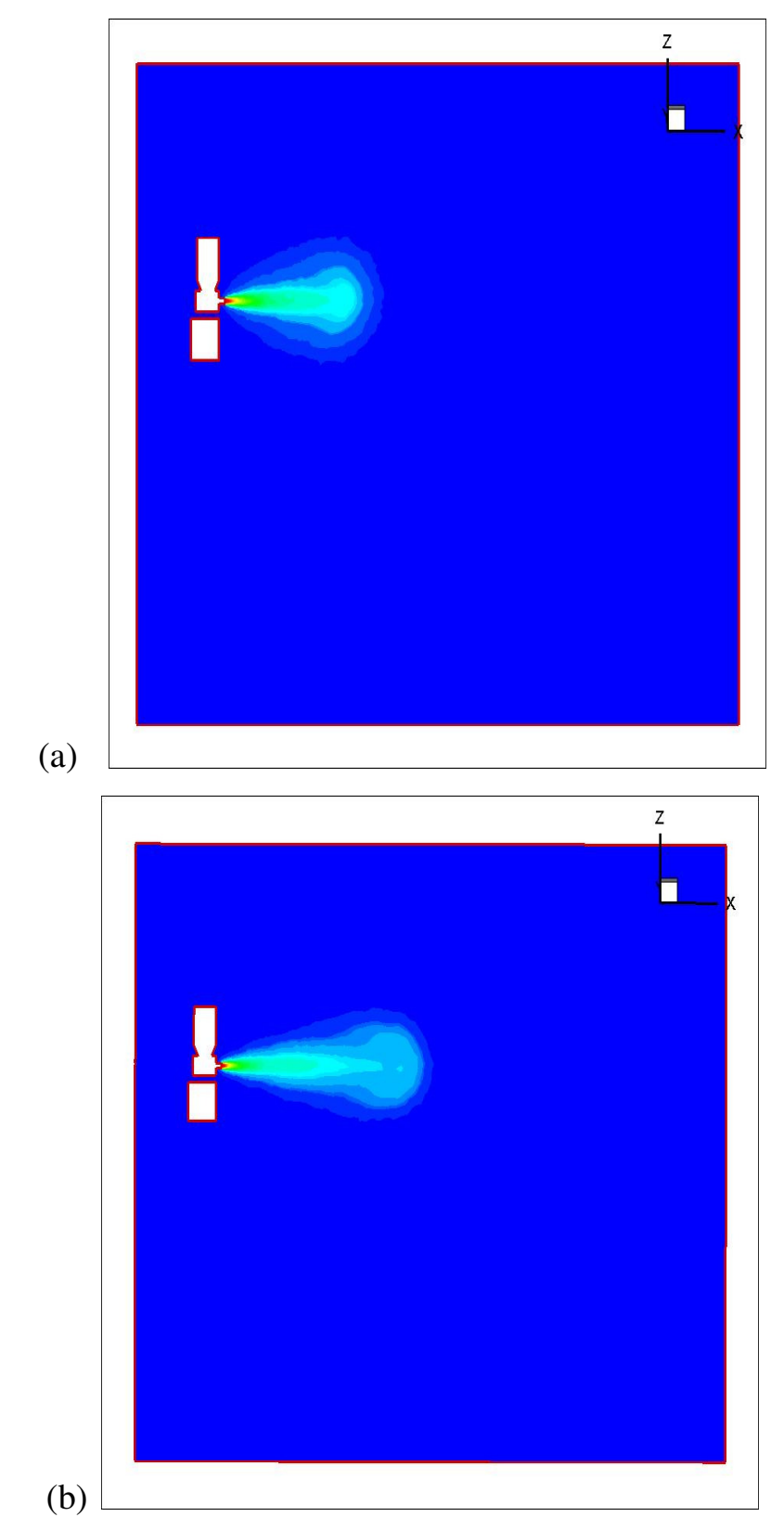

Figure 23. Scalar distribution in computational domain at (a) $0.25 \mathrm{~s}$, and (b) $0.5 \mathrm{~s}$.

In order to compare scalar and experimental results, it should be brought down to same base. The basis is selected as particle number density, defined as number of particles captured per 100 number expelled from cough machine (during experiments) and in CFD simulation (in computer program). Scalar concentration can be reduced to particle density by integrating it numerically over the time followed by division by total scalar introduced in the computational domain. Comparison of scalar simulation and experimental results is shown in Figure 24. Two experiments were performed with setup-1. Figure 24 shows the average data of two experiments with error bars on it. The error bars are obtained by taking 
mean value of particle counts from all the experiments in the setup and taking mean deviation from this value. The results obtained from computer model are plotted on this to see if it falls in the range of experimental data.

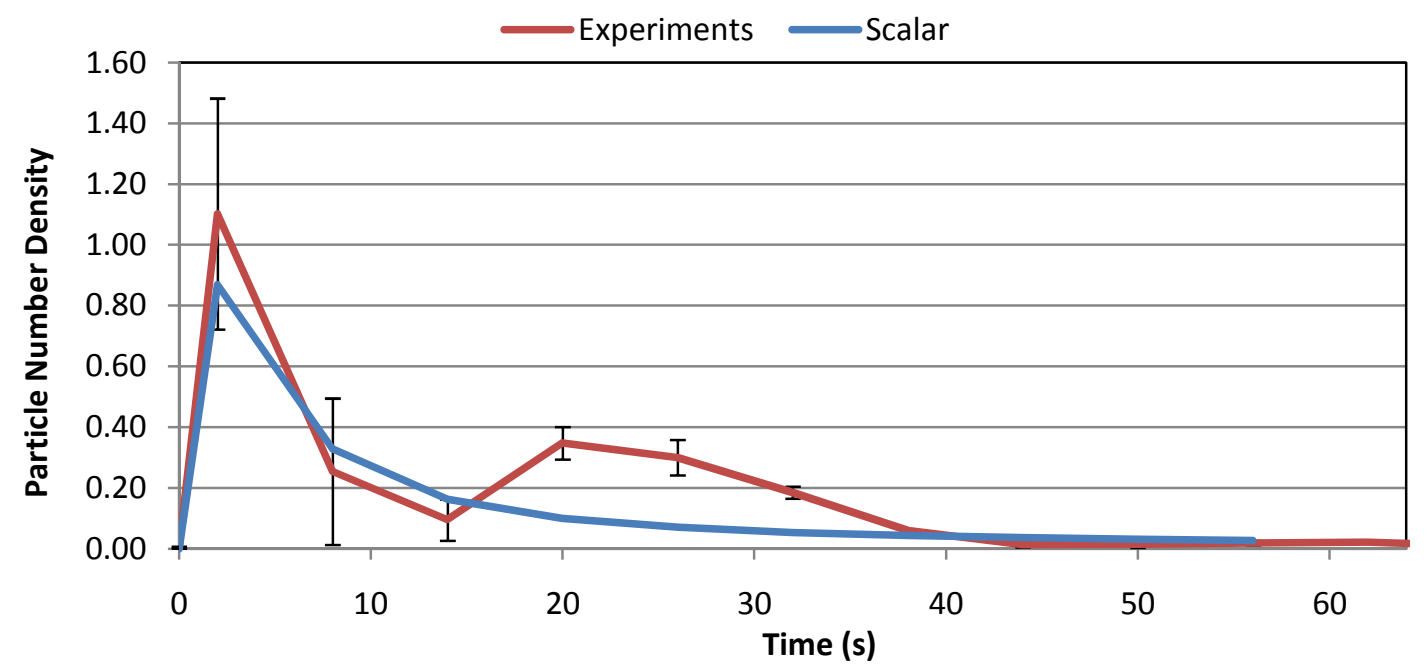

(a)

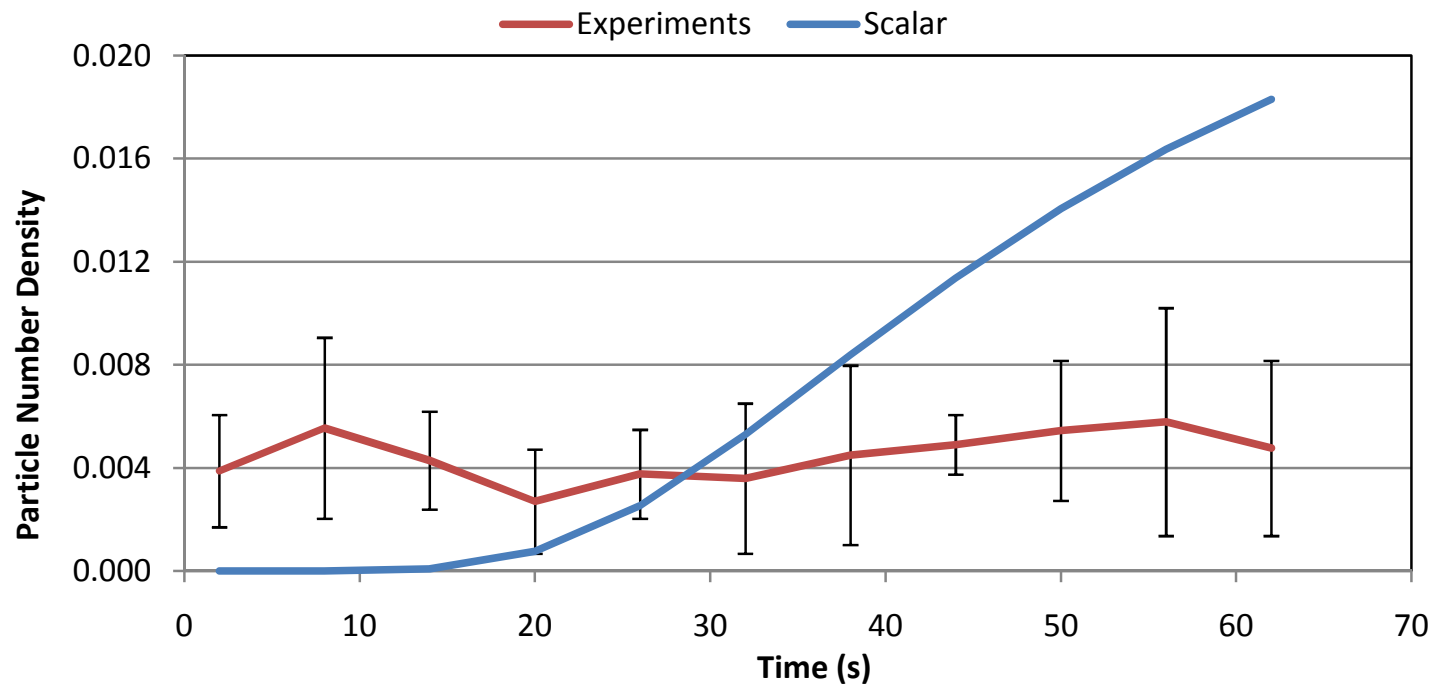

(b) 


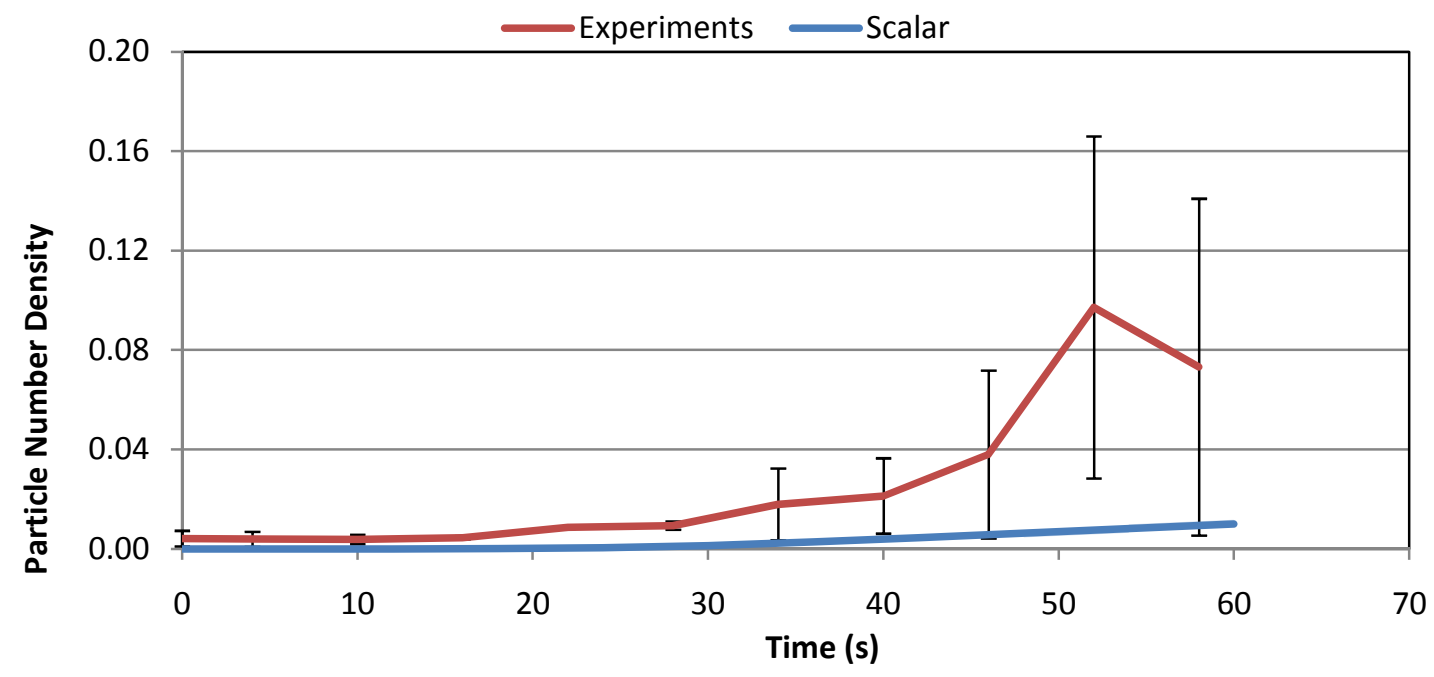

(c)

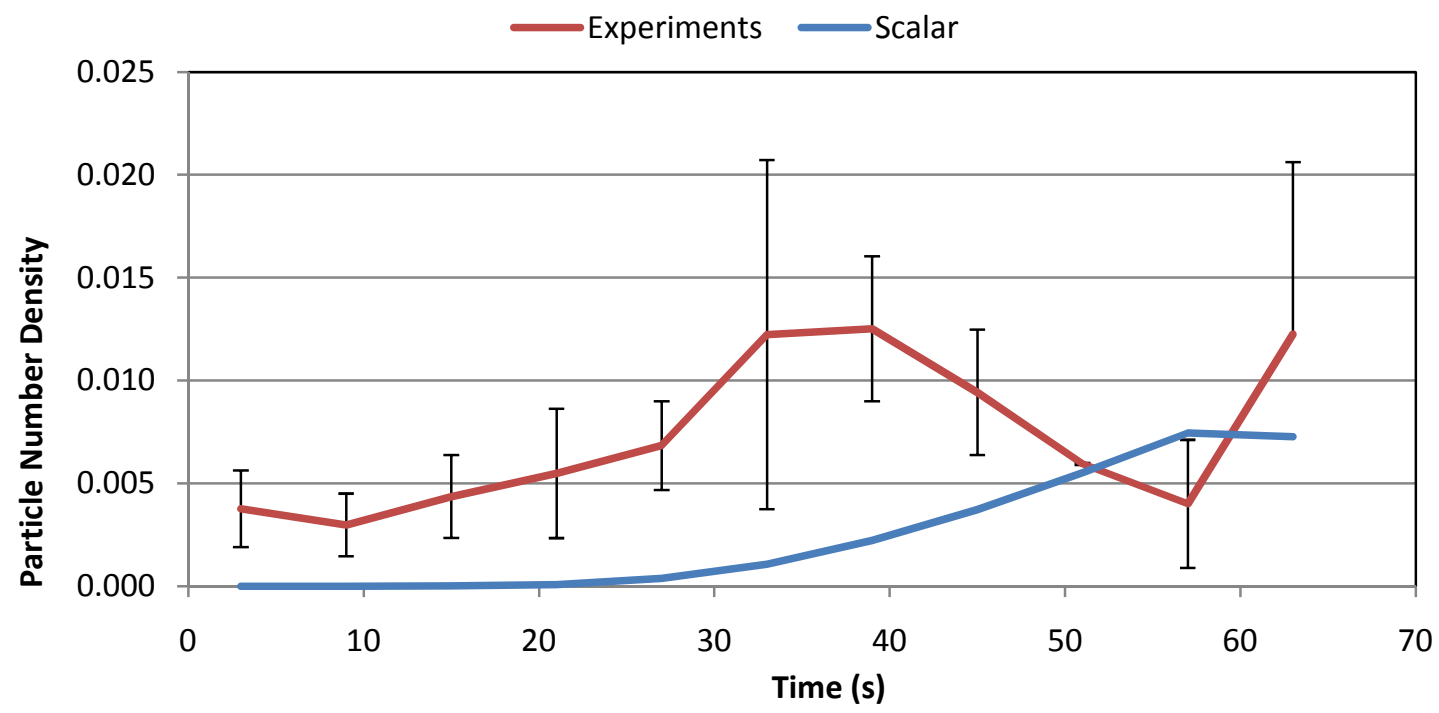

(d) 


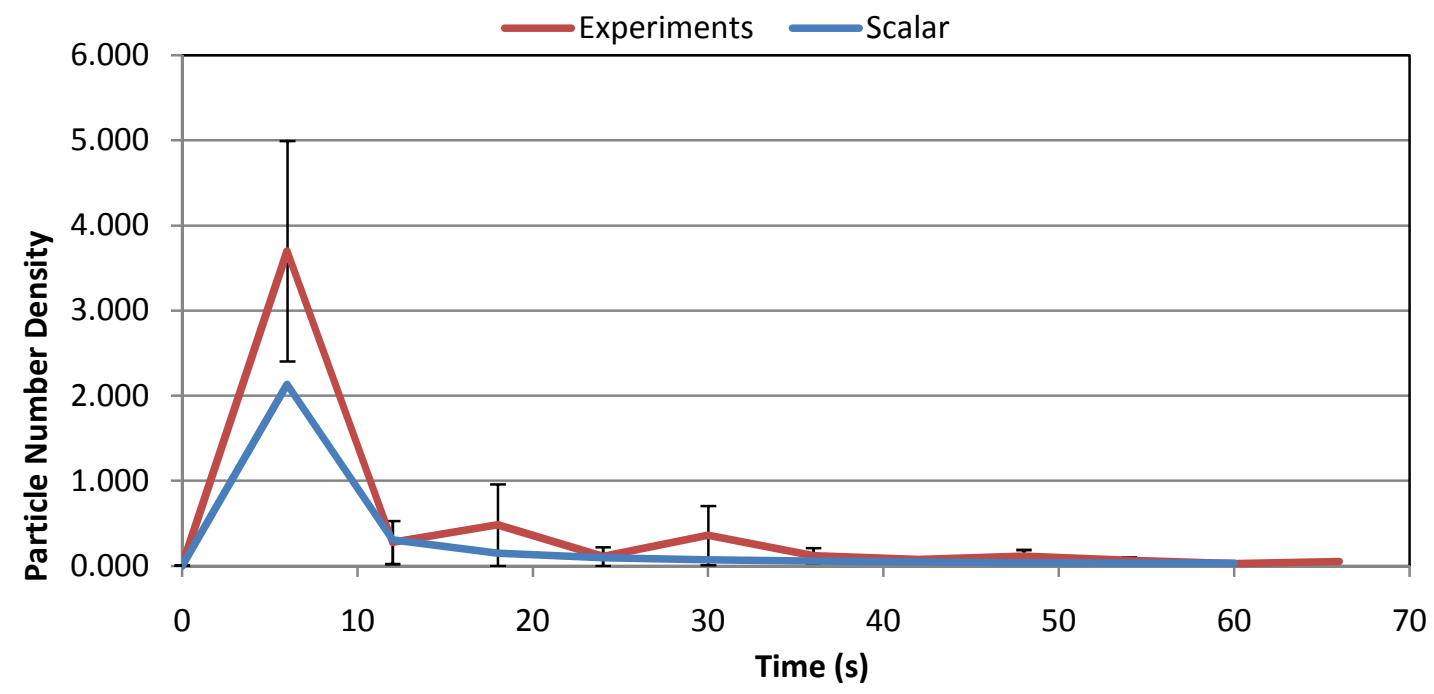

(e)

Figure 24. Experiment v/s scalar simulation for setup-1:

(a) GRIMM-1, (b) GRIMM-2, (c) GRIMM-3, (d) GRIMM-4, and (e) GRIMM-5

Figure 25 shows the results of scalar simulation compared with experimental setup-2. In this setup, three experiments were carried out and the results of all three are averaged to compare with CFD results. It can be seen that the scalar simulation results are in good accordance with experiments in both setups.

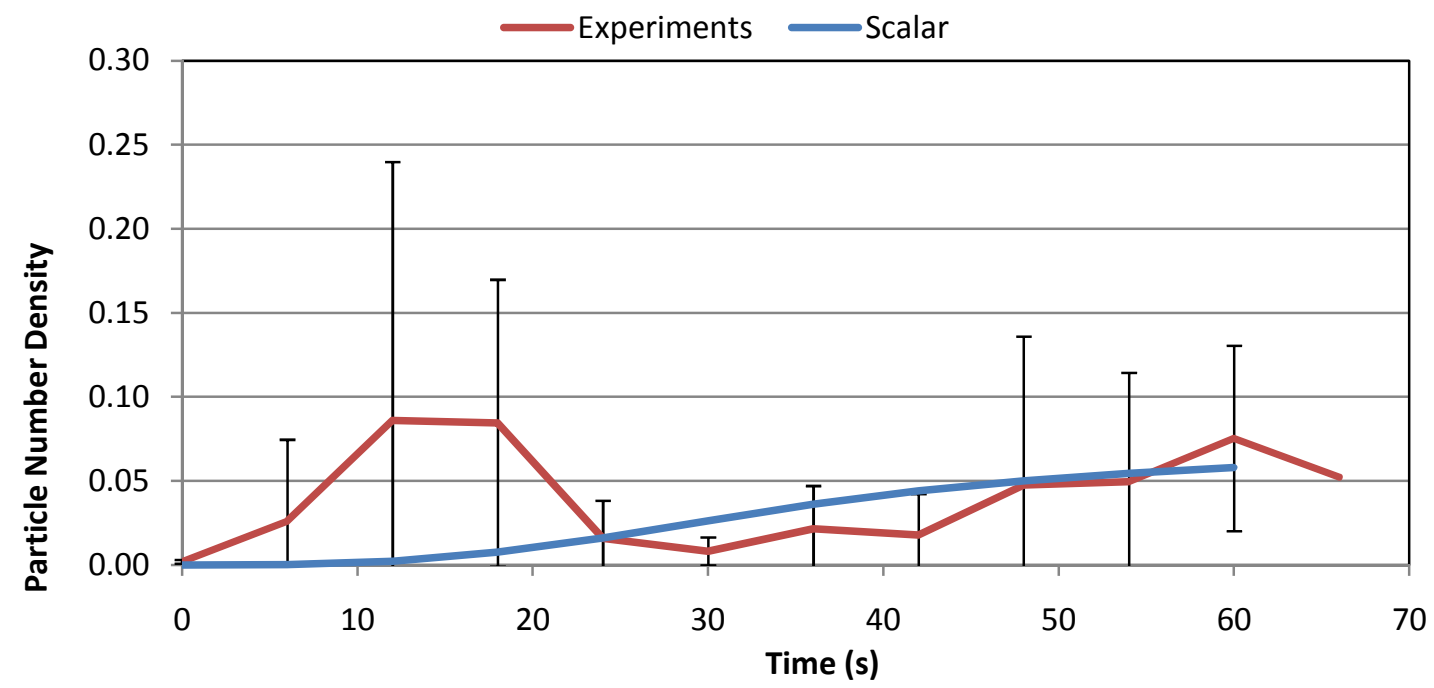

(a) 


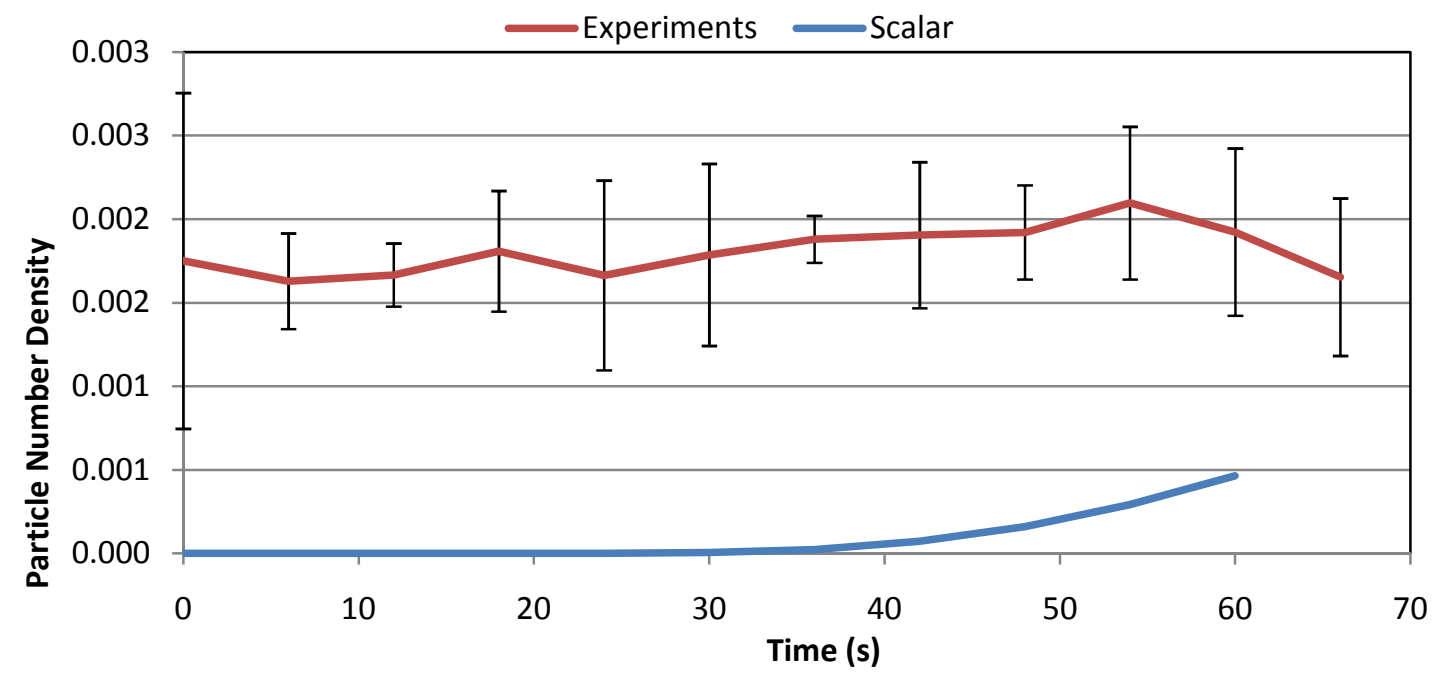

(b)

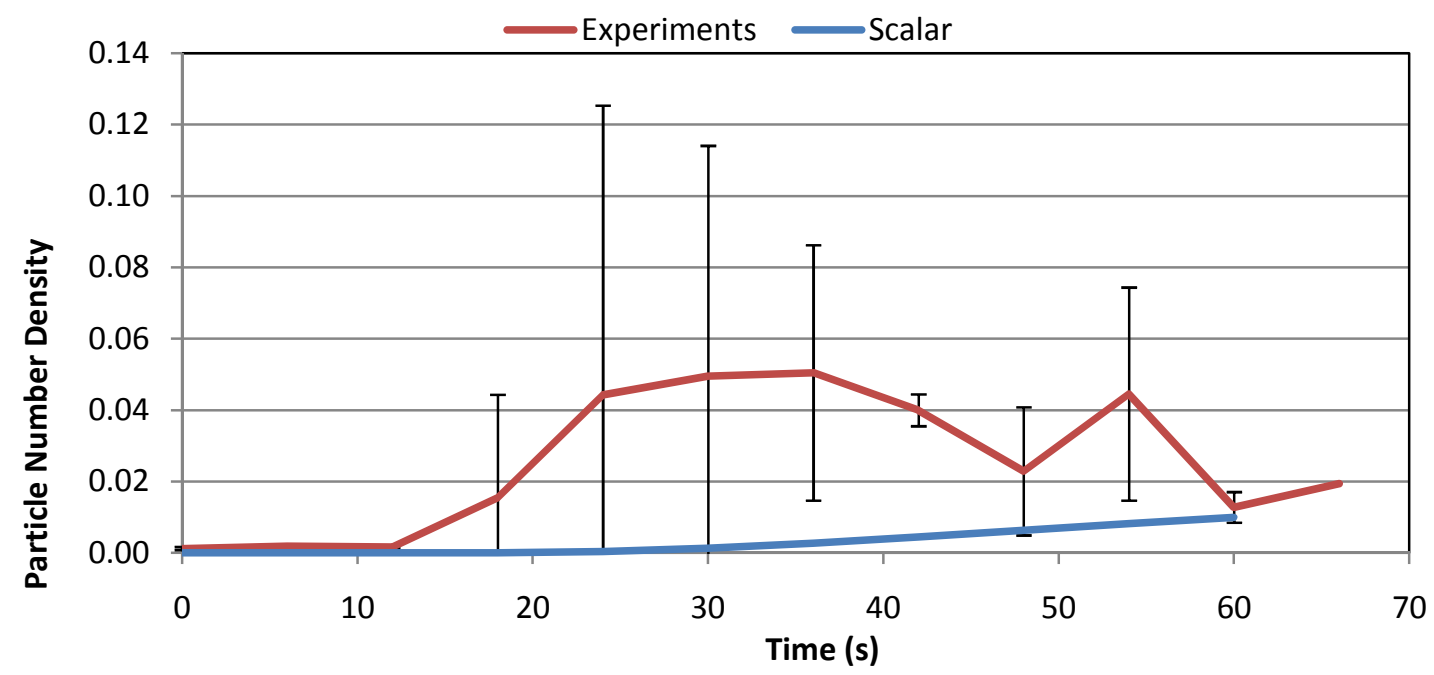

(c) 


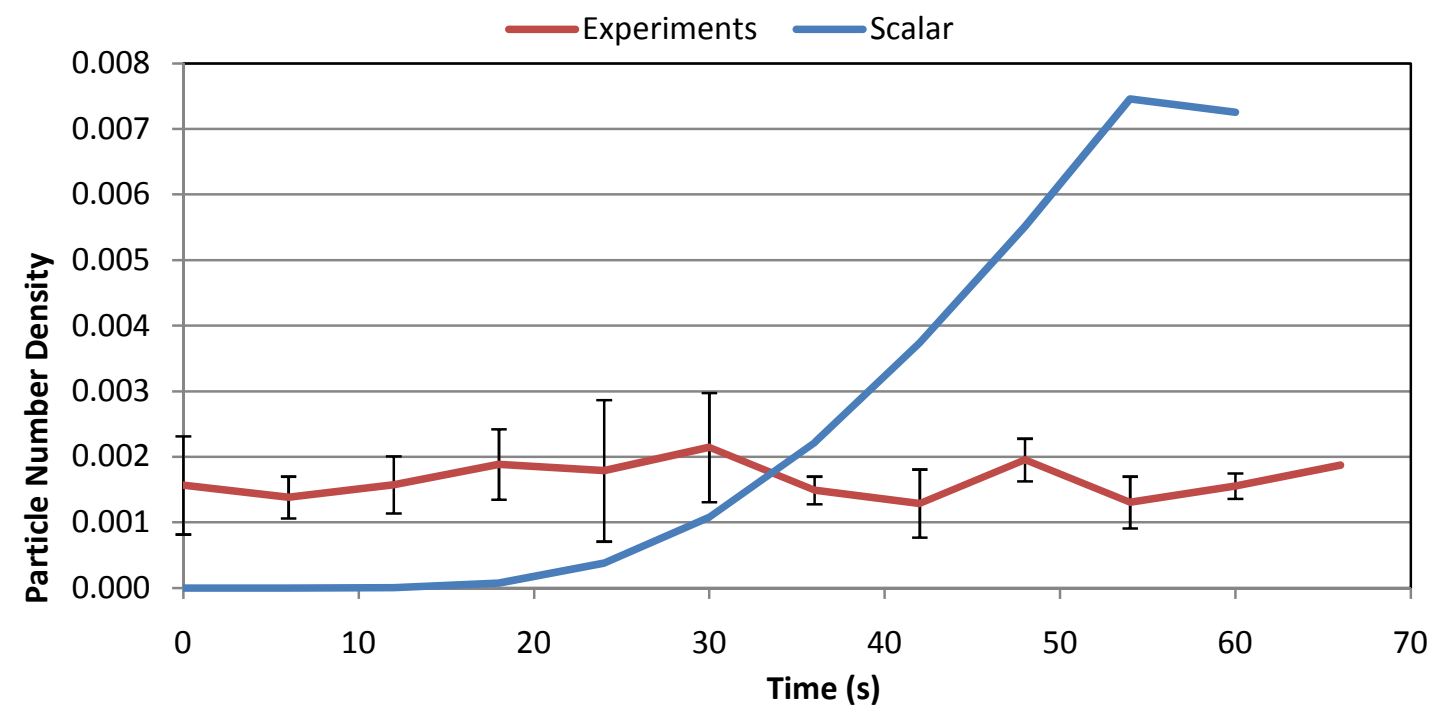

(d)

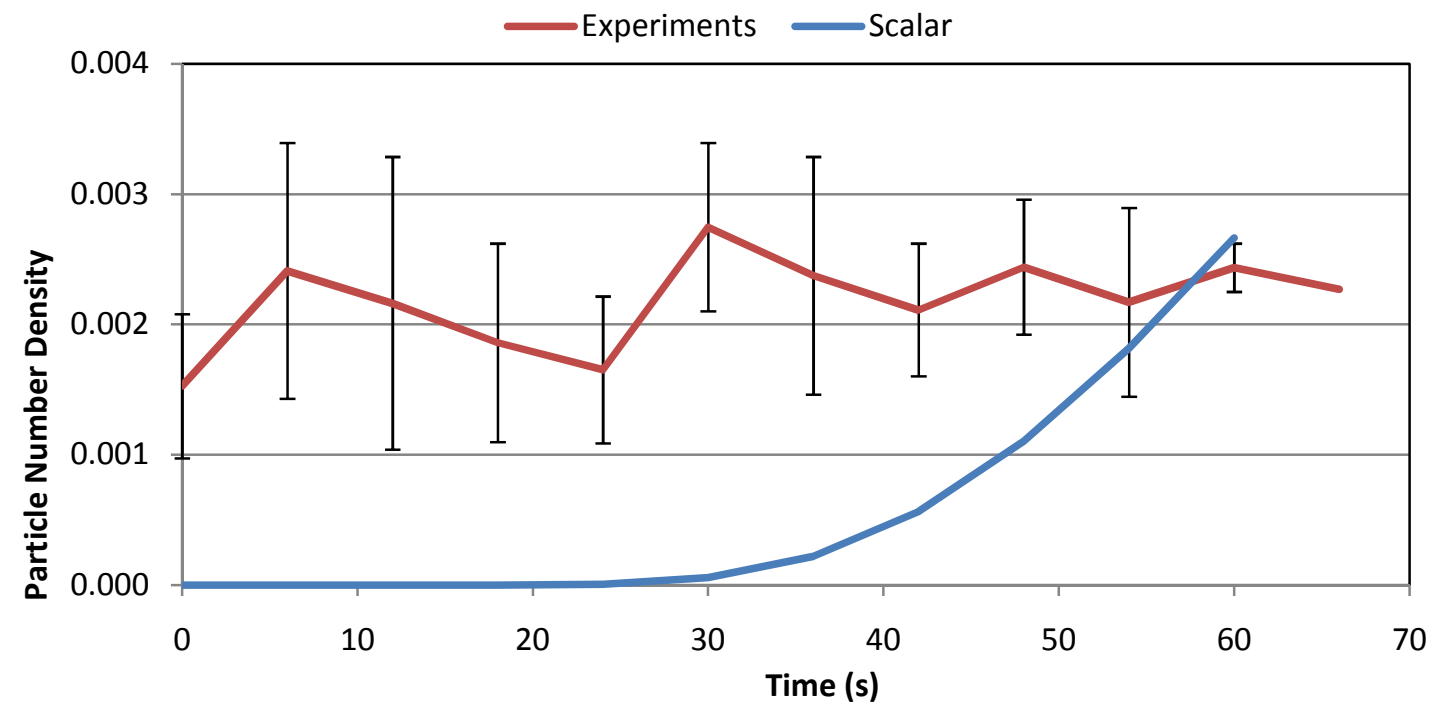

(e)

Figure 25. Experiment v/s scalar simulation for setup-2

GRIMM-1, (b) GRIMM-2, (c) GRIMM-3, (d) GRIMM-4, and (e) GRIMM-5

A working scalar simulation is used further for particle injection simulations. Same boundary and initial conditions are used in particle simulation as in scalar simulation inert particles of 0.45 micrometer were injected during the cough duration. The density of injected particles was set to $1,987 \mathrm{~kg} / \mathrm{m}^{3}$, which is same as potassium chloride density used during experiments. The density of solids in human cough particles is $2200 \mathrm{~kg} / \mathrm{m}^{3}$ (Papineni \& Rosenthal, 1997). The simulation and particle time step was 0.001 sec. Simulation was set to inject 20 particles at every time step, hence during complete cough period a 
total of 14,980 particles were injected in the domain. After a cough period of 0.75 seconds particle injection was stopped with mouth being now set as wall.

Cough simulation was set to save case and data files at every 1 millisecond (time step) for the first 14 second of simulation; producing a total of 10,000 files. Simulation after 10 seconds was set to save case and data files at an interval of 10 millisecond. Case and data files obtained from FLUENT simulation undergo post-processing in two steps.

Step 1: Obtaining 'particle files'

A journal was developed in FLUENT for post-processing of case and data files. A journal is a sequence of text commands edited in text editor. A journal file is useful when it comes to execute a series of commands in regular pattern (Fluent, 2005). In this case it was set to open individual case-data files to obtain a corresponding particle data file. This operation was repeated to create particle data from each case-data file. Particle files contain a tabulated data of rows representing particles and across column are the details of corresponding particle. The details include the position and velocities of all particles that are in the domain, along with other information as tabulated below in Table 5:

Table 5: Details in Particle Data Files

\begin{tabular}{|c|l|l|}
\hline Column & Variable & Unit \\
\hline 1 & Time & seconds \\
\hline 2 & x-Position & meters \\
\hline 3 & y-Position & meters \\
\hline 4 & z-Position & meters \\
\hline 5 & u-Velocity & $\mathrm{m} / \mathrm{sec}$ \\
\hline 6 & v-Velocity & $\mathrm{m} / \mathrm{s}$ \\
\hline 7 & w-Velocity & $\mathrm{m} / \mathrm{s}$ \\
\hline 8 & Diameter & $\mathrm{meters}$ \\
\hline 9 & Temperature & $\mathrm{K}$ \\
\hline 10 & Density & $\mathrm{kg} / \mathrm{m}^{3}$ \\
\hline 11 & Mass & $\mathrm{kg}$ \\
\hline 12 & Number & \\
\hline 13 & Color by & - \\
\hline
\end{tabular}


Step 2: Process particle files in Matlab code

Particle files were processed in an in-house developed Matlab code. Coordinates of GRIMM samplers from experiments and measurements of $\mathrm{dx}$, $\mathrm{dy}$ and $\mathrm{dz}$ from PIV were used in this step of data postprocessing. Particle details were compared with the coordinates of sampler to understand if the particle is in the vicinity of aerosol sampler. Hence, details in column number 2, 3, and 4 of particle files are important to pin-point the location of a particle in the room. Columns 5, 6 and 7 which gives the velocities in $\mathrm{x}, \mathrm{y}$ and $\mathrm{z}$ directions are also important to calculate the future position of a particle.

Matlab code makes the processing simple as GRIMM spectrometer can be placed in the simulation domain. The spectrometer is not placed in the domain during simulation for time and cost saving purpose. The size of spectrometer is very small compared to size of the calculation domain which calls for fine meshing around the spectrometer for efficient trapping of particles. Also the Matlab code makes it easy to study and compare various experimental setups (where only spectrometer locations are changed).

Figure 26(a) and 26(b) presents a practical scenario, where movements of two particles 'I' and 'II', are shown. Let Figure 26(a) represent particle positions at time $\mathrm{t}=\mathrm{n}$ and $\mathrm{n}+1$ with particle locations represented by I and II at $\mathrm{t}=\mathrm{n}$ and I' and II' at $\mathrm{t}=\mathrm{n}+1$. Let particles I and II have velocities Vi and Vii (assuming $\mathrm{V}_{\mathrm{i}}>\mathrm{V}_{\mathrm{ii}}$ ). Hence, particle $\mathrm{I}$ travels to a distance greater than dimensions of sampler spectrometer while particle II remains in the spectrometer in next time step. At $\mathrm{t}=\mathrm{n}+2$ let I' and II', shows new position of particles. It can be seen that the particle I is still in the spectrometer and there is possibility of this particle being recorded twice or thrice (if particle continues to be in the same spectrometer in next time step). 

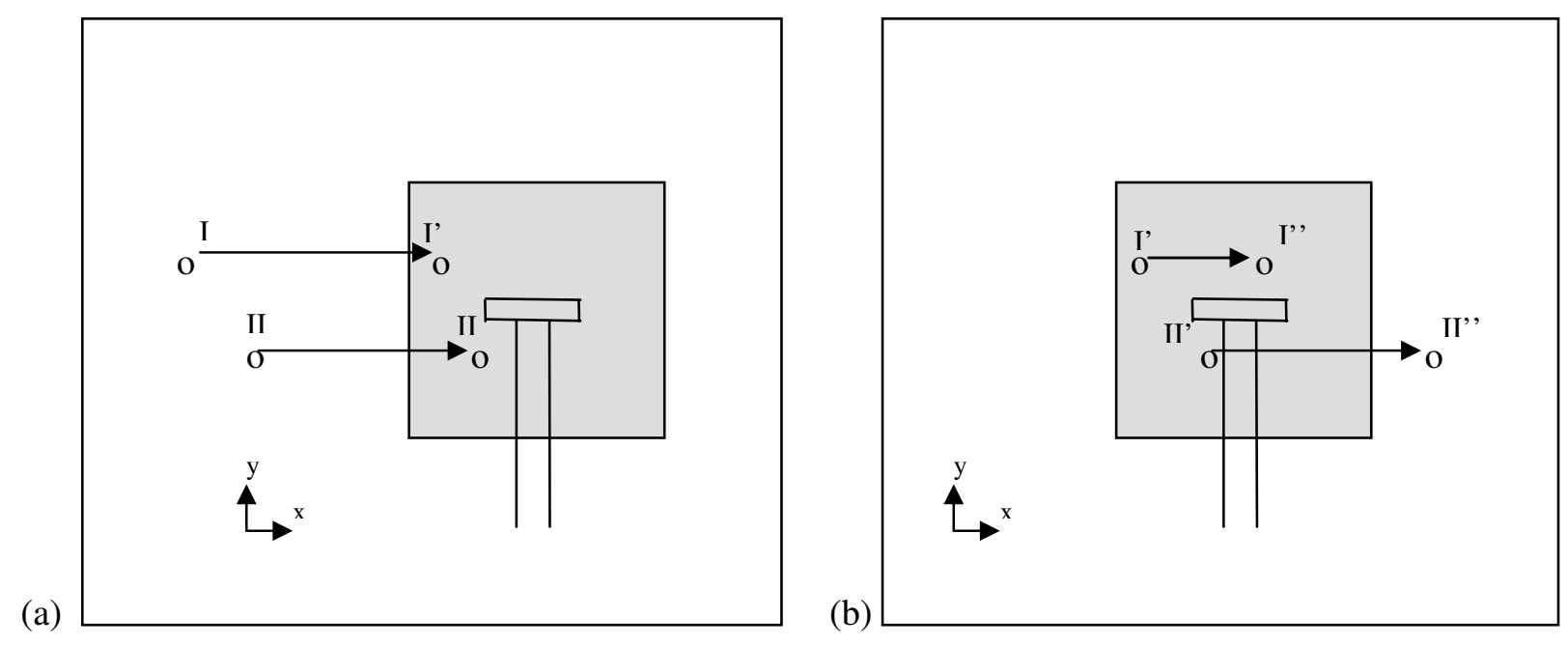

Figure 26. Graphical Representation of the virtual sampling procedure.

The logic in Matlab code can be explained briefly as:

The simulation time step of 1 millisecond is selected to ensure high velocity particles do not travel in and out of spectrometer region. Particles with low velocity can be trapped in spectrometer for more than one time steps; therefore if a particle is traced more than once in a particular spectrometer then it should be recorded only when it leaves spectrometer. This makes velocity of recorded particles an important parameter to be taken into account. Future position of particle can be calculated from $\mathrm{u}, \mathrm{v}$, and $\mathrm{w}$ velocity of each particle, which can again be compared with GRIMM coordinates. Now, if a future position of particle is inside spectrometer area it should not be counted but when the particle future location is out of spectrometer then a counter is rotated with corresponding time.

Matlab code developed for successful trapping of particles in GRIMM spectrometer is given in Appendix 1. The code opens every particle file and performs the logical tests on every particle. Code counts the particle count from CFD simulation which can be compared directly with particle count from experiments. The basis of comparison is same as used earlier for scalar simulation; particle number density. Data from experiments is averaged for respective setups to compare with simulation.

Figure 27 show the comparison between simulation and experiment for the first setup with the inclusion of error bars i.e. deviation from for the experimental averages. No particles were captured at locations 2, 3 , and 4 for the first setup in the simulation over 60 seconds. 


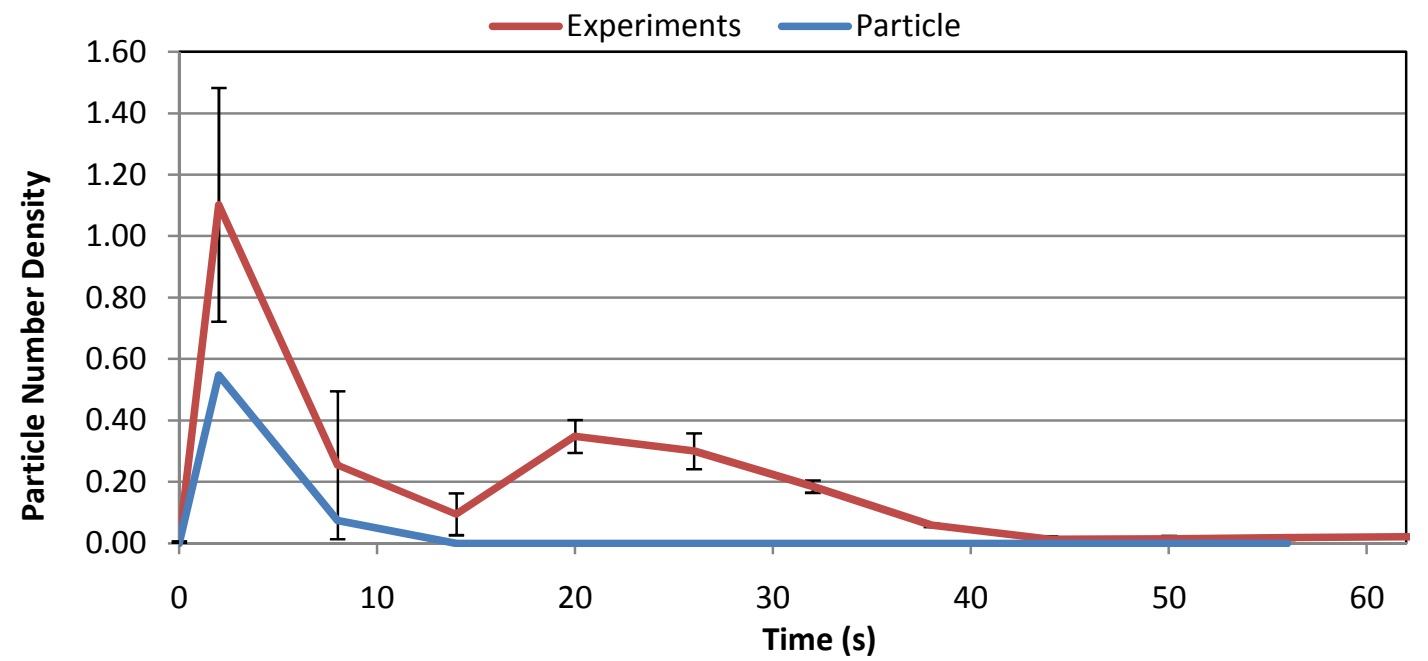

(a)

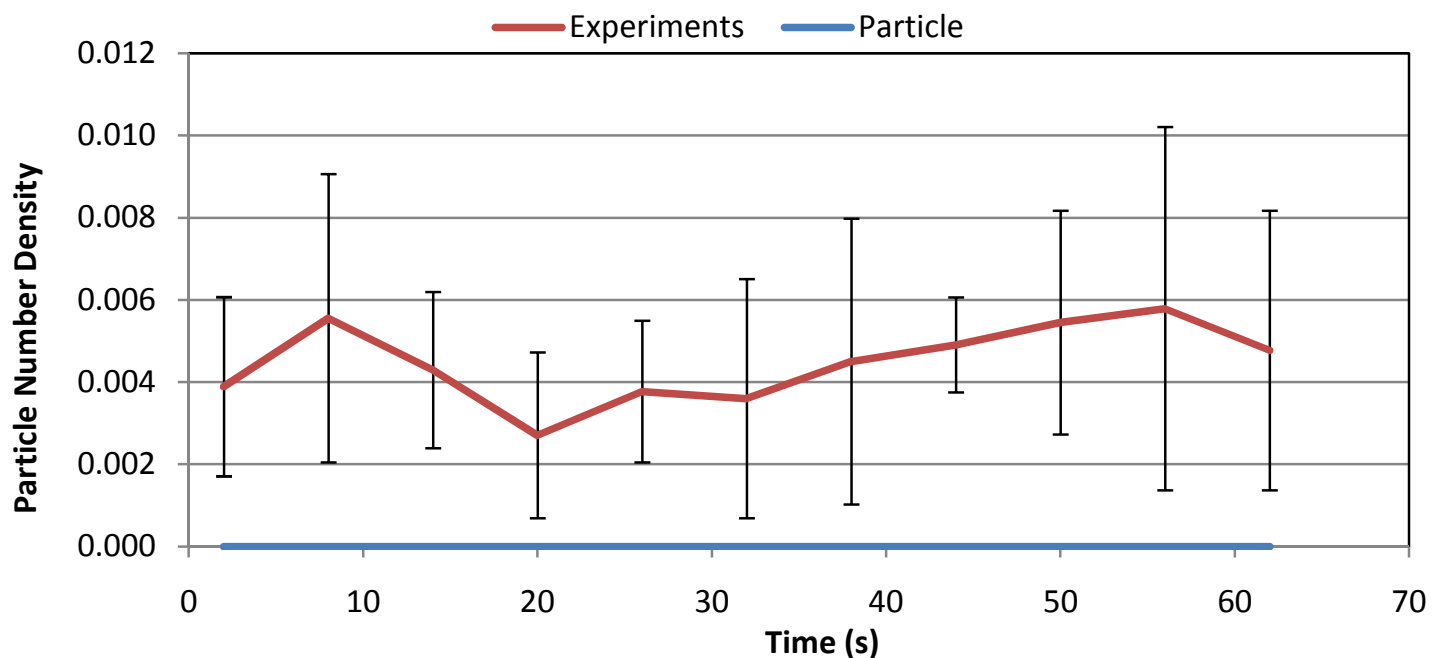

(b)

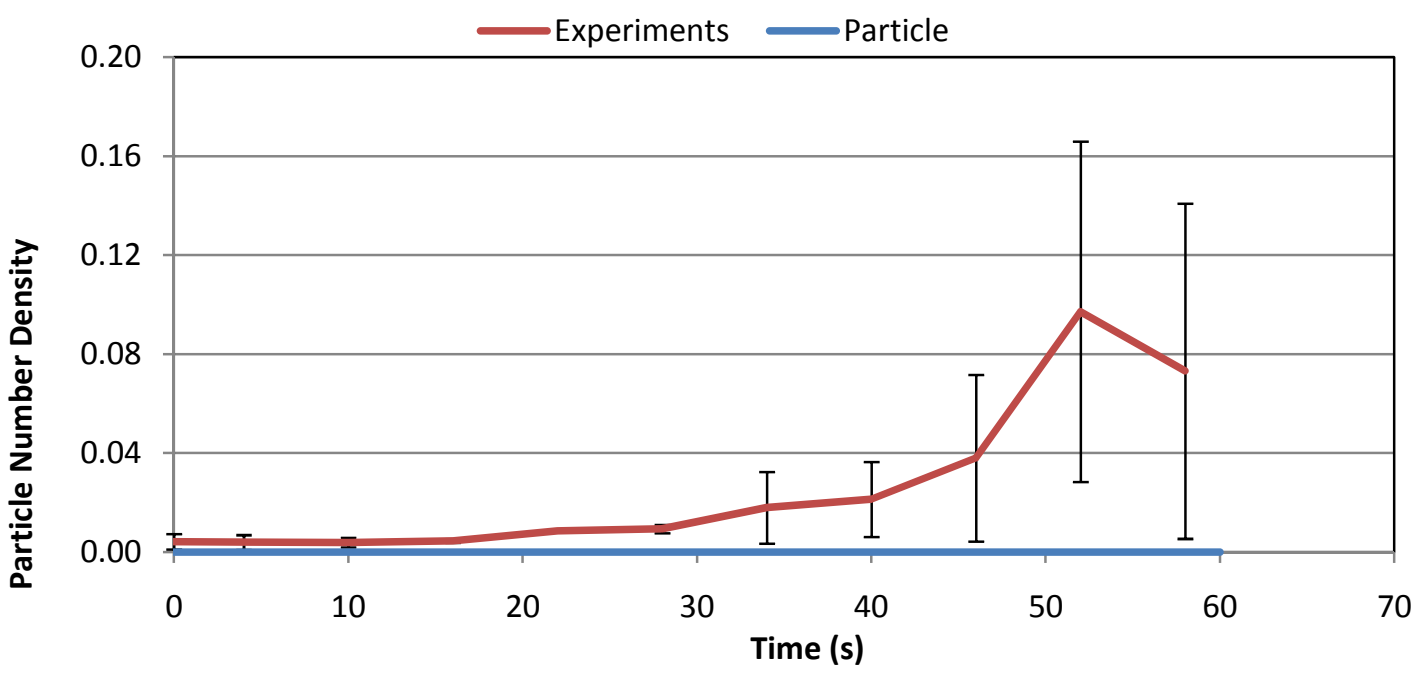

(c) 


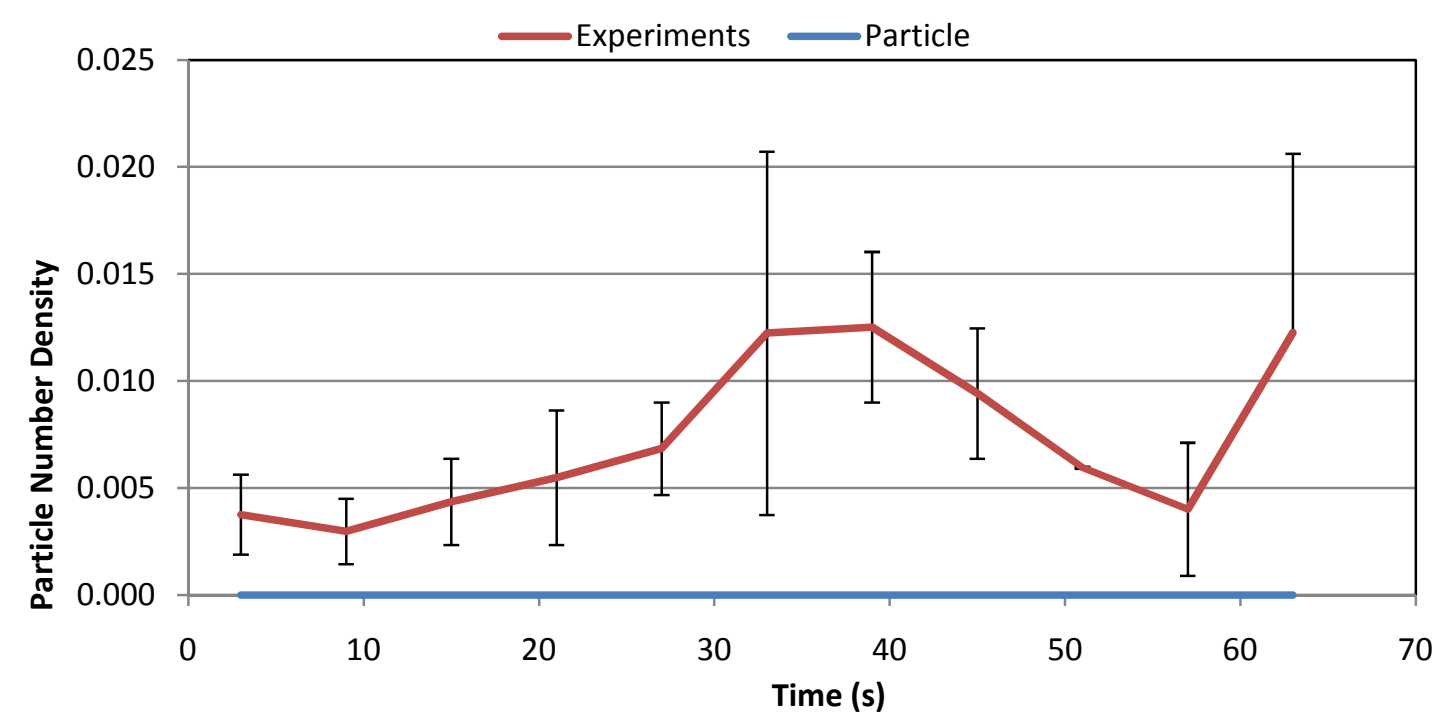

(d)

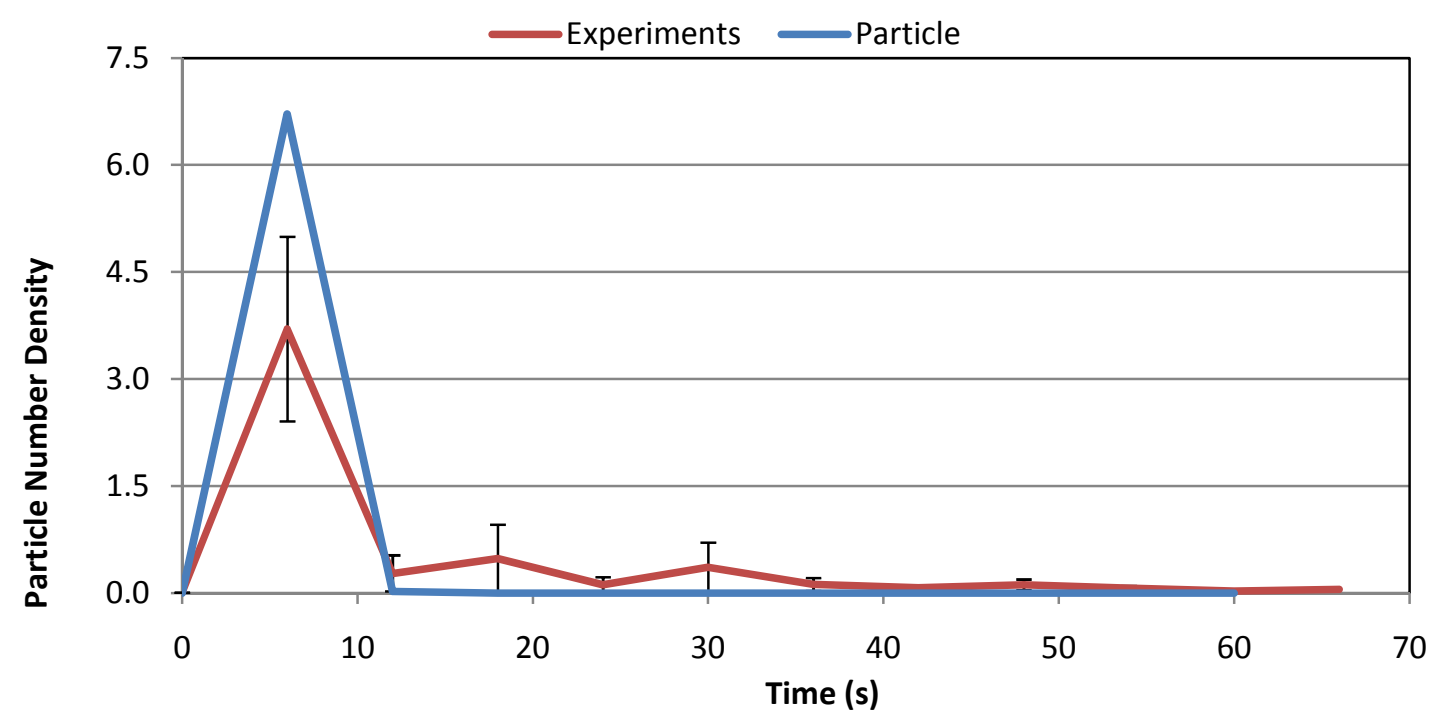

(e)

Figure 27. Experiment v/s Particle simulation for setup-1:

(a) GRIMM-1, (b) GRIMM-2, (c) GRIMM-3, (d) GRIMM-4, and (e) GRIMM-5.

Particle concentration at GRIMM 1 and 5 in setup- 1 shows more particle count in first minute of data collection, whereas concentration at other positions is comparatively very low. The low concentration at other locations can be assumed to be the noise in ambient air or could be a small environmental disturbance created by the cough. More particle concentration is recorded in the line of cough direction with very less or no concentration in initial one minute of time when it is measured at different locations, this shows cough travels more like a jet. 


\subsection{Effect of Air Ventilation on Particles Dispersion}

Droplet transmission via airborne route is studied in the previous section. Smaller cough particles can become airborne and hence have the potential to travel long distances while larger particles have tendency to settle down over a shorter distance. Suspended particles in atmosphere can remain in ambience for prolonged time following the air currents in indoor environment. Thus air flow rate in a room is an important factor to be studied along with direction of the flow. Preventing the spread of agents that are transmitted by the airborne route requires the use of special air handling and ventilation systems.

Buildings are usually air tightened with advanced materials and thermal sealing. This is important from energy consumption point of view, but is achieved at the cost of air ventilation thus polluting indoor environment (Zhu et al., 2004). In recent years, more emphasis is given to air recirculation in buildings. One of the important building related factors is the rate of air ventilation and air recirculation. Lower ventilation and recirculation rates increase the potential of virus infection (Morawska, 2006). Ventilation can be achieved in two different ways: either by mixing contaminated air with filtered air, or by diluting contaminated air using fresh air.

A study was carried out in NIOSH environmental chamber with the help of coughing machine and aerosol samplers. This time air in EC was ventilated with fresh air at 0,6 and 12 air changes per hour (ACH). The selection of $\mathrm{ACH}$ rate in $\mathrm{EC}$ is according to American Institute of Architects (AIA) standards for hospital and health care facilities. Main areas in hospital like intensive care units, laboratories, therapy and examination rooms, etc., are recommended to have $6 \mathrm{ACH}$; while nursing, endoscopy, radiology, etc., should have $12 \mathrm{ACH}$ ventilation requirements (AIA, 2001). The effect of ventilation on particle concentration was studied with a new setup of GRIMM samplers. The experimental setup for this study is shown in Figure 28. 


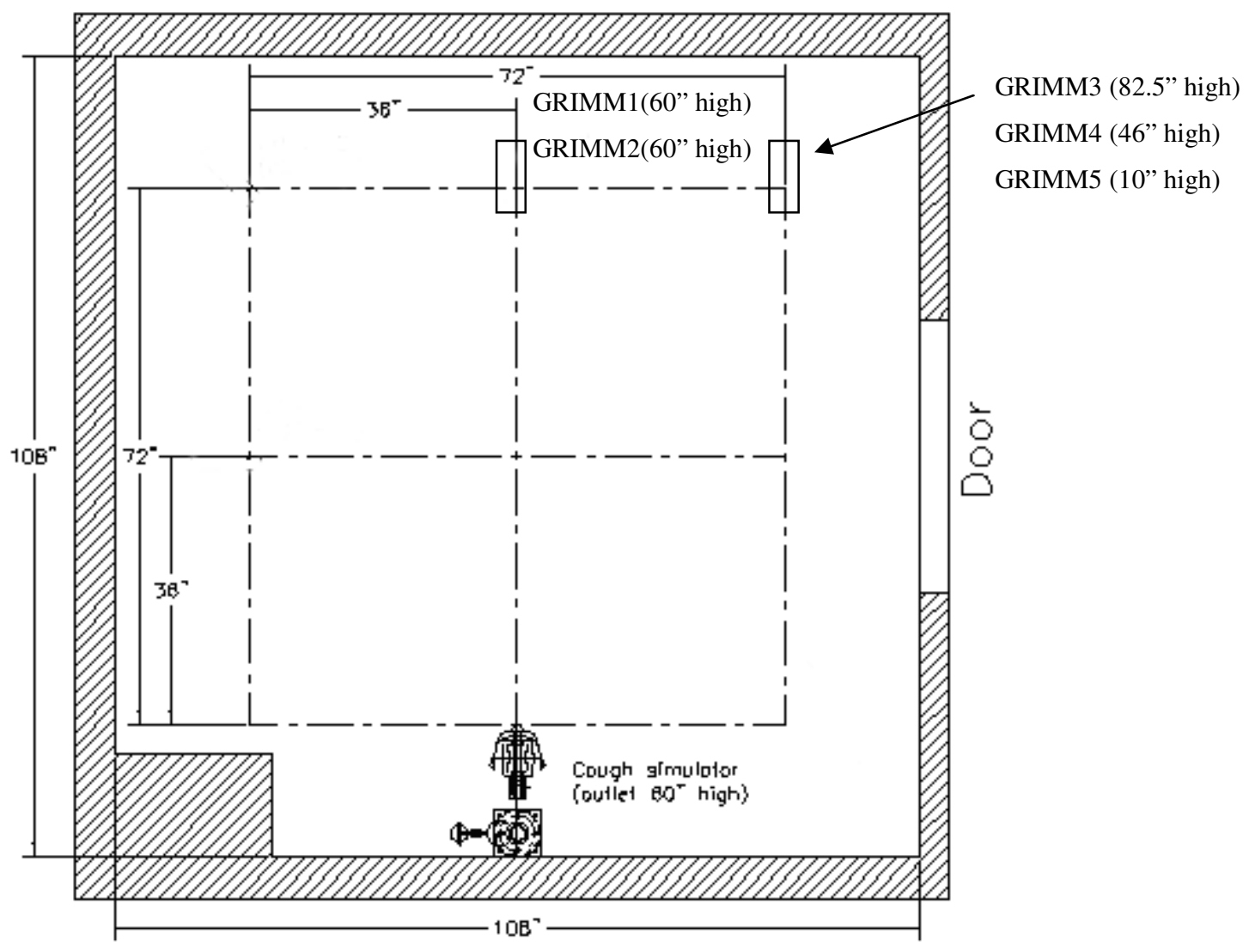

Figure 28. Experimental setup for study of air ventilation (Image courtesy of Dr. W.G. Lindsley, NIOSH)

Each experiment has been repeated three times. During every experiment the room was sealed to avoid any air leakage through door. HEPA filtration system was employed for considerable time before the cough was triggered to reduce ambience particle noise recorded at GRIMMs. Results obtained from experiments on the effect of ventilation for GRIMM 1 and 2 are shown in Figure 29. Other GRIMM data is not plotted since the trend of particle count shown by other GRIMMs is same as seen for GRIMM 1 and 2. 


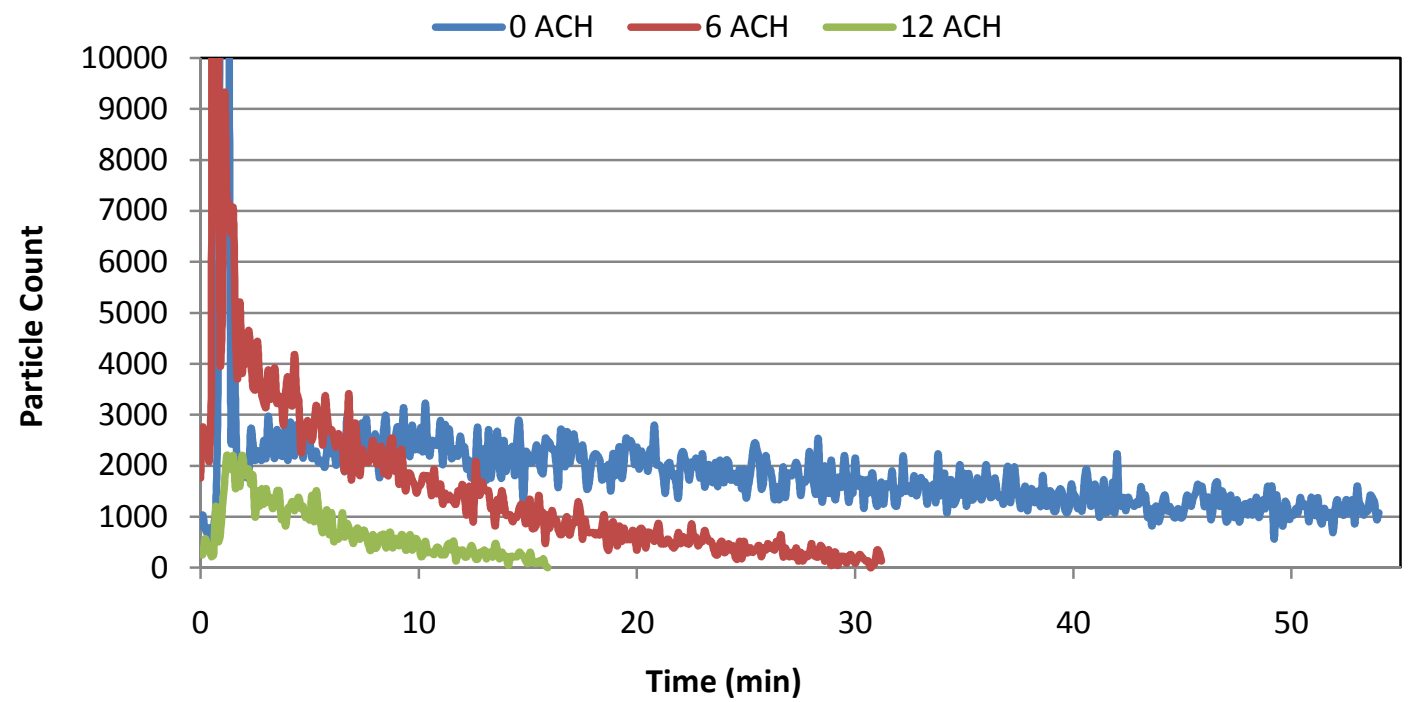

(a)

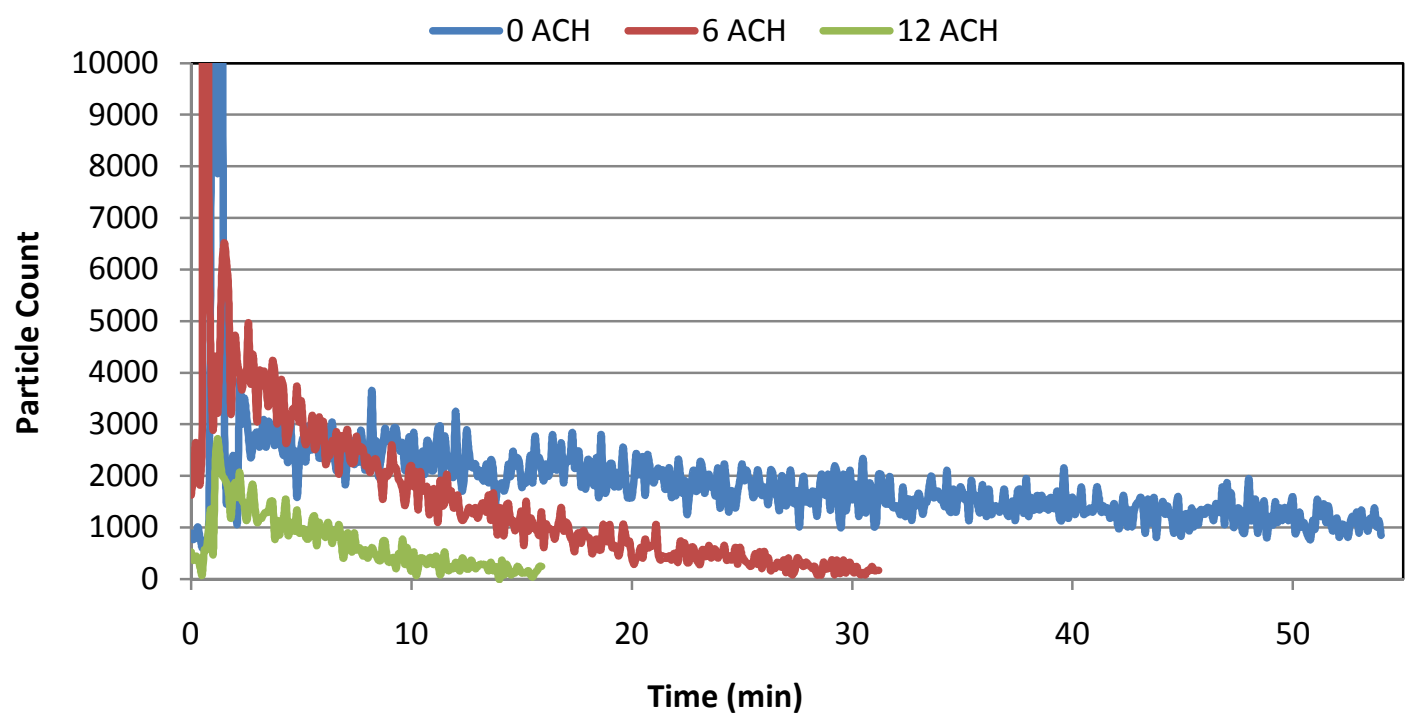

Figure 29. Effect of Ventilation on particle count at various locations in EC:

(a) GRIMM-1, (b) GRIMM-2 


\subsection{Effectiveness of Personal Protective Equipment (PPE)}

The primary strategies for preventing influenza infection are: vaccination, early detection and treatment with antiviral medications, and the use of infection control measures to prevent transmission. The ability to limit transmission in healthcare settings relies heavily on the appropriate and thorough application of infection control measures. Precautions from influenza infection should also be taken. PPE which may be used to provide health care includes surgical or procedure masks, as recommended for droplet precautions, and gloves and gowns, as recommended for standard precautions. Additional precautions include use of hand sanitizers, covering the cough/sneeze, etc.

An effectiveness study of surgical face masks and N95 respirators for limiting influenza transmission by droplets produced during cough was carried out. This study used the same environmental chamber setup used in the previous study. Grimm 1 was the human mannequin equipped with simulated breathing cycle. The experiments were carried out with three types of mannequin: (a) No mask condition, (b) mannequin with surgical mask, and (c) with N95 respirator. Figure 30 below shows a graph plotted to illustrate the variation of particle count at the nose/mouth of the mannequin during experiments. The graph is shown for the case when ventilation system is not applied in the EC ( $0 \mathrm{ACH}$ case). As can be seen from graph, surgical mask has recorded more number of particles compared to no mask condition. This may be because, the surgical mask is made of porous material which covers mouth/nose of a person and breathing process creates a diffused region near mouth/nose resulting from pressure variation. Whereas N95 respirator is highly efficient as during the complete process of experimental time there are a very few particles recorded in the mannequin. 


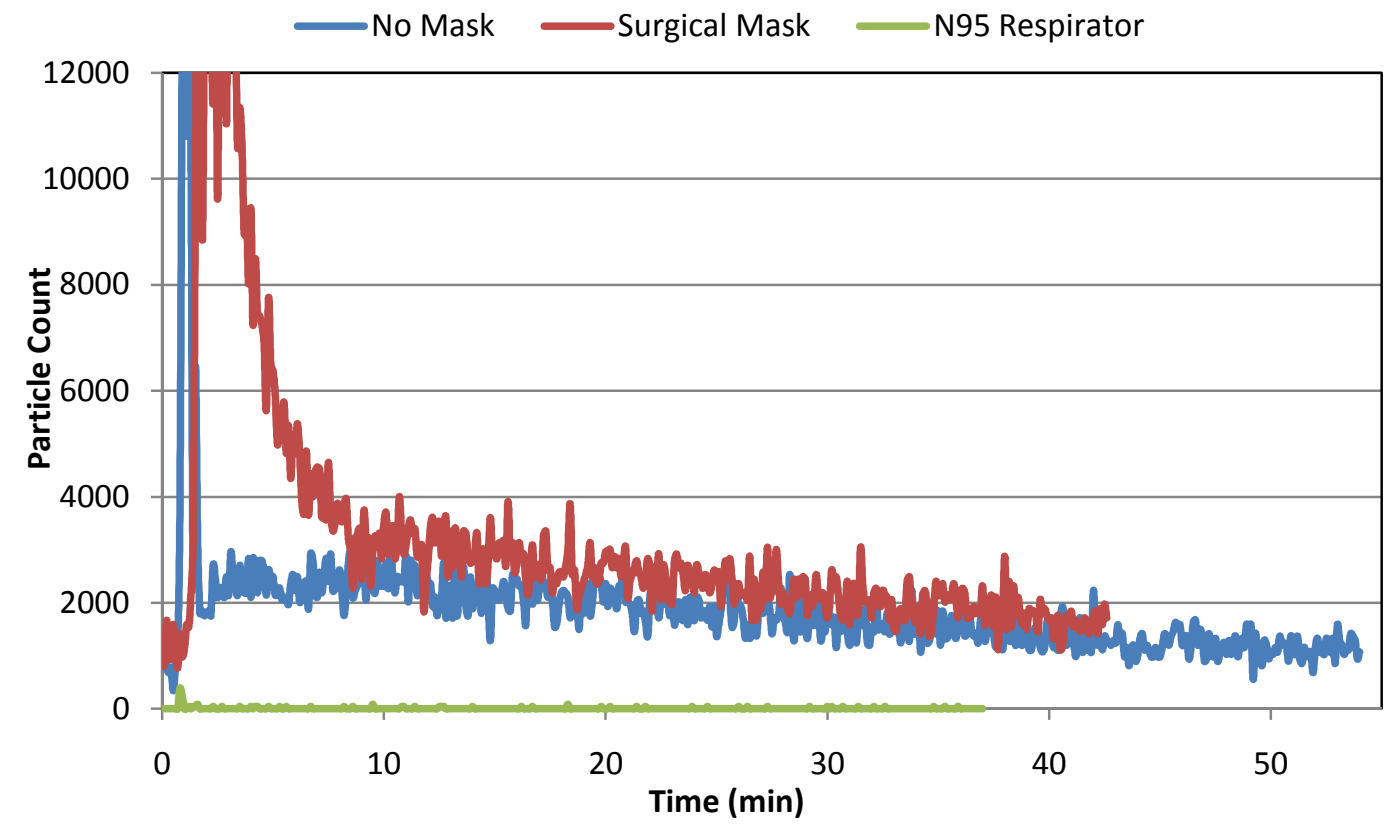

Figure 30: Particle count for mannequin condition at no mask, with surgical mask and with N95 respirator 


\section{Chapter 4}

\section{Influence of Breathing Zone}

\subsection{Introduction}

One interesting question is how airborne transmission takes place when infected host does not come into actual contact with susceptible host. Airborne transmission is possible when both infected and susceptible hosts share the same space containing coughed particles from infected person. Airborne particles could be inhaled by susceptible host during the breathing from nose or mouth. Breathing is a repetitive process involving air being inhaled from environment followed by exhalation of air in the surrounding; this process goes on in a repeated pattern. Understanding the distance from which air is inhaled from surrounding into the respiratory tract is important. This study is aimed to understand the movement of air in the surrounding atmosphere under influence of human respiration. This can help in setting the parameters of ventilation system so that the contaminants can be removed from the indoor environment sooner, also defining appropriate use of personal protection equipment (PPE) like surgical or respirator mask.

A wide range of research has been carried out to study human respiration area (Gao \& Niu, 2005; Gupta et al., 2009; Liden \& Waher, 2009). Zhao et al., with the help of CFD model, showed that in the breathing process the concentration of the droplets reduce to $0.001 \%$ within $1 \mathrm{~m}$ distance from human body. Zhu et al. (2005) carried out a similar study to compare CFD results with experimental results of human inhalation. They concluded the research showing the concentration reduces to $0.1 \%$ at $5 \mathrm{~cm}$ from nose as per CFD while it reduces to $4 \%$ according to experiments.

CFD has become a powerful tool to study the infection transfer in enclosed spaces. In previous chapter, a close binding in experimental and CFD results of human cough is shown. Particle concentration measured at various locations in environmental chamber agrees with results obtained from CFD model. Similar study is carried out to understand the region in surrounding of human where influence of breathing is experienced. A simple two dimensional CFD model is proposed to study breathing zone of human respiration. Study based on CFD can be effective way of analysis and is less expensive when compared 
with experimental measurement. Information required for CFD simulation can be fulfilled by applying correct boundary conditions. Data like breathing flow rate and nose opening area is required to start computations.

\subsection{Breathing Cycle}

Breathing cycle may vary from person to person depending on individual's body structure. However some similarity can be noticed in respiration process. ISO standards are proposed to classify breathing in classified in six segments number. Respiration process for various classes is stated in terms of metabolic rate. The classes are proposed from 1 to 8 based on the work an average human being performs in a given time. Type of work may vary from rest, light work, moderate work, to maximal work (ISO, 2005). Based on available standards researchers had adopted different forms of breathing cycles. They assumed breathing cycle be sinusoidal, trapezoidal or a triangular wave as discussed below.

Researchers have conducted experiments with human as subject and predicted various ways to simulate an average breathing process. There are studies involving human subjects to study the nature of respiration process (Gao and Niu, 2005; Gupta et al., 2009) and with the help of CFD analysis also (Zhao et al., 2004; Zhu et al., 2005; Hayashi et al., 2001). Literature reviewed to collect such data is described below in brief. Few of the breathing parameters studied from literature are also shown below.

a) Hayashi et al. (2002) used a breathing cycle as shown in Figure 31. They studied the inhalation region with the help of CFD model for a human occupant in standing, sitting and sleeping postition. They concluded that when occupant is standing and sitting the inhales the air which is drawn upward by the thermal metabolic heating. Whereas when the occupant is sleeping, the region of inhalation extends horizontally out from head over the floor on both sides. 


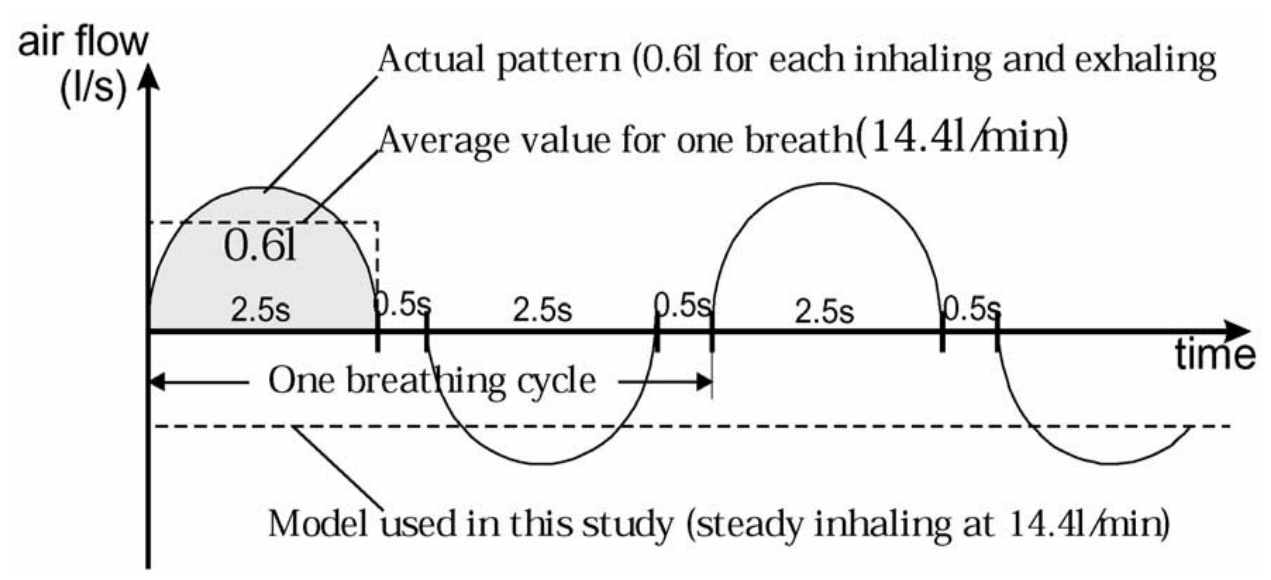

Figure 31. Assumed Model for Steady Inhalation (Hayashi et al., 2001)

b) In 2005, Gao and Niu (2006) performed a CFD simulation of respiration process and inter-person exposure assessment. They assumed a frequency of respiration under light work of 17 times per minute with mean flow rate of $8.41 \mathrm{1} / \mathrm{min}$. They modeled the breathing cycle as a sine wave (Figure 32). The study revealed that the personal exposure to the exhaled air from the other person was very low in presence of displacement ventilation.

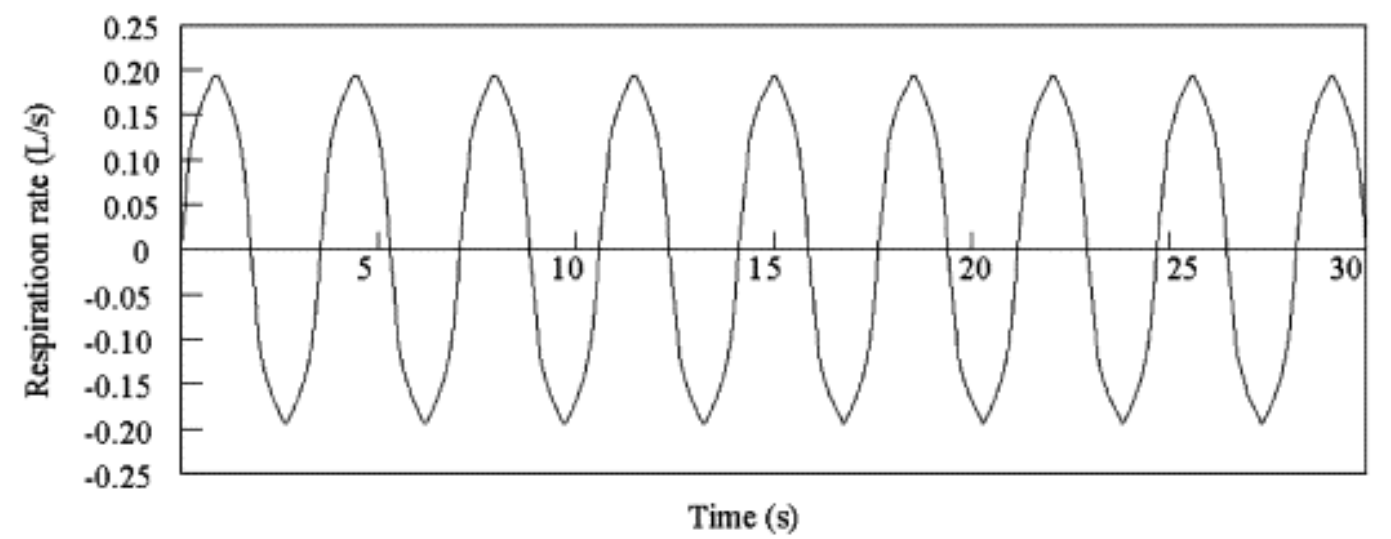

Figure 32. Transient Respiration Process during light work (Gao and Niu, 2005) 
c) Zhu et al. (2004) determined the inhaled volume from the amount of oxygen consumption. They assumed 10 breathing cycles per minute with 0.6 liter per inhalation. A breathing cycle was modeled in 8 stages from A to H (Figure 33) assumming the occupant is breathing through nose with an opening area of $4.2 \mathrm{~cm}^{2}$. The conclusions of this study were that the inhalation region is from lower parts of body from the air pulled up by rising streams caused by metobolic heating, which is similar to the findings of Hayashi et al. (2002).

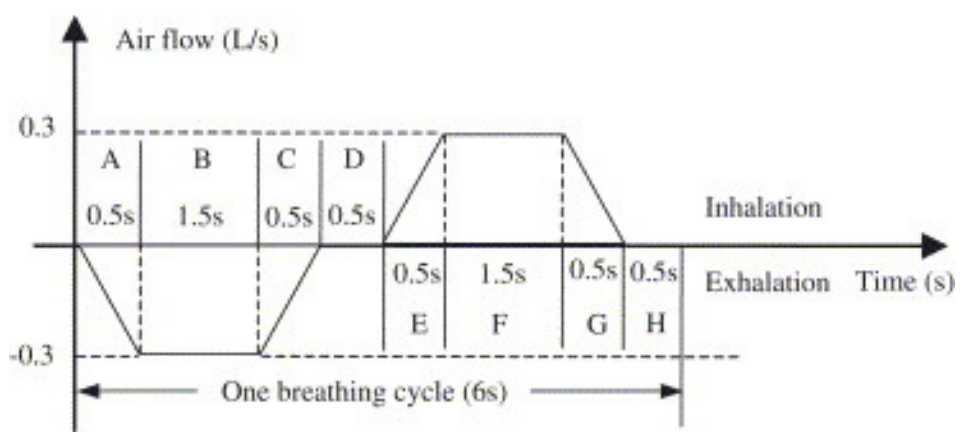

Figure 33. Assumption of Breathing Process (Zhu et al., 2004).

Among all the forms of exhalation, coughing and breathing have higher velocity and particle concentration but lower event occurrence, on the other hand breathing and talking has lower velocity with less particle concentration but higher frequency of event occurrence (Gupta et al., 2009).

\subsection{Numerical Simulation}

A simple two dimensional model of $5 \mathrm{~m} \times 5 \mathrm{~m}$ is modeled in grid generating software GAMBIT. A plane perpendicular to a human body at nose is assumed as a computational domain. The total number of cells is 36,450 . The nose opening is $4 . \mathrm{cm}^{2}$ (Zhu, et al. 2004). The mesh used for computation is shown in Figure 34 . 


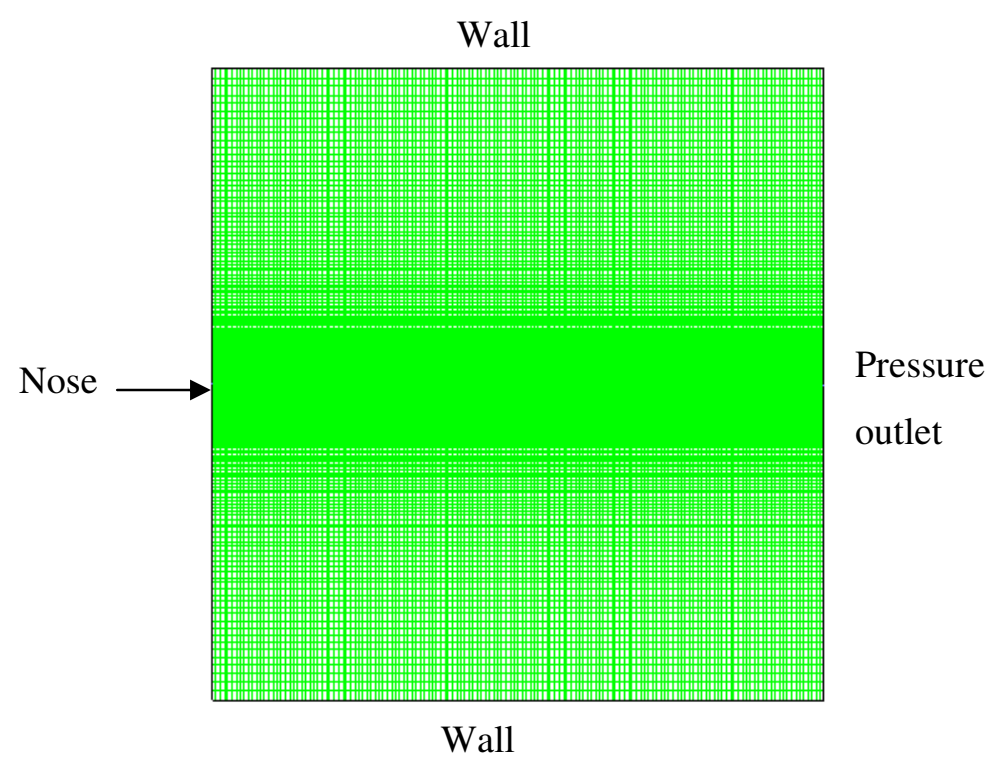

Figure 34. Computational grid generated in Gambit for breathing region.

A 2D grid generated in GAMBIT was imported in FLUENT module. The inside domain was set at scalar 1.0 throughout at the beginning of the simulations. This scalar assumes a uniform distribution of contaminants in room. Ceiling and floor were set to wall boundary conditions and right wall was set at pressure outlet, as shown in Figure 34. Spalart-Allmaras turbulent model was employed for the simulation with a coarse time step of $0.1 \mathrm{sec}$. The nose was given the breathing velocity profile similar to the one adopted by Zhu et al. in 2004. The start of the simulation was with inhalation, i.e. with negative velocity profile, followed by exhalation. The simulation was set to run for five breathing cycles to study the breathing zone. During inhalation the zero flux was given at the nose assuming the contaminants in the surrounding being inhaled and was given zero scalar during exhalation indicating clean air being exhaled. The scalar contours for first two breathing cycles are shown in Figure 35. Figure 35(a) and (b) refers to the first breathing cycle where: (a) corresponds to the end of inhalation, and (b) corresponds to the end of exhalation. Similarly Figure 35(c) and (d) are at end of $2^{\text {nd }}$ inhalation and at end of $2^{\text {nd }}$ exhalation respectively. It can be noted that the inhalation region is small compared to exhalation region, i.e. distance from which scalar is inhaled in the human body is less compared to distance travelled by exhaled air. In continuous process of breathing, some portion of previously exhaled air is also inhaled in the human body. Study performed by Zhu et al. in (2004) revealed that approximately 16 to $17 \%$ exhaled air was inhaled during the continuous breathing; also that the exhaled air travels more like a jet while inhalation is from surrounding region. 
(a)

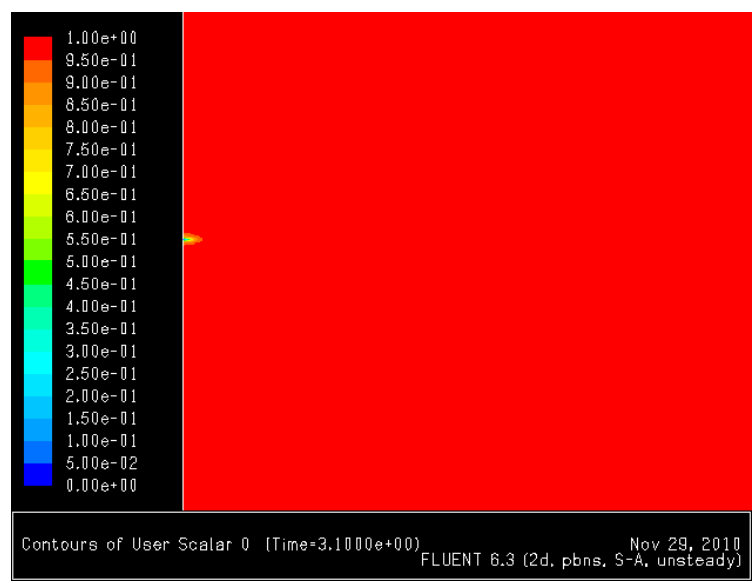

(c)

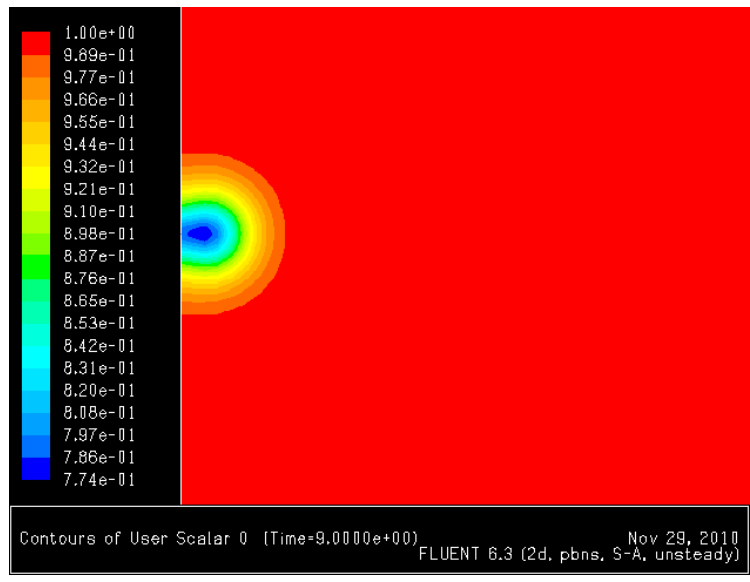

(d)

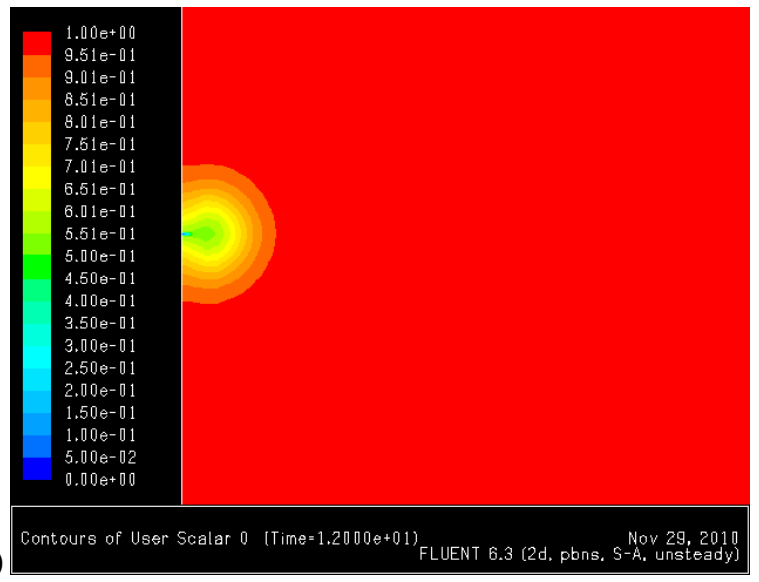

Figure 35: Scalar contours for breathing zone study

(a) end of $1^{\text {st }}$ inhalation, (b) end of $1^{\text {st }}$ exhalation, (c) end of $2^{\text {nd }}$ inhalation and (d) end of $2^{\text {nd }}$ exhalation

These images are exported from FLUENT runs are further imported in TecPlot360 (Tecplot Inc., Bellevue, WA) software for post-processing. In this process, the behavioral movement of scalar contours is studied for the breathing cycle shown above in Figure 35. As the inhalation of second cycle starts the exhaled air from previous breathing continues to travel away from nose where as some proportion of this exhaled air is inhaled again. 


\section{Chapter 5}

\section{Conclusions}

More research is needed to understand influenza transmission modes. Virus transmission takes place when virus trapped in droplet is exhaled by infected host in atmosphere. Droplet fate in indoor environment depends on environmental parameters like temperature and RH. It was proposed that indoor parameters have a higher impact on virus viability than outdoor parameters. Experiments were performed in controlled environment to learn dynamics of expelled particles from human cough. Employing various CFD techniques, the experimental data and numerical simulation data are compared. Purpose of modeling a droplet dispersion helps practice calculated control measures ahead of time to minimize the severity of virus attack. Potential of inhalation of infected particles from ambience into human respiratory system is also studied with the help of a CFD model. Findings of this study are explained below in brief.

A validated model of calculation of indoor RH from outdoor parameters worked well in winter months while in summer the model deviates from the measured values. This indicates the assumption of zero humidification does not work in summer because of condensation in air conditioning system in summer. The measured and calculated data agrees well in summer for NETL case than compared to four buildings in WVU; the possible reason could be the NETL building could be with better controlled weather parameters than the ones in WVU. Figures 8, 9, 10 and 11 show the correlation of ILI with indoor RH (calculated from the model), which falls down to low value of $10 \%$ during winter and is the same time when more number of ILIs is reported in these cities. Probability distribution curve is fitted to the ILI trend plotted over indoor RH with good accuracy. The probability of ILI occurrence is $50 \%$ in temperate region when indoor RH is in $10 \%$ to $30 \%$ range as can be seen from Figure 12(d).

The ILI trend looks similar for all four cities during first four flu-seasons; however there was an unusual outbreak of influenza H1N1 during 2009 summer. This may not be because of weather parameters; it can be due to introduction of a new virus. Tests showed, usually all of the influenza cases through the winter of 2009-2010 were pandemic H1N1, not seasonal influenza. Graph in Figure 6 shows the influenza cases three to four months ahead of time compared to previous flu seasons. The peak in ILI was recorded in January/February for previous influenza season, but this peak was not seen in flu season 2009-10. It can be concluded that the pandemic was brought in control by the January/February period in 2010. As can be 
seen from Figures 8(c) to 11(c), thought the new analysis has shown different bars in histogram the conclusion of higher occurrence of ILIs at low indoor RH does not deviate. With the new analysis, the difference in ILI is no longer as pronounced with a smoother curve. This analysis takes into account the effect of time at each RH range. This study concludes the occurrence of ILI cases are more correlated with indoor RH or AH more than the correlation to school calendar claimed by (Chao et al. 2010) because the school calendar is the time of year when fall season starts; temperature also starts falling down which in turn results in falling of indoor $\mathrm{RH}$ or $\mathrm{AH}$.

In comparing results of numerical analysis, scalar simulation of cough showed much better agreement with experiments than that of particle injection. Even though there was no considerable particle collection at GRIMM 2, 3, and 4 in setup-1, small peaks are better related to scalar simulation than particle injection. Trend of scalar simulations over first 60 seconds is much smoother than compared to particle injection, hence it is difficult to comment if scalar can predict sudden peaks or jumps as can be seen in experiments. Graphical comparison of particle injection simulation and experiment for setup-2 is not shown because there are no particles recorded from simulation in either of the GRIMM sampler position; even experiments do not show a considerable particle count at any location except for GRIMM-1. Particle counts can be achieved from simulation by increasing the GRIMM spectrometer dimensions, but this is not a feasible way of comparison as GRIMM spectrometer remains same throughout the use irrespective of experimental setups. The NIOSH experiments could be improved if a consistency of particle generation from cough machine could be achieved. Also the particle count at each GRIMM should be ensured to be less than 100 before the cough trigger; this can result in obtaining particle counts which is free of noise caused by ambient particles. This practice was adopted while performing the study of ventilation and PPE but the initial experiments where data comparison of experiments and simulation is carried out; the experimental data had noise in it.

In further part of study a set of experiments were carried out in EC, to learn the effect of ventilation on infectious particles in a closed environment. From graphs in Figure 29, particle concentration at any given position reduces faster as higher air changes are imposed in environmental chamber. The case with 0 $\mathrm{ACH}$ lowers particle count at any location very marginally, which may be because of particle settlement over a period of time. However in case of $6 \mathrm{ACH}$, particle count drops as time progress. The time taken to reduce particles count to a very low level in case of $12 \mathrm{ACH}$, indicates that the air ventilation is very important aspect of reducing infected particle concentration in indoor environment. Also the findings in the study of efficacy of PPE leads to conclusion that use of PPE can reduce the exposure to influenza infection by blocking the infected particles being inhaled in the respiratory tract. 
In the study of breathing zone, it was found that the first exhalation can reach the distance of $1.0 \mathrm{~m}$ while inhalation is from $5 \mathrm{~cm}$ to $7 \mathrm{~cm}$ from nose. This findings from a simple CFD model agree well with the more realistic model developed by Zhu et al. in 2005 . They showed that $0.1 \%$ of the contaminants are inhaled by human from a distance of $5 \mathrm{~cm}$. In this work, though a 2D model worked good to illustrate the results a more practical and realistic 3D model can be developed to take into account the effect of 3 dimensional mannequin model, air ventilation and recirculation and effect of human body temperature. 


\section{Appendix 1}

\section{Matlab Code}

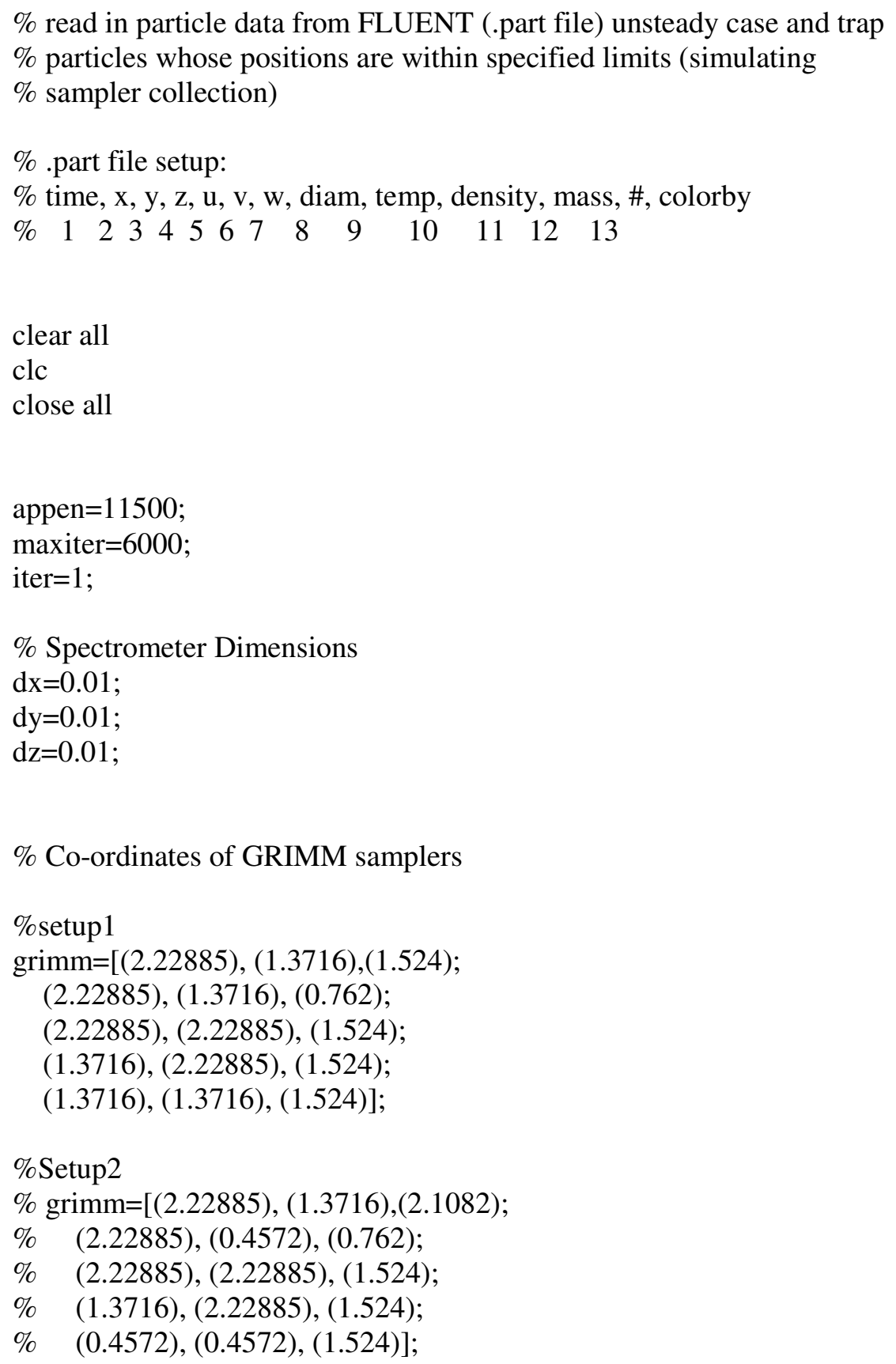




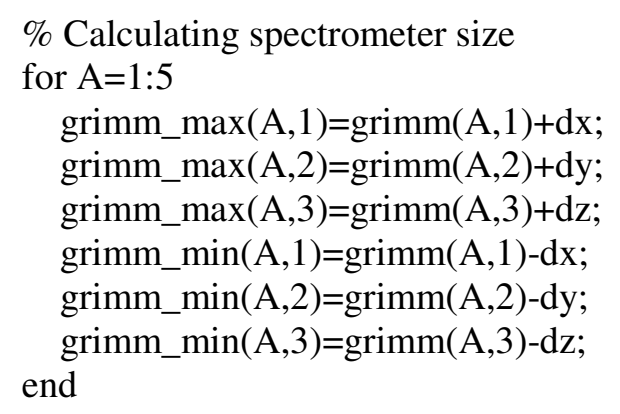




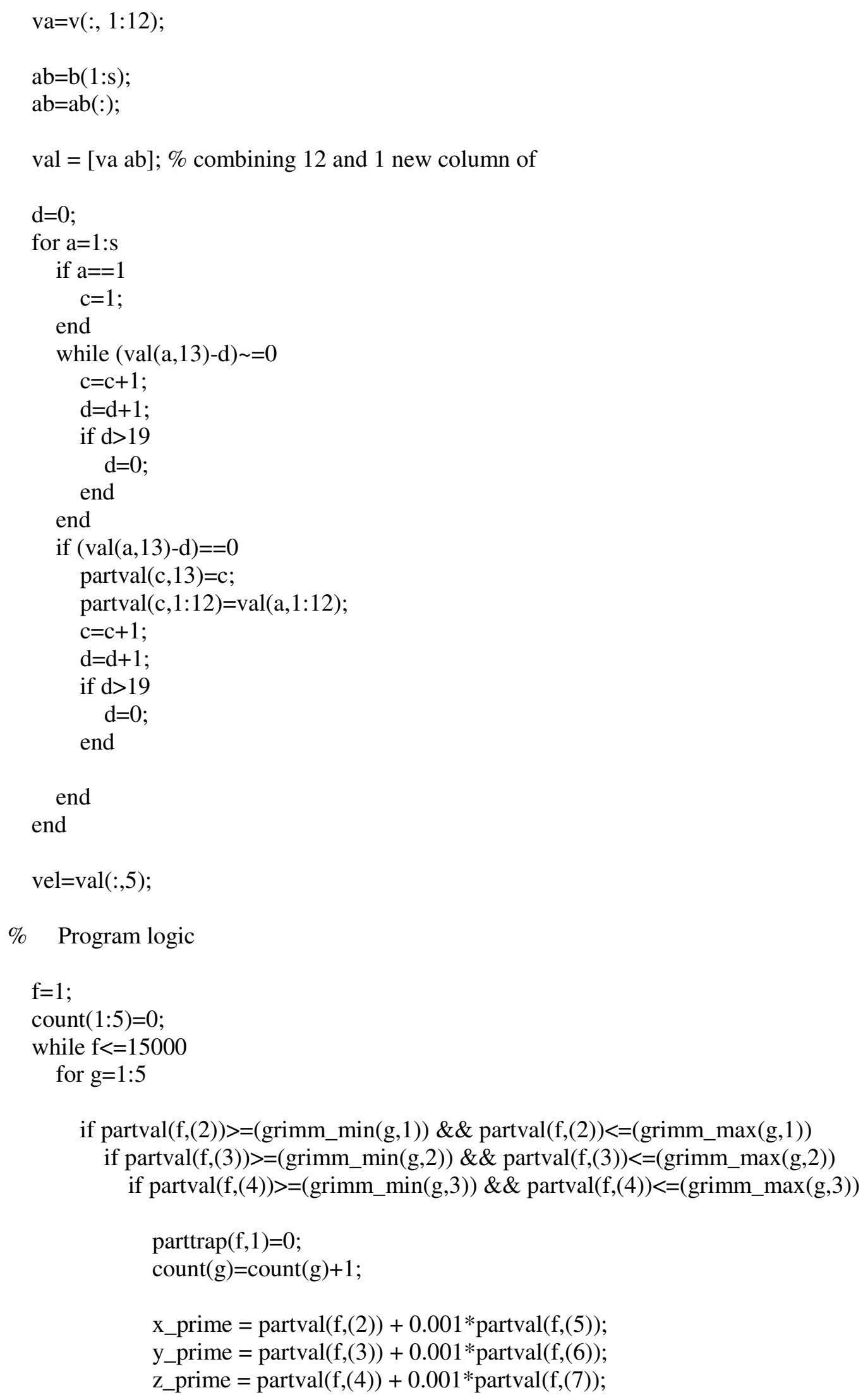




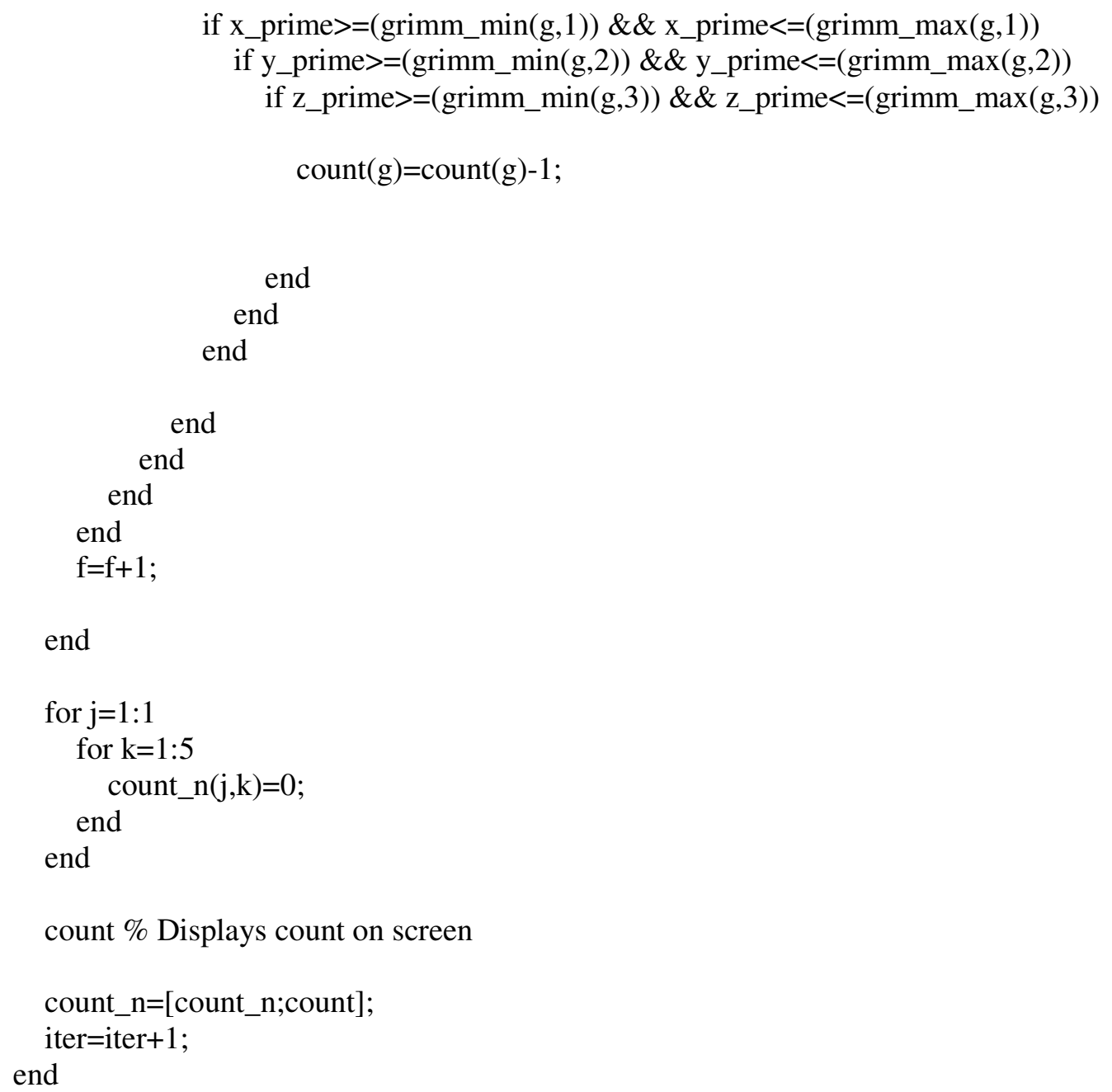




\section{Bibliography}

AIA. (2001). Guidelines for deign and construction of hospital and health care facilities. Washington, DC: AIA.

Arundel, A. V., \& Sterling, E. M. (1986). Indirect Health Effects of Relative Humidity in Indoor Environments. Environmental Health Perspective, 65, 351-361.

Atkinson, M., \& Wein, L. (2008). Quantifying the Routes of Transmission for Pandemic Influenza. Society for Mathematical Biology, 70, 820-867.

Bjørn, E., \& Nielsen, P. (2002). Dispersal of exhaled air and personal exposure in displacement ventilated rooms. Indoor Air, Vol. 12 , 12; 147-164, 147-164.

CDC. (2010). Seasonal Influenza: The Disease. Retrieved Aug 2010, from http://www.cdc.gov/flu/about/disease/

Celik, I. B. (2008). Introductory Numerical Methods for Engineering Applications. Morgantown WV: Ararat Books and Publishing.

Chao, C., Wan, M., Morawska, L., Johnson, G., Ristovski, Z., Hargreaves, M., et al. (2008). Characterization of expiration air jets and droplet size distributions immediately at the mouth opening. Elsevier, Aerosol Science, 122-133.

Chao, D., Halloran, E. M., \& Longini Jr, I. M. (2010). School Opening Dates Predict Pandemic Influenza A (H1N1) Outbreaks in the United States. The Journal of Infectios Diseases, 877-880.

EPA. (2010). EPA. Retrieved 2010, from The Inside Story: A Guide to Indoor Air Quality: http://www.epa.gov/greenbuilding/pubs/gbstats.pdf

Fluent. (2005). Fluent6.3: User Guide. Lebanon, NH, NH: Fluent.

Gambit. (2006). Gambit 2.3; User's Guide. Labanon, NH: Fluent.

Gao, N., \& Niu, J. (2005). Transient CFD Simulation of the Respiration Process and Inter-person Exposure Assessment. Elsevier, Building and Environment, 1214-1222.

Ginsberg J, M. M. (2009). Detecting influenza epidemics using search engine query data. Nature 457, Vol 457, 1012-1014.

Google. (2010). Google Flu Trends. Retrieved May 4, 2010, from Google:

http://www.google.org/flutrends

GRIMM. (2008). Aerosol Spectrometer and Dust Monitor Model 1.108.

Grimm, T. I. (2008). Aerosol Spectrometer and Dust Monitor. D_E_1108_IAM_Rev3 . 
Gupta, J., Lin, C. H., \& Chen, Q. (2009). Flow Dynamics and Characterization of Cough. Indoor Air, 19, 517-525.

Gupta, J., Lin, C.-H., \& Chen, Q. (2009). Characterizing Exhaled Airflow from Breathing and Talking. Indoor Air, 31-39.

Hall, J., \& Brouillard, R. (1985). Water Vapor Pressure Calculation. Journal of Applied Physiology, 2090-2090.

Harper, G. (1961). Airborne micro-organism: survival tests with four viruses. Journal of Hygiene Cambridge, 478-486.

Hayashi, T., Ishizu, Y., Kato, S., \& Murakami, S. (2001). CFD Analysis on characteristic of contaminated indoor air ventilation and its application in the evaluation of the effects of contaminant inhaled by a human occupant. Building and Environment, 219-230.

Hemmes, J. H. (1960). Virus Survival as a Seasonal Factor in Influenza and Poliomyelitis. Nature Publishing Group, 430-431.

Hinklet, H. (2010, May). Influenza like illnesses in Monongalia County.

ISO. (2005). Respiratory Protective Devices - Human Factors - Part1:Work rates and physiology. ISO TC 94/SC 15 WG1.

J. Szalajda, W. K. (2010). N95 Respirator and Surgical Mask Efficacy for Cough Aerosols. AIHA .

Lester, W. (1948). The Influence of Relative Humidity on the Infectivity of the Airborne Influenza A Virus (PR8 Strain). Department of Medicine, The University of Chicago, 361-368.

Liden, G., \& Waher, J. (2009). Experimental Investigation of the Concept of a 'Breathing Zone' using a Mannequin Exposed to a point source of Intertial/Sedimenting Particles Emitted with Momentum. British Occupational Hygiene Society, 1-17.

Lowen, A. C., Mubareka, S., Terrence, T., Adolfo, G.-S., \& Palese, P. (2006). The guinea pig as a transmission model for human influenza viruses. Proceedings of the National Academy of Sciences of the United States of America, 9988-92.

Lowen, A., Mubareka, S., Steel, J., \& Palese, P. (2007). Influenza Virus Transmission Is Dependent on Relative Humidity and Temperature. PLoS Pathogenes, 1470-1476.

Lowen, A., Steel, J., Mubareka, S., \& Palese, P. (2008). High Temperature $\left(30^{\circ} \mathrm{C}\right)$ Blocks Aerosol but Not Contact Transmission of Influenza Virus. Journal of Virology, Vol 82, 56505652 . 
McKay, B. (2010). the flue season that fizzled. Retrieved March 2, 2010, from The Wall Street Journal:

http://online.wsj.com/article/SB10001424052748703429304575095743102260012.html?KEYW ORDS=flu+season

Morawska, L. (2006). Droplet fate in indoor environments, or can we prevent the spread. Indoor Air, 335-347.

Mubareka, S., Lowen, A. C., Steel, J., Coates, A. L., Garcia-Sastre, A., \& Palese, P. (2009). Transmission of Influenza Virus via Aerosol and Fomites in the Guinea Pig Model. The Journal of Infectious Disease, 858-865.

Papineni, R., \& Rosenthal, F. (1997). The Size Distribution of Droplets in the Exhaled Breath of Healthy Human Subjects. Journal of Aerosol Medicine, 105-116.

Raffel, M., Willert, C., Wereley, S., \& Kompenhans, J. (2007). Particle image velocimetry: a practical guide. Springer.

Redrow, J. (2009). An Investigation into the Theoretical and Analytical Basis for the Spread of Airborne Influenza. Morgantown: West Virginia University.

Redrow, J. (2009). An Investigation into the Theoretical and Analytical Basis for the Spread of Airborne Influenza. Morgantown, WV.

Richmond-Bryant, J. (2008). Transport of exhaled particulate matter in airborne infection isolation rooms. Building and Environment, 44-55.

Shaman, J., \& Kohn, M. (2009). Absolute humidity modulates influenza survival, transmission, and seasonality. PNAS, 1-6.

Sobsey, M., \& Meschke, J. (2003). Virus Survival In The Environment With Special Attention To Survival In Sewage Droplets Andother Environmental Media of Fecal Orrespiratory Origin. $1-87$.

Szalajda, J., Reynolds, J., \& Lindsley, W. (2010). N95 Respirator and Surgical Mask Efficacy for Cough Aerosols. American Industrial Hygiene Association.

Sze To, G., Wan, M., Chao, C., Wei, F., Yu, S., \& Kwan, J. (2008). A Methodology for Eliminating Airborne Virus Exposure in Indoor Environments using the Spatial Distribution of Expiratory Aerosols and Virus Viability Characteristics. Indoor Air, 425-438.

Tang, J. (2009). The effect of environmental parameters on the survival of airborne infectious agents. Jorunal of the Royal Society, 1-10. 
Tang, J., Lai, F., Wong, F., \& Hon, K. (2009). Incidence of Common Respiratory Viral Infections Related to Climate Factors in Hospitalized Children in Hong Kong. Epidemiological Infection Cambridge Univeristy Press, 138, 226-236.

Tang, J., Li, Y., Eames, I., Chan, P., \& Ridgway, G. (2006). Factors involved in the aerosol trasnmission of infection and control of ventilation in healthcare premises. Journal of Hopistal Infection, 100-114.

Tellier, R. (2009). Aerosol Transmisison of Influenza A Virus: A Review of New Studies. Journal of Royal Society, 1-8.

WeatherUnderground. (2010). Retrieved May 4, 2010, from Weather Underground: http://www.weatherunderground.com

Weber, T. P., \& Stilianakis, N. I. (2008). Inactivation of Influenza A Viruses in the Environment and Modes of Transmission: A Critical Review. Journal of Infection, British Infection Society, 113.

WHO. (2010). Retrieved May 09, 2010, from WHO:

http://www.who.int/mediacentre/factsheets/fs211/en/index.html

Zhao, B., Zhang, Z., \& Li, X. (2004). Numerical Study of the Transport of Droplets or Particles Generated by Respiratory System Indoor. Elsevie, 1032-1039.

Zhu, S., Kato, S., \& Yang, J.-H. (2005). Study of transport characteristics of saliva droplets produced by coughing in a calm indoor environment. Building and Environment, 41, 1691-1702.

Zhu, S., Kato, S., Murakami, S., \& Hayashi, T. (2004). Study on Inhalation Region by means of CFD Analysis and Experiment. Building and Environment, 1329-1336.

Zuk, T., Rakowski, F., \& Randomski, J. R. (2009). Probabilistic Model of Influenza Virus Transmissibility at Various Tempereature and Humidity Conditions. Elsevier, 339-343. 